\title{
Manual for Seismic and Windstorm Evaluation of Existing Concrete Buildings for
} The Dominican Republic

H. S. Lew

Emil Simiu John L. Gross

Monica A. Starnes

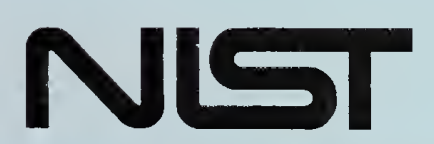

Notinnal Institute of Standards and Technology nology Administration, U.S. Department of Commerce

QC

100

. $\mathrm{U} 56$ 



\section{Manual for Seismic and Windstorm Evaluation of Existing Concrete Buildings for The Dominican Republic}

H. S. Lew

Emil Simiu

John L. Gross

Monica A. Starnes

Building and Fire Research Laboratory

National Institute of Standards and Technology

Gaithersburg, MD 20899

Prepared for

U.S. Agency for International Development

Ronald Reagan Building

Washington, D.C. 20523

April 2002

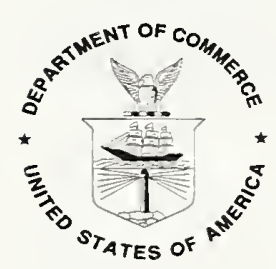

U.S. Department of Commerce

Donald Evans, Secretary

Technology Administration

Phillip J. Bond, Under Secretary for Technology

National Institute of Standards and Technology

Arden L. Bement, Director 



\section{PREFACE}

The National Institute of Standards and Technology (NIST) is participating in the Dominican Republic Hurricane Reconstruction Project supported by the U.S. Agency for International Development (AID), Department of State. As part of this project, NIST has prepared a manual for screening of reinforced concrete buildings for potential seismic and wind hazards in the Dominican Republic. This manual is primarily designed for the evaluation of critical structures such as hospitals, emergency response centers, fire stations, and communication centers. This manual has adopted the building evaluation procedures described in two documents published by the U.S. Federal Emergency Management Agency (FEMA): the NEHRP Handbook for the Seismic Evaluation of Existing Buildings (FEMA 178), and the Handbook for the Seismic Evaluation of Buildings - A Prestandard (FEMA 310), published in 1992 and 1998, respectively. While the building evaluation methodology is adopted from FEMA 178, many features in FEMA 310 are incorporated in this manual to reflect the knowledge gained from recent earthquake investigations in the U.S. and elsewhere.

The U.S. AID Office in the Dominican Republic provided support throughout the course of this project and assisted NIST in obtaining the building data used in this manual. A draft version of this manual was reviewed by Ing. Roger Acosta, Ing. Daniel Comarazamy, Ing. Emilio E. Cruz Herasme, Ing. Jacqueline Medrano, Ing, Hector O'Reilly, and Ing. Victor F. Pizano-Thomen. Their constructive comments are gratefully acknowledged. Dr. Nicholas J. Carino and Dr. Kang Seok Lee assisted in the preparation of graphical illustrations in this manual. The authors acknowledge their contributions.

The manual has been translated into Spanish. The English version supersedes any discrepancies between the two documents. 


\begin{abstract}
This manual is prepared for seismic and wind hazards evaluation of reinforced concrete buildings in the Dominican Republic. The evaluation procedures presented in this manual can be applied to any ordinary cast-in-place concrete buildings, but are directed mainly to the evaluation of critical facilities such as hospitals, fire stations, communication centers, and emergency response centers. The procedures identify potential deficiencies in existing buildings that pose risks to human life. Additional evaluation guidance is given for immediate occupancy of buildings after a seismic and windstorm event. The evaluation examines through a series of checklists potential weak links in structural systems, foundations, nonstructural systems, and site geology. The evaluation covers three different types of buildings: moment resisting frame buildings, shear wall buildings, and moment frames with infill walls. The manual provides two examples that illustrate the use of the evaluation procedure for two critical facilities in the Dominican Republic that were determined to be structurally inadequate.
\end{abstract}

Keywords: Building technology concrete buildings; earthquake; evaluation; immediate occupancy; life safety; moment frames; shear walls; windstorm 


\section{TABLE OF CONTENTS}

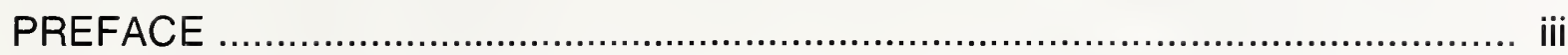

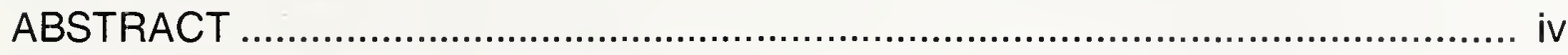

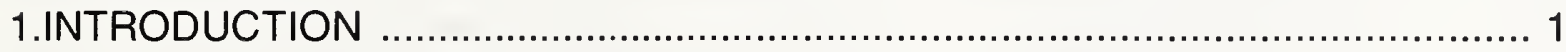

1.0 Purpose of the Manual ...................................................................... 1

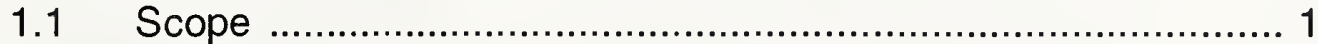

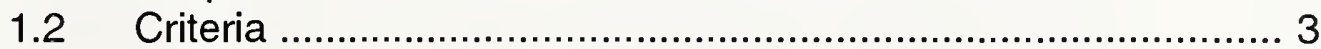

$1.3 \quad$ Force Level for Analysis .........................................................

1.4 Demand versus Capacity .............................................. 4

1.4.1 Evaluation............................................................. 4

1.4.2 Special Concerns................................................ 5

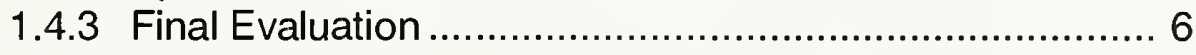

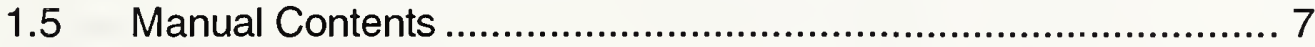

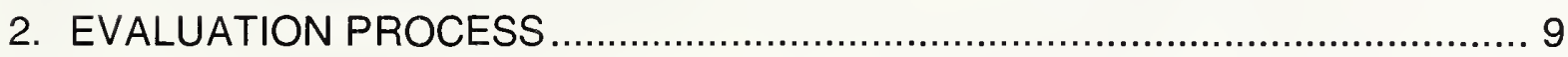

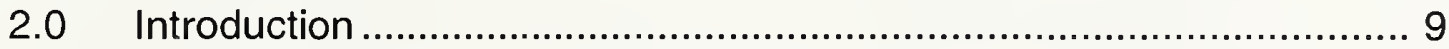

2.1 Site Visit and Data Collection ............................................ 9

2.2 Selection and Review of Evaluation Statements .................... 11

2.3 Follow-up Field Work...................................................... 12

$2.4 \quad$ Analysis of the Building ................................................... 13

2.4.1 Scope of Analysis ................................................ 13

2.4.2 Demand ........................................................ 14

2.4.3 Seismic Analysis of the Building ............................. 15

2.4.4 Demand on Diaphragms ....................................... 15

2.4.5 Demand on Parts and Portions of the Building .......... 15

2.4.6 Quick Checks of Strength and Stiffness.................... 17

2.4.7 Shearing Stress in Concrete Frame Columns............ 17

2.4.8 Shearing stress in Shear Walls ................................ 18

2.4.9 Element Capacities ............................................... 18

2.4.10 Dynamic Analysis................................................. 18

2.4.11 Acceptance Criteria............................................... 19

2.5 Final Evaluation...................................................................... 19

2.5.1 Review the Statements and Responses ............................ 19

2.5.2 $Q$ versus $C$................................................................. 19

2.5.3 $D_{E} / C_{E}$ Ratios ........................................................... 19

2.5.4 Qualitative Issues....................................................... 20

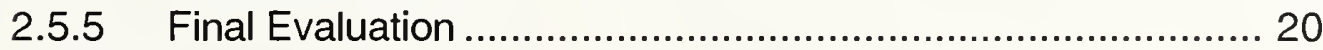

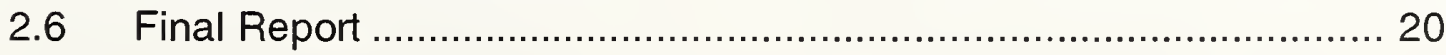




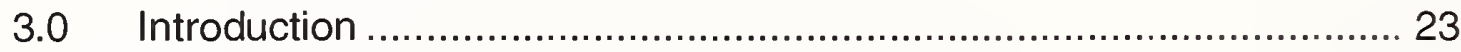

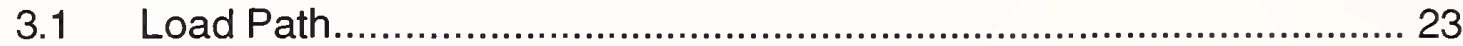

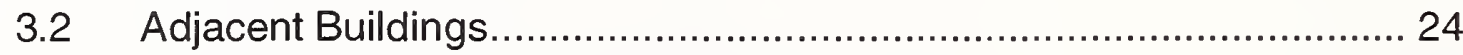

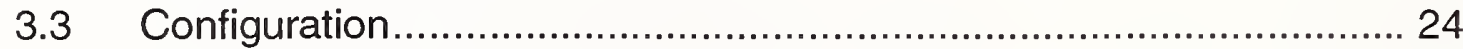

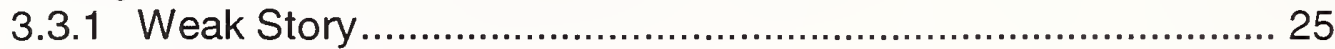

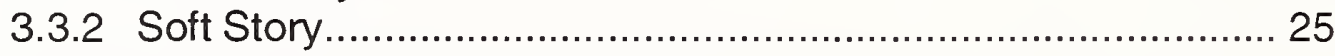

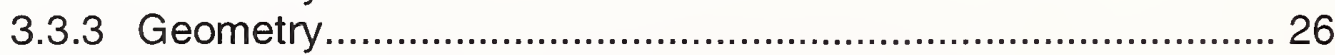

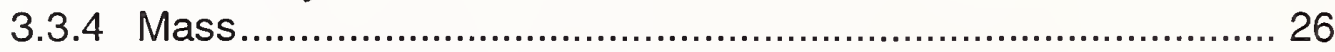

3.3.5 Vertical Discontinuities .................................................... 27

3.3.6 Earthquake Induced Torsion ............................................ 27

3.3.7 Wind Induced Torsion ........................................................ 29

3.4 Short Captive Columns .................................................................. 30

3.5 Column Bar Splices................................................................... 30

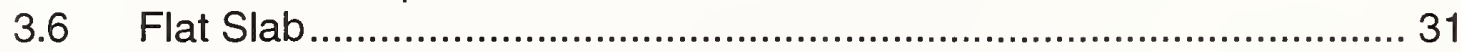

3.7 Deterioration of Concrete ............................................................. 31

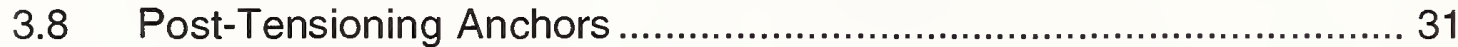

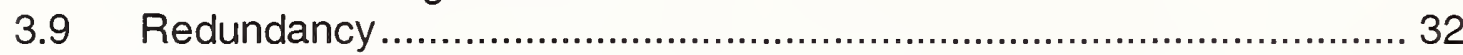

3.10 Interfering Walls ....................................................................... 33

3.11 Shearing Stress Check ............................................................... 33

3.12 Axial Stress Check ....................................................................... 33

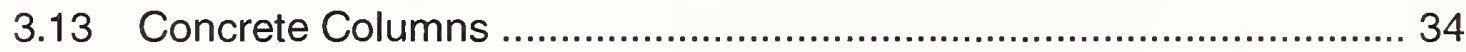

3.14 Prestressed Frame Elements ................................................... 34

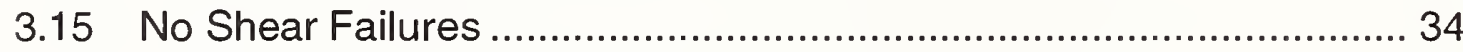

3.16 Strong Column / Weak Beam........................................................ 35

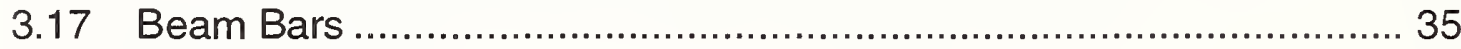

3.18 Beam Bar Splices...................................................................... 36

3.19 Column-Tie Spacing................................................................ 36

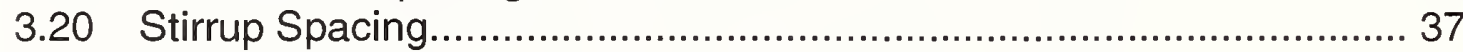

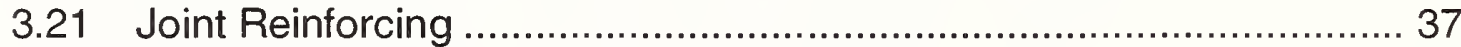

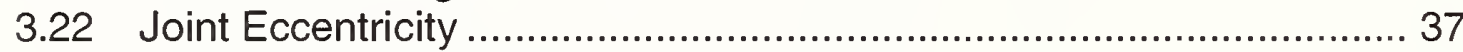

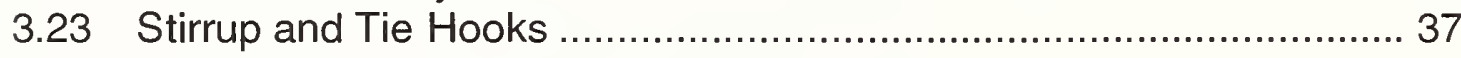

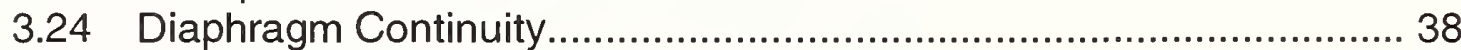

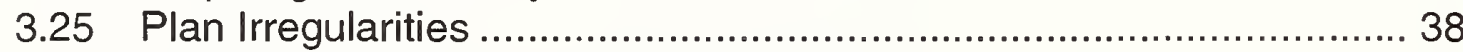

3.26 Diaphragm Reinforcement at Openings .......................................... 38

3.27 Lateral Load at Pile Caps ............................................................ 39

3.28 Concrete Wall Cracks .................................................................... 39

3.29 Complete Frames.................................................................... 40

3.30 Reinforcing Steel........................................................................ 40

3.31 Diaphragm Openings at the Shear Walls ...................................... 40

3.32 Transfer to Shear Walls ............................................................. 41

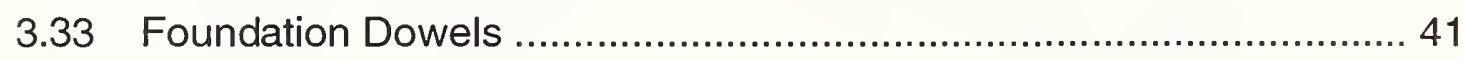

3.34 Deflection Compatibility.......................................................... 42

3.35 Coupling Beams........................................................................ 42

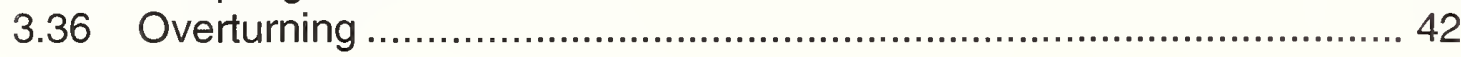


3.37 Confinement Reinforcing ......................................................... 43

3.38 Reinforcing at Openings......................................................... 43

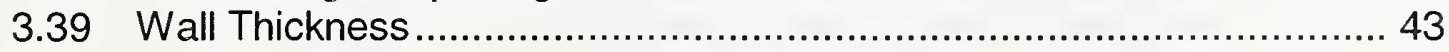

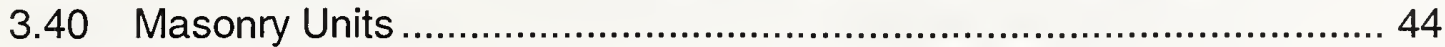

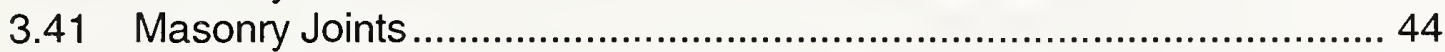

3.42 Cracks in Infill Walls ......................................................................... 44

3.43 Cracks in Boundary columns ...................................................... 45

3.44 Shear Stress Check ................................................................... 45

3.45 Shear Stress Check in URM Walls................................................. 45

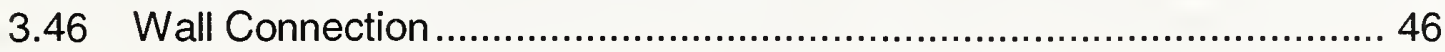

3.47 Proportions of Infill Walls............................................................. 46

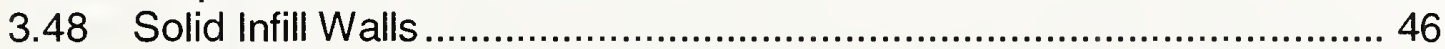

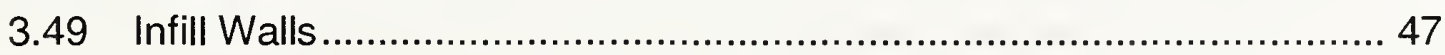

4. PROCEDURES AND COMMENTARY FOR GEOLOGIC SITE

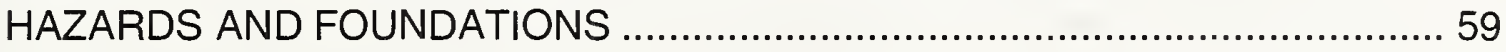

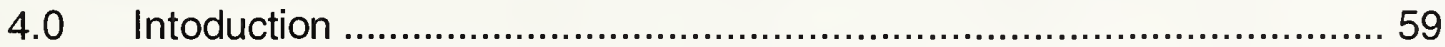

4.1 Geologic Site Hazards .......................................................... 59

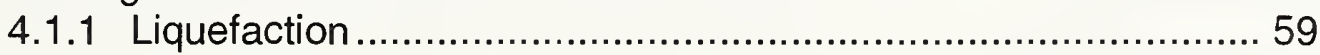

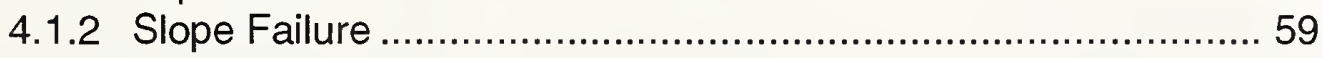

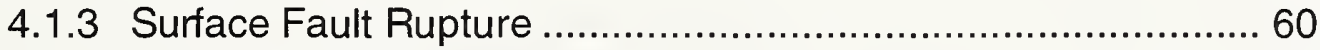

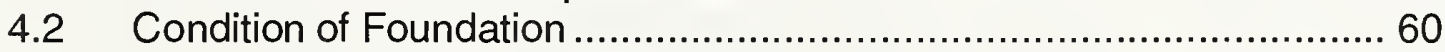

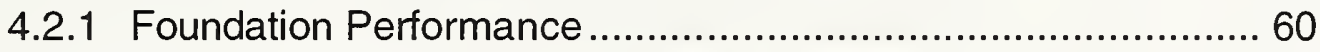

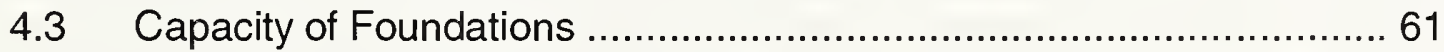

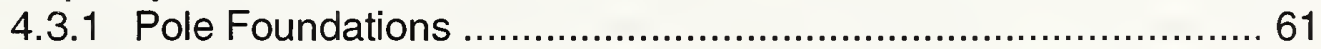

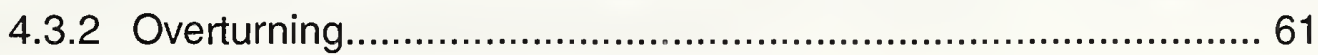

4.3.3 Ties Between Foundation Elements ..................................... 61

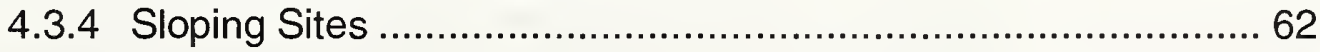

\section{PROCEDURES AND COMMENTARY FOR NONSTRUCTURAL}

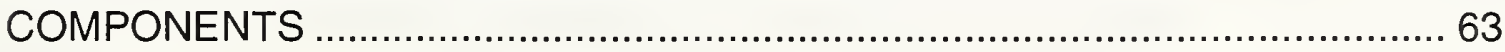

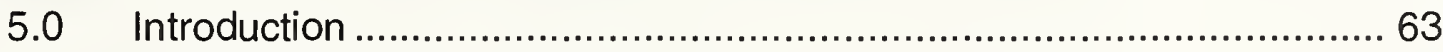

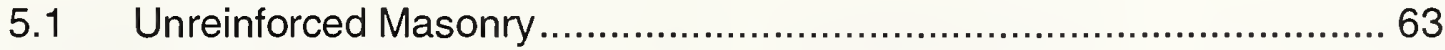

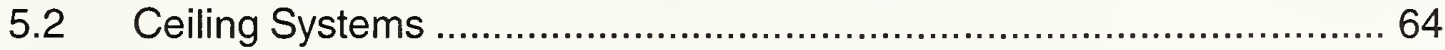

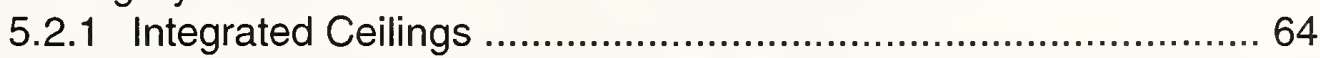

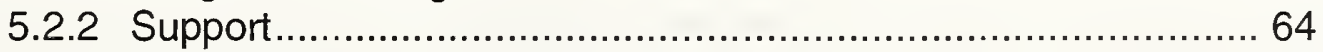

5.2.3 Suspended Lath and Plaster ............................................... 64

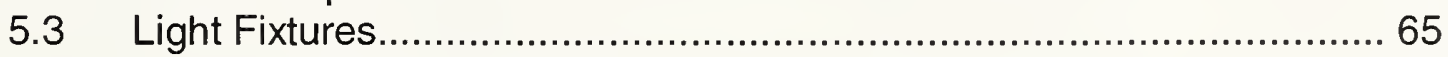

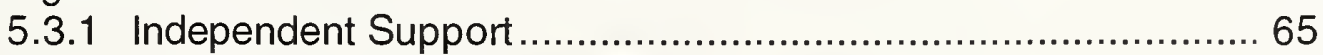

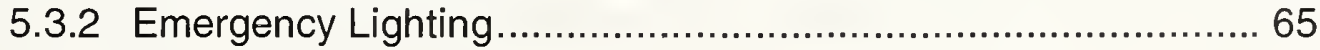

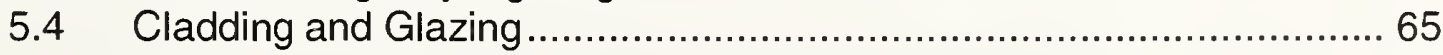

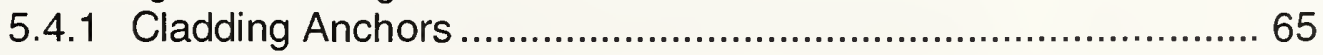

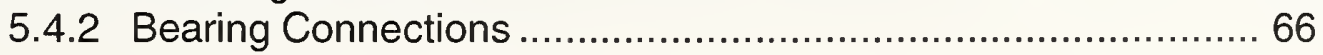




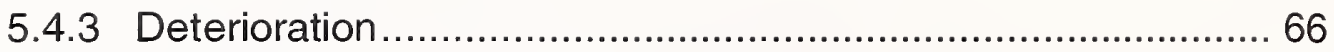

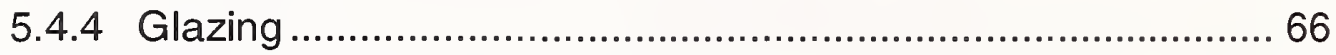

5.5 Parapets, Cornices and Appendages........................................ 67

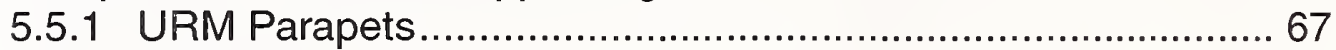

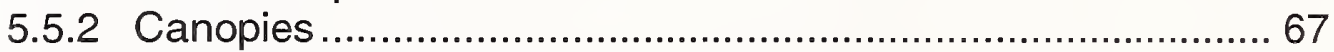

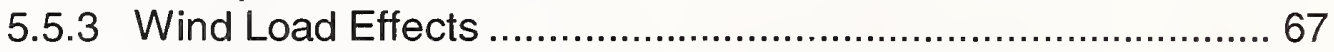

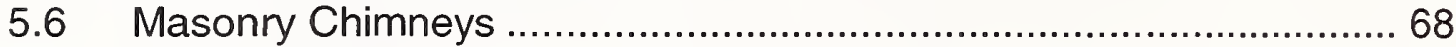

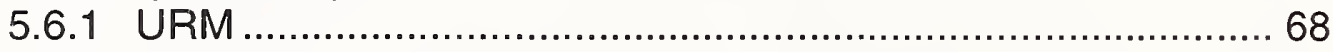

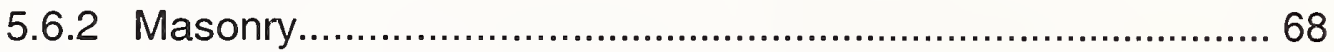

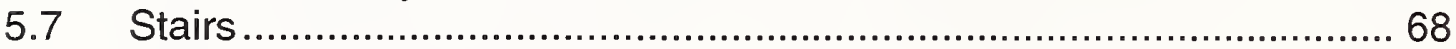

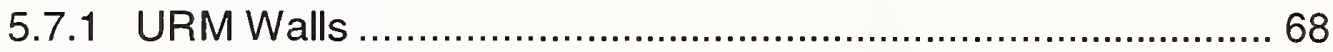

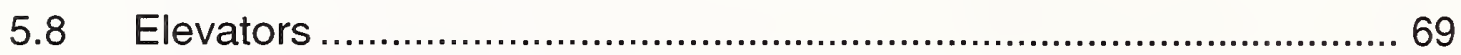

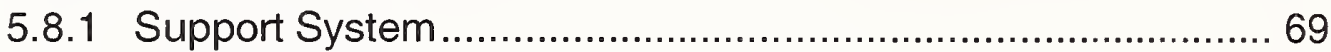

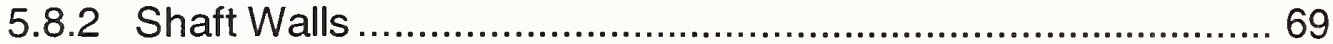

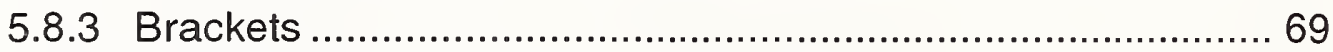

5.9 Roofs, Glazing and Cladding ................................................. 70

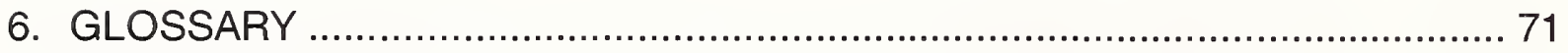

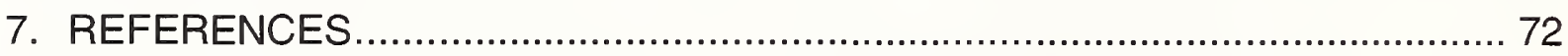

APPENDIX A EVALUATION STATEMENTS FOR CONCRETE

MOMENT FRAME BUILDINGS......................................... 73

APPENDIX B EVALUATION STATEMENTS FOR CONCRETE

SHEAR WALL BUILDINGS WITH STIFF DIAPHRAGMS ....... 79

APPENDIX C EVALUATION STATEMENTS FOR CONCRETE

MOMENT FRAMES WITH INFILL MASONRY SHEAR

WALLS AND STIFF DIAPHRAGMS .................................. 85

APPENDIX D EVALUATION STATEMENTS FOR GEOLOGIC SITE

SITE HAZARDS AND FOUNDATIONS............................... 91

APPENDIX E EVALUATION STATEMENTS FOR NONSTRUCTURAL COMPONENTS ............................................................. 93

APPENDIX F DATA SUMMARY SHEET ............................................ 97

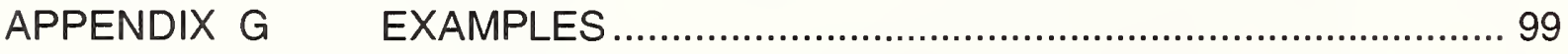

Example 1: Concrete Frame Building ............................. 100

Example 2: Concrete Shear Wall Building ....................... 124 


\section{INTRODUCTION}

\subsection{Purpose of the Manual}

This manual presents simple procedures for seismic and wind hazards evaluation of reinforced concrete buildings in the Dominican Republic. The evaluation procedures primarily identify potential deficiencies in existing reinforced concrete buildings that pose risks to human life. Additional evaluation guidance is given for immediate occupancy of buildings after a seismic and windstorm event. A building does not meet the life-safety objective if, after a design earthquake or design windstorm, the entire building collapses, portions of the building collapse, components of the building fail and fall, or exit and entry routes are blocked preventing the evacuation and rescue of the occupants. A building does not meet the immediate occupancy objective, if after a design earthquake or design windstorm, the basic vertical and lateral-force-resisting systems do not retain nearly all of their pre-earthquake or pre-windstorm strength, and sustain damage to both structural and nonstructural components so that it cannot be occupied. Facilities such as hospitals, fire stations, and emergency operations centers generally should meet the immediate occupancy objective.

This manual provides guidance to the evaluating engineer on determining if there are any weak links in the structure that could precipitate structural or component failure by making appropriate response to a series of checklists. If a building is found to be noncompliant to the checklists, further detailed analysis, not part of this manual, should be performed to determine the extent of the deficiencies. Detailed guidance for analytical procedures may be found in "Prestandard and Commentary for the Seismic Rehabilitation of Buildings, FEMA 356 "[FEMA 2000].

This manual adopts the evaluation procedures in the NEHRP Handbook for the Seismic Evaluation of Existing Buildings (FEMA 178) [FEMA 1992b] and Handbook for the Seismic Evaluation of Buildings-A Prestandard (FEMA 310) [FEMA 1998].

This manual should be updated from time to time as additional knowledge becomes available from research and damage investigations following earthquakes and windstorms.

\subsection{Scope}

While the evaluation procedures presented in this manual can be applied to any ordinary cast-in-place reinforced concrete buildings, the procedures are directed mainly to the evaluation of critical facilities such as hospitals, fire stations, communication centers, and emergency response centers. This manual should not be used for seismic and windstorm evaluation of special facilities such as power stations, industrial plants, and other buildings that are designed for special loading conditions. It also should not be used for the evaluation of precast concrete frame buildings with diaphragms 
consisting of precast elements such as single- or double-T elements and hollow-core elements.

The concrete buildings covered by this manual are of three common types:

(a) Concrete moment frames: These buildings posses a frame assembly of castin-place concrete beams and columns. Floor and roof framing consist of cast-in-place concrete slabs and concrete beams, one-way joists, two-way waffle joists, or flat slabs. Lateral forces are resisted by concrete moment frames that develop their stiffness through monolithic beam-column connections. In older construction, the moment frames may consist of the column strips of two-way flat slab systems. Modern frames have joint reinforcing, closely spaced ties, and special detailing to provide ductile performance.

(b) Concrete shear wall buildings with stiff diaphragms: These buildings have floor and roof framing that consists of cast-in-place concrete slabs and beams, one-way joists, two-way waffle joists, or flat slabs. Floors are supported on concrete columns or bearing walls. Lateral forces are resisted by cast-in-place concrete shear walls. In older construction, shear walls are lightly reinforced, but often extend throughout the building. In more recent construction, shear walls occur in isolated locations and are more heavily reinforced with boundary elements and closely spaced ties to provide ductile performance. The diaphragms consist of concrete slabs and are stiff relative to the walls.

(c) Concrete frames with infill masonry shear walls with stiff diaphragms: This is an older type of building construction that consists of a frame assembly of cast-in-place concrete beams and columns. The floors and roof consist of cast-in-place concrete slabs. Walls consist of infill panels constructed of solid clay brick, concrete block, or hollow clay tile masonry. The diaphragms consist of concrete floors and are stiff relative to the walls.

The analysis required as part of the evaluation process should be carried out following simple procedures so that deficiencies can be quickly identified. With this approach, some buildings may be identified as deficient buildings. Failure to pass the checklists of this manual does not automatically indicate that these buildings are hazardous for occupancy. For marginal or questionable buildings, a more detailed investigation may be justified.

Deficiencies identified during an evaluation based on this manual may be rehabilitated in accordance with FEMA 356. However, the engineer needs to understand the overall deficiencies of the building before attempting to identify appropriate rehabilitation techniques since the overall deficiencies may be due to a combination of component deficiencies, inherently inadequate design and construction features, or weak links. 


\subsection{Criteria}

The criteria followed by this manual are those of the 1991 Edition of the NEHRP Recommended Provisions for the Development of Seismic Regulations for New Buildings (referred to herein as the 1991 Provisions) [FEMA 1992a]. The criteria of the 1991 NEHRP Recommended Provisions, developed for the design of new buildings, are modified in this manual for the purpose of evaluating existing buildings. The design approaches for new buildings in the 1991 Provisions are comparable to the existing design requirements in the 1979 Recomendaciones Provisionales para el Analisis Sismico de Estructuras (referred herein as the 1979 Provisionales) [DNRS 1979] issued by the Departamento de Normas, Reglamentos y Sistemas, the Dominican Republic. The reference document for wind loading is the 1980 Recomendaciones Provisionales para el Analisis por Viento de Estructuras [DNRS 1980] issued by the Departamento de Normas, Reglamentos y Sistemas, the Dominican Republic (referred herein as the 1980 Provisionales).

\subsection{Force Level for Analysis}

In general, seismic design provisions are based on the concept of an elastic singledegree-of-freedom (SDOF) oscillator responding to random excitation at its base. The concept assumes that the displacement of a nonlinear SDOF system is the same as its elastic counterpart. The 1991 Recommended Provisions and the 1979 Provisionales are based on the equivalent lateral force procedure. The lateral force is determined by use of a seismic design coefficient, $C_{b}$, and a response modification factor, $R_{d}$, in the 1979 Provisionales.

Alternatively, the lateral forces may be computed using peak ground acceleration values (PGA). It is recommended that PGA values be determined for earthquake ground motions that are based on an estimated $10 \%$ probability of being exceeded in a 50-year period. PGA values for the Dominican Republic are shown in Fig. 2.1.

Some criteria for the evaluation of existing buildings specify seismic design forces that are lower than those prescribed by the seismic design criteria for new buildings. This concept is generally acceptable because it is believed that the seismic capacity of the existing building should be below the capacity required by the current codes and standards before triggering the requirement for a seismic upgrade. Furthermore, some level of earthquake damage is acceptable in an existing building. Based on this concept, a reduction in the seismic force to be used for evaluation is considered in this manual. A reduction of $25 \%$ is recommended. This is reasonable as compared to the reduction factor used in FEMA 178. 
The provisions to be used for the evaluations of wind-induced loads are those in the 1980 Provisionales. Where it is deemed that these provisions are not sufficient (e.g., for dynamic calculations), the ASCE 7-98 Standard [ASCE 1998] may be used.

\subsection{Demand versus Capacity}

\subsubsection{Evaluation}

There is a fundamental difference between design and evaluation of a building. In design, a building is modeled as elastic system with stresses proportional to strains. Although forces and deflections due to actual earthquake or wind may be larger than code forces and calculated elastic deflections, a building will survive by dissipating energy in the yielding of its components if the code provisions concerning the force level and detailing have been applied properly. For earthquakes, the design lateral forces are obtained from a base shear formula that includes a system response modification factor $(R)$, that reflects a trade-off between required strength and ductility; systems with greater ductility qualify for a larger $R$ factor, which leads to lower required forces for design.

In evaluation, the goal is to determine how a building will respond to the design earthquake or windstorm. In other words, the goal is to find "weak links" and to identify how their behavior will affect the response of the structural system. For example, the capacity reduction factor for shear design of a reinforced concrete shear wall is less than the capacity reduction factor specified for flexural design. The intent of this provision is to provide a shear capacity in excess of flexural capacity and to force flexural yielding rather than brittle shear displacement. For a number of reasons, however, an existing shear wall may have flexural capacity greater than the coderequired capacity, and the shear associated with this moment capacity may exceed the code-required shear capacity. In such a case, the shear wall design meets or exceeds the required capacity but, in the event envisioned by the code, a brittle failure that the code intended to prohibit will occur.

The location and behavior of a weak link in the load path of a lateral-force-resisting system must be evaluated. For the shear wall building, the excitation of the structural system will be limited by the flexural or shear capacity of the shear walls, not the codespecified forces. Further, if the base shear of the lateral-force-resisting system is equal to the minimum required capacity, the excitation of the structural system is related to the expected capacity of the system and not to elastic structural response forces. The expected capacity of the structural system is the limit-state base shear capacity of the system. This limit state is the development of as many yield zones as necessary to describe a limit yield state. For reinforced concrete or masonry shear wall, it would be the limit state when all vertical reinforcement outside of the compressive stress block has yielded. A second case of a limit state for a shear wall may be the uplifting of one edge of the foundation from the soil. Any of these limit states may define a "weak link." 
The analysis of the specified demand versus capacity of the elements of the lateralforce-resisting system should determine when excess capacity exists as well as where the capacity is less than the specified demand. The evaluation of the load path could begin at the building base with the elements that couple the structure. The required demand on each link in the load path can be compared to its existing capacity pursuing the following process:

a) If the existing capacity exceeds the demand, the link above should be evaluated for both the required demand and the existing capacity of the element below.

b) If there is a probability of a brittle failure in the second link in the load path, the required capacity should be equal to the existing capacity of the preceding link.

c) If the behavior of the link being evaluated is expected to be ductile, the existing capacity is compared to the required demand.

\subsubsection{Special Concerns}

Elements that have been observed to be especially vulnerable in earthquakes or windstorms are of special concern. All lateral loads exerted on the building must be transferred through horizontal members to vertical members and finally, to the foundation. This load transfer process involves the use of structural members which include beams and columns, shear walls, diaphragms, struts, ties, and collectors. The principal concern is to determine whether these critical load-carrying members have adequate strength to avoid local failure that may lead to partial or total collapse of the building.

a) Short columns - In general, the forces are distributed in proportion to the stiffness of the resisting elements. The stiffness of a column varies approximately as the cube of its length. Thus, when more than one column is resisting the lateral load, short columns having larger lateral stiffness attract a greater share of the horizontal load than long columns. Figure 1.1 illustrates this important aspect of the distribution of the horizontal load to the columns having varying lengths. For example, if the columns have the same cross section but the short columns are half the length of the long columns, the short columns will be eight times stiffer and will take eight times the horizontal load of the long columns.

b) Collectors and Chords in Diaphragm - Figure 1.2 illustrates how the lateral load is transferred to the vertical walls. For lateral loading in the east-west direction, the structural members labeled as "A" serves as collectors. Depending upon the direction of the lateral force, they are either in tension or in compression. The same members function as chords of the diaphragm for lateral loading in the north-south direction. Again, depending upon the direction of the lateral load, they are either in tension or in compression. The members labeled as "B" serve as collectors for lateral loading in the north- 
south direction. They are sometimes referred as "drag struts. They are in compression (functioning as struts) when the load is in the northerly direction and in tension (dragging the diaphragm load into the wall) when the load is in the southerly direction. These collectors and chords, often part of the slab or beams, must have adequate strength to transfer tension and compression forces.

c) Discontinuous Shear Wall - A shear wall that stops at an upper level instead of continuing to the foundation is one such element. The horizontal shear is transferred to other horizontal load resisting elements through struts or a diaphragm at that level. The overturning forces, however, continue down to the ground in the columns that support the wall. Because shear walls often have excessive strength, they may be able to develop shears and overturning forces much higher than the design required. The supporting columns, however, may have only minimum design strength and may be overwhelmed by the large overturning forces. Modern building codes require such critical elements to be designed to a higher force level related to probable response. Figure 3.7 illustrates this condition.

d) Soft and Weak Stories - The most serious condition of vertical irregularity is that of the soft and weak story in which one story, usually the first, is more flexible and significantly weaker than others. The difference between "soft" and "weak" stories is the difference between stiffness and strength. A column may be limber but strong, or stiff but weak. A high first story is often architecturally desirable to accommodate larger rooms such as lobbies, banking floor, or hotel meeting rooms. The weak story creates a major stress concentration at the points of discontinuity and, in extreme circumstances, may lead to collapse of that story. Figure 3.4 illustrates the soft or weak story condition.

Other special concerns can be reflected in questions that can be answered by yes or no. Is an adjacent building too close? Are the columns of a moment frame disproportionately bigger than the beams? Does the frame have the kind of details that are required?

\subsubsection{Final Evaluation}

At the conclusion of the initial analysis and the examination of special concerns using this manual, the engineer should assemble the results and compile a list of deficiencies. The detailed evaluation must be followed by further investigation of the elements that do not meet the basic acceptance criteria. The earthquake or windstorm portion of the demand (denoted by $D_{E}$ ) is compared to the capacity that is available to resist earthquake or wind forces (denoted by $C_{E}$ ). The elements with the highest $D_{E} / C_{E}$ ratios are the ones of most concern and their importance must be assessed in terms of how high the $D_{E} / C_{E}$ ratios are and the consequences of the failure of these elements. 
The assessment also should include qualitative answers to the other concerns. The most difficult task in the evaluation is to make a reasonable judgment concerning the building so that the building is not incorrectly identified as a life-safety hazard. The report should conclude with a "bottom line" statement to the owner. This statement should include a comment on the engineer's level of confidence in the available building information and the applicability of the methodology to the building. This statement also might include a suggestion concerning a more detailed evaluation.

\subsection{Manual Contents}

Chapter 2 provides a guide to the evaluation process from the initial site visit to the identification of deficiencies of the building that require detailed analysis for the final judgment of the building. Chapters 3 through 5 provide commentary on building systems and procedures for dealing with statements (checklists) that are found to be false. The following are addressed:

1. Building systems (Chapter 3 )

2. Geologic hazards and foundations (Chapter 4)

3. Nonstructural components (Chapter 5)

The references cited in the Manual are listed in Chapter 6. Appendices A through $E$ present the evaluation statements (checklists) for three concrete building types, geologic site hazards and foundations, and nonstructural components. Appendix $F$ presents a data summary sheet. 

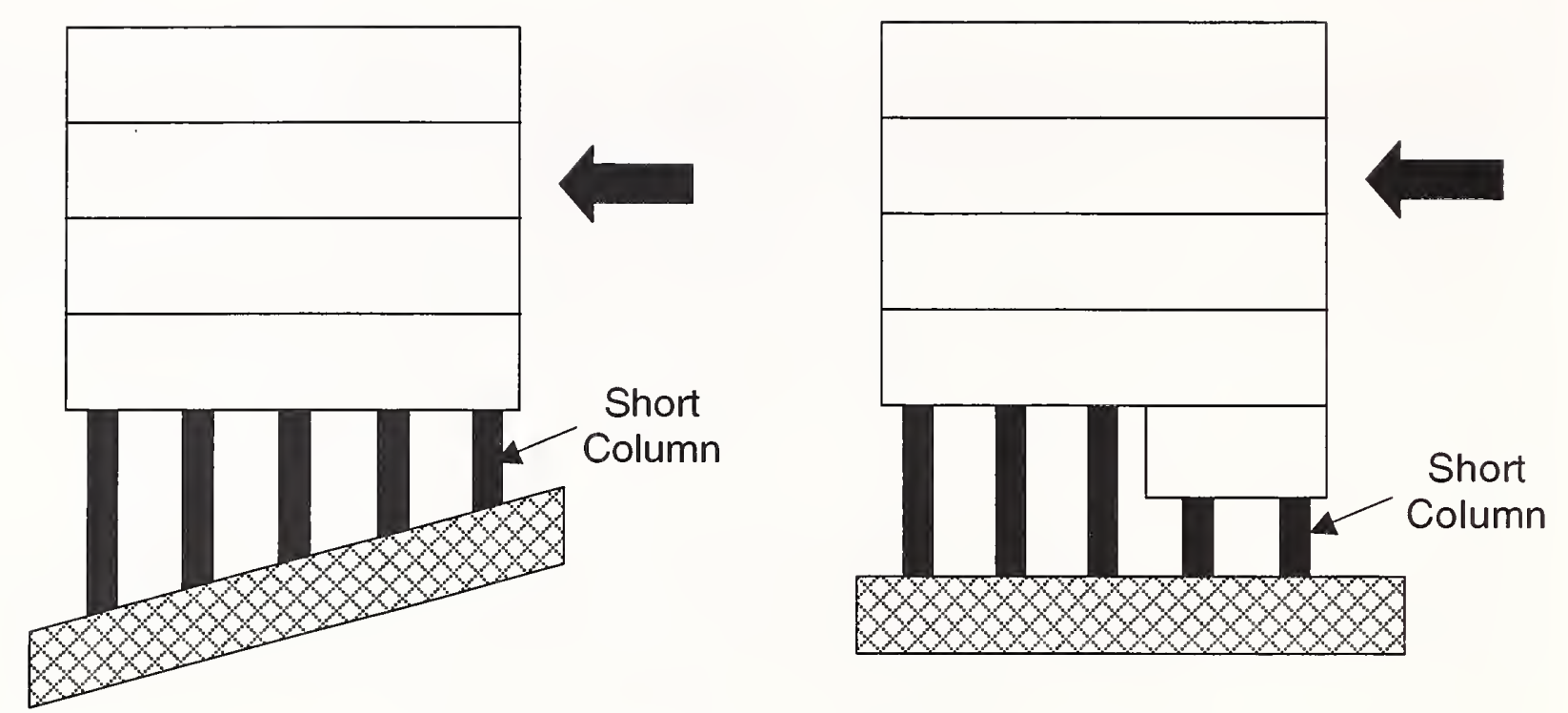

Figure 1.1 - Short Columns

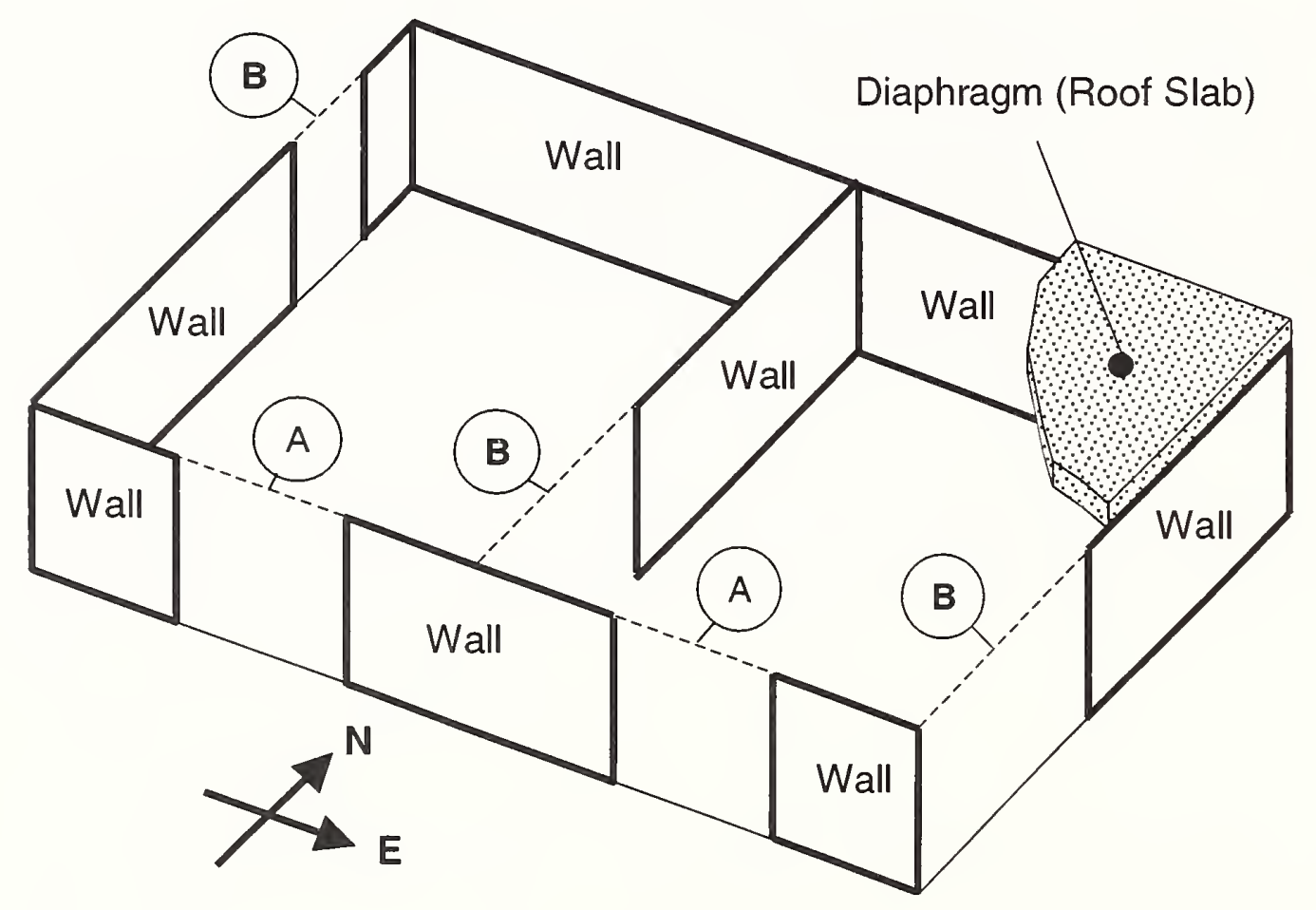

Figure 1.2 - Diaphragm and Collector System 


\section{THE EVALUATION PROCESS}

\subsection{Introduction}

The evaluation methodology is based on addressing sets of questions designed to uncover deficiencies and weaknesses of a building using the data collected from the building site and the relevant design and construction documents. The questions are in the form of positive evaluation statements (checklists) describing building characteristics that are essential if the failures observed in past earthquakes or windstorms are to be avoided. The evaluating engineer should address each statement and determine whether it is compliant, non-compliant or not applicable. Compliant statements identify conditions that are acceptable, and non-compliant statements identify conditions in need of further investigation. This manual recommends a process for dealing with statements that are found to be non-compliant.

The following steps are suggested for the evaluation process:

1. Collect and review, prior to a site visit, available documents pertaining to the design and construction of the building for evaluation.

2. Select a set of the basic and supplemental evaluation statements appropriate for the building type and review. Also review the statements related to geologic site hazards and foundations and nonstructural components.

3. Conduct a site visit. Complete the data collection sheet (Appendix F). If construction documents are available, verify that the building was constructed in accordance with the documents.

4. Perform a checklist evaluation.

5. Conduct analysis required for the evaluation statements that have been found to be Non-Compliant.

6. Perform final evaluation of the building.

7. Prepare an evaluation report.

\subsection{Site Visit and Data Collection}

The evaluating engineer should be present on the first visit to the building. At this time, the engineer should take photographs and make the initial evaluation of the building using the checklists. The evaluating engineer then should: 
1. Determine site soil conditions, refer to the geotechnical report if available.

2. Establish the following site and soil parameters:

a. Peak Ground Acceleration (PGA) coefficient from Fig. 2.1 if, in lieu of the 1979 Provisonales, the lateral force is determined in accordance with more refined provisions.

b. Soil Profile Type (1, 2, 3, or 4) derived from the geotechnical report or from Table 2.1

c. Site Coefficient, (S), from Table 2.1.

3. Assemble building design data including original contract drawings and specifications, as-built drawings, and calculations.

4. Look for other data such as assessments of building performance following past earthquakes or windstorms.

5. Evaluate the terrain surrounding the structure from the point of view of its roughness (i.e., whether it is open terrain, suburban terrain, or urban terrain). This information shall be used if, in lieu of the 1980 Provisionales, it is deemed necessary to use the more refined provisions of the ASCE 7-98 Standard.

6. Note whether the terrain upwind of the structure contains features that may result in an amplification of wind loads.

7. Prepare a summary of the data using the form in Appendix F.

TABLE 2.1 Soil Profile Types * and Site Coefficients

\begin{tabular}{|c|l|c|}
\hline $\begin{array}{l}\text { Soil Profile } \\
\text { Type }\end{array}$ & \multicolumn{1}{|c|}{ Profile with } & $\begin{array}{c}\text { Site } \\
\text { Coefficient, S }\end{array}$ \\
\hline 1 & $\begin{array}{l}\text { Soil profile with crystalline rock, or stiff soils of } \\
\text { igneous and metamorphic rocks }\end{array}$ & 1.00 \\
\hline 2 & Sedimentary deposit of marine origin & 1.20 \\
\hline 3 & Recent alluvial deposit of mixed origin & 1.50 \\
\hline 4 & Soil profile not defined above & 1.35 \\
\hline
\end{tabular}

*These soil types are defined in the 1979 Recomendaciones Provisionales. 
It is often difficult to collect necessary information for building evaluation. In many instances, the needed information is not readily available and requires diligent effort by the evaluating engineer. The following are typical examples:

a) One difficulty is the matter of uncovering the structure. In many buildings the structure is concealed by architectural finishes, and the engineer will have to get into attics, crawl spaces, and plenums.

b) Lack of plans and calculations also may be a problem, and this is particularly frustrating with respect to concrete work.

c) Assessing material quality and allowable stresses also is difficult, and some destructive testing may be necessary. Destructive and nondestructive testing of reinforced concrete and masonry elements may be necessary to determine capacity and quality.

d) If reinforcing plans are available, a limited amount of exposure of critical reinforcement may be made to verify conformance to the plans. If the plans are not available, the quantity of reinforcement may be determined by nondestructive methods. The results of the nondestructive testing should be verified by a limited amount of reinforcement exposure.

When the nature of a structural element or system is not clear, more field work may be needed. The original design engineer should be consulted if possible. The evaluating engineer may find it helpful to do some research on historical building systems, to consult old handbooks, and perhaps to consult with older engineers who have knowledge of early structural work in the community or region. A good knowledge of former construction practices and construction requirements may be gained through study of the building code requirements applicable at the building location when it was constructed. The evaluation, however, should be based on facts, not assumptions, to the greatest extent possible.

\subsection{Select and Review of Evaluation Statements}

Having seen the building and assembled all available plans and other data, the engineer should determine the building type and address the evaluation statements (checklists) as follows:

1. Look for and define in words and by three-dimensional sketch the lateralforce-resisting system; make use of whatever components are available and effective to constitute a system.

2. Judgment should be used in selecting the appropriate evaluation statement set.

3. Reproduce from Appendix A, B, C, D and $E$ and a set of evaluation statements that applies to the building being evaluated. 
4. Tentatively answer the statements; see Chapters 3 through 5 for guidance.

If a statement is found to be compliant, the condition being evaluated is acceptable and the issue may be set aside. If a statement is found to be non-compliant, a condition exists that needs to be addressed further. Each statement includes a reference to a particular section in Chapters 3 through 5 where commentaries on the issues are given. These chapters are organized according to the basic building systems, the geologic site hazards and foundations, and the nonstructural components.

Each commentary section starts with a general discussion of the relevant system, component, or element, and ends with specific discussions of related evaluation statements from one or more of the lists in Appendix A, B, or C. The evaluating engineer should always read the general discussion at the beginning of each chapter and section. The statement is repeated and discussed in detail, and the deficiency is described. In the simplest cases, the issue might be resolved simply by obtaining more information from the field or the defect may be so obvious that recommendations can be made without further investigation.

When all the statements have been addressed, the engineer should assemble the list of deficiencies and the results of the analysis and proceed to the final evaluation discussed in Sec. 2.5.

\subsection{Follow-up Field Work}

The first assessment of the evaluation statements may indicate a need for more information about the building. The engineer should plan to do the following:

1. Verify existing data;

2. Develop other needed data (e.g., measure and sketch building if necessary);

3. Verify the vertical and lateral load resisting systems;

4. Check the general condition of the building;

5. Look for special conditions, anomalies, and oddities;

6. Address the evaluation statements again while in the field; and

7. Perform material tests that are justified through a weighing of the costs of destructive testing and the cost of corrective work. 


\subsection{Analysis of the Buildings}

The general requirements for building analysis (including the determination of force level, horizontal distribution of lateral forces, accidental torsion, and overturning) are discussed in this section. For seismic evaluations, the procedure is based on the 1991 NEHRP Recommended Provisions, and the 1979 Recomendaciones Provisionales para el Analisis Sismico de Estructuras. For cases where dynamic analysis is required, the general requirements are given in Sec. 2.4.10. For wind resistance evaluations, the methods for estimating wind effects specified in the 1980 Provisionales should be used, unless it is deemed necessary to use the more refined provisions of the ASCE 7-98 Standard.

\subsubsection{Scope of Analysis}

In dealing with evaluation statements that are found to be non-compliant and require analysis, it may be better to plan an appropriate round of analyses that will cover the requirements rather than to proceed one by one. The usual analysis will consist of the following steps:

1. Calculate the building weight.

2. Calculate the building period.

3. Calculate the lateral force on the building due to seismic effects and, separately, to wind effects.

4. Distribute the lateral force over the height of the building and calculate the story shears and overturning moments.

5. Distribute the story shears to the vertical resisting elements in proportion to their relative stiffnesses.

6. Analyze individual elements as required by the evaluation statements.

a. Make load and reaction diagrams for diaphragms and for the vertical resisting elements (forces for diaphragm, wall and frame analysis are taken from these diagrams).

b. Calculate shearing stresses and chord forces in the diaphragm.

c. Analyze the vertical components (walls and frames) and the member forces.

d. Calculate total forces according to the specified load combinations.

If original design calculations are available, the analyses therein may be usable with a scaling factor to relate the original design base shear to the base shear of this manual. 
The distribution of story shears to the vertical lateral-force-resisting elements in that story in proportion to their relative stiffnesses is a convenient procedure that should yield reasonable results for the case of moment frames consisting of beams and columns. However, in multistory frame-shear wall structures or in structures where the vertical resisting elements have significantly different lateral stiffnesses or where the stiffnesses of the vertical resisting elements change drastically over the height of the structure, a distribution of story shears in proportion to the relative stiffnesses of the vertical resisting elements in the individual story can lead to erroneous results. For these and similar cases, an analysis of the entire structure under the prescribed lateral loads is recommended.

It should be noted that if the seismic load, on an ordinary working-stress basis, is less than about one third of the total load including gravity and seismic loads, there may not be overstress in a member properly designed for gravity loads because the usual onethird increase in allowable stresses for seismic loads would provide the necessary capacity. However, nothing should be taken for granted, and even if stresses are acceptable, it is necessary to follow the procedures in this manual including checking of the adequacy of the load paths, the lateral-force-resisting components, and the details.

\subsubsection{Demand}

All building components under evaluation should be able to resist the effects of the seismic forces prescribed herein and the effects of gravity loading from dead and live loads. The following load combinations will be used:

$$
Q=1.1\left(Q_{D}+Q_{L}\right) \pm Q_{E}
$$

or

$$
Q=0.9 Q_{D} \pm Q_{E}
$$

where

$$
\begin{aligned}
& Q=\text { the effect of the combined loads; } \\
& Q_{D}=\text { the effect of dead load; } \\
& Q_{L}=\text { the effective live load is equal to } 25 \% \text { of the unreduced design live load } \\
& \text { but not less than the actual live load; } \\
& Q_{E}=\text { the effect of lateral (seismic or wind) forces }(0.75 \mathrm{~V}) .
\end{aligned}
$$

The seismic or wind portion of the demand, $\left(Q_{E}\right)$, is obtained from analysis of the building using the seismic or wind base shear, (V). 


\subsubsection{Seismic and Wind Analysis of the Building}

The seismic or wind base shear is the basic seismic or wind demand on the building. Element forces obtained from analysis based on this demand are the element demands, $\left(Q_{E}\right)$, to be used in the load combinations of Eq. 2-1 and 2-2.

The base shear, $(\mathrm{V})$, in a given direction, vertical distribution of forces, and story shear should be determined in accordance with the 1979 Provisionales for seismic loading and from the 1980 Provisionales for calculating wind effects, unless it is deemed necessary to use the more refined provisions of the ASCE 7-98 Standard. When the 1980 Provisionales are used, the wind velocities should be multiplied by 1.2 to obtain nominal 500-year wind velocities.

\subsubsection{Demand on Diaphragms}

The deflection in the plane of the diaphragm, as determined by engineering analysis, should not exceed the permissible deflection of the attached elements. Permissible deflection should be that deflection which will permit the attached element to maintain its structural integrity under the individual loading and continue to support the prescribed loads without endangering the occupants of the building.

Floor and roof diaphragms should be designed to resist the seismic forces determined as follows. A minimum force equal to 0.5 PGA (peak ground acceleration, see Fig. 2.1) times the weight of the diaphragm and other elements of the building attached thereto plus the portion of the seismic shear force at that level required to be transferred to the components of the lateral-force-resisting system. For wind forces the floor and roof diaphragms should resist the horizontal wind forces they must transmit to the lateralforce-resisting system.

Diaphragms should resist for both the shear and bending stresses resulting from lateral forces. Diaphragms should have ties or struts to distribute the wall anchorage forces into the diaphragm.

\subsubsection{Demand on Parts and Portions of the Building}

This section addresses those building elements that are not part of the lateral-forceresisting system. These elements include nonstructural architectural elements (e.g., appendages and exterior cladding) and structural elements that are not part of the lateral-force-resisting system or are part of the lateral-force-resisting system only in the other direction (e.g., walls when considered with an orientation perpendicular to the direction of the lateral forces). Parts and portions of structures and permanent nonstructural components should be evaluated to verify that they are capable of resisting the seismic or wind forces specified below. All attachments or appendages, 
including anchorages and required bracing, should be evaluated for seismic or wind forces.

Each element or component evaluated should be capable of resisting a total lateral force equal to 1.3 times the wind force as specified in the 1980 Provisionales, or a seismic force as follows:

$$
F_{p}=0.67\left(A C_{c} W_{c}\right)
$$

where

$$
\begin{aligned}
& A=\text { peak ground acceleration values given in Fig. 2.1, } \\
& C_{c}=\text { a coefficient given in Table 2.2, and } \\
& W_{c}=\text { the weight of the element or component. }
\end{aligned}
$$

TABLE 2.2 Seismic Coefficient, $C_{c}$

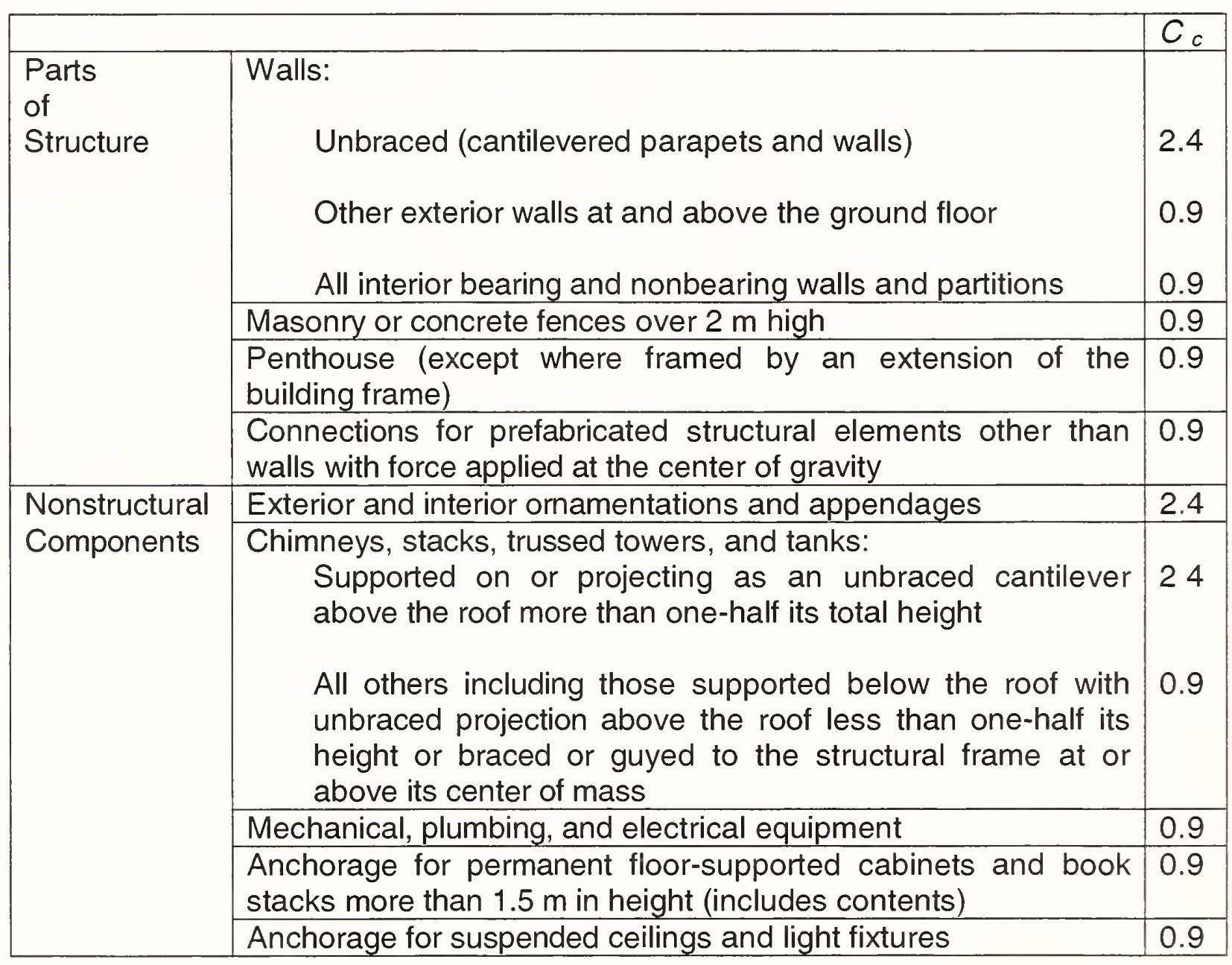


When the roof and cladding are evaluated for wind load, both localized positive and negative (suction) pressure distributions must be considered. Figure 2.2 is an illustrative schematic of local pressure distributions on a low-rise building.

\subsubsection{Quick Check of Strength and Stiffness}

Before starting an analysis of a complete building, the evaluating engineer is encouraged to make a quick check of the strength and stiffness of the building. "Quick Checks," are triggered by evaluation statements (checklists) in Appendices A, B and C.

In the review of an existing structure, it may be necessary to check the average shear stress for upper stories in addition to the first story. In this case, the seismically-induced story shear for an upper story may be approximated as follows

$$
V_{j}=\left(\frac{n+j}{n+1}\right)\left(\frac{W_{j}}{W}\right) 0.9 V
$$

where

$$
\begin{aligned}
& \mathrm{V}_{\mathrm{j}}=\text { maximum story shear at story Level } \mathrm{j}, \\
& \mathrm{n}=\text { total number of stories above ground level, } \\
& \mathrm{j}=\text { number of story level under consideration, } \\
& \mathrm{W}_{\mathrm{j}}=\text { total dead load of all stories above Level } \mathrm{j}, \\
& \mathrm{W}=\text { total dead load, and } \\
& \mathrm{V}=\text { base shear from the } 1979 \text { Provisionales. }
\end{aligned}
$$

\subsubsection{Shearing Stress in Concrete Frame Columns}

The equation for a quick estimate of the average shearing stress, $\left(v_{\text {avg }}\right)$, in the columns of concrete frames is as follows:

$$
v_{\text {avg }}=\left(\frac{n_{c}}{n_{c}-n_{f}}\right)\left(\frac{V_{j}}{A_{c}}\right)
$$

where

$$
\mathrm{n}_{\mathrm{c}}=\text { total number of columns, }
$$




$$
\begin{aligned}
& n_{f}=\text { total number of frames in the direction of loading, } \\
& A_{c}=\begin{array}{l}
\text { summation of the cross sectional area of all columns in the story under } \\
\text { consideration, and }
\end{array} \\
& V_{j}=\text { story shear from induced by earthquake or wind. }
\end{aligned}
$$

Eq. 2-5 assumes that nearly all of the columns in the frame have similar stiffnesses. . Eq. 2-5 should not be used if the stiffnesses of the columns in a story are not uniform.

\subsubsection{Shearing Stress in Shear Walls}

The equation for a quick estimate of the average wall shear stress, $\left(V_{\text {avg }}\right)$, is as follows:

$$
v_{\text {avg }}=\frac{V_{j}}{A_{w}}
$$

where

$$
\begin{aligned}
V_{j}= & \text { story shear at the level under consideration, and } \\
A_{w}= & \begin{array}{l}
\text { summation of the horizontal cross sectional area of all shear walls in the } \\
\text { direction of loading. The wall area should be reduced by the area of any } \\
\text { openings. For masonry walls use the net area. }
\end{array}
\end{aligned}
$$

\subsubsection{Element Capacities}

Calculate element capacities on the ultimate-strength basis of $\mathrm{ACl}$ 318-99. When calculating capacities of deteriorated elements, the evaluating engineer should make appropriate reductions in the material strength, the section properties, and other aspects of the capacity affected by the deterioration.

\subsubsection{Dynamic Analysis}

The procedures given in this Manual use the equivalent lateral force procedure. The use of a dynamic analysis procedure is required for tall buildings, for buildings with vertical irregularities caused by significant mass or geometric irregularities, and for other buildings where the distribution of the lateral forces departs from that assumed in the equivalent lateral force procedure. 


\subsubsection{Acceptance Criteria}

The analysis should be performed according to the procedures given in the sections above. The total demand, $Q$, is calculated by Eq. $2-1$ or $2-2$. The capacity, $C$, is calculated according to the procedures of Sec. 2.4.9. The basic acceptance criterion is:

$$
Q<C
$$

Where elements or portions of a lateral-force-resisting system are expected to behave in a less ductile manner than the system as a whole, the term $Q_{E}$ in Eq. (2-1) and (2-2) should be modified to account for the different failure modes of the various elements. Less ductile elements may fail prematurely unless they are strong enough to remain elastic.

If all significant elements meet the basic acceptance criteria as specified herein, no further analysis is needed. Elements that do not meet the acceptance criteria are the deficiencies that should be addressed in a further study.

\subsection{Final Evaluation}

\subsubsection{Review the Statements and Responses}

Upon completion of the field work and the analysis, the evaluating engineer should review the evaluation statements and the responses to the statements to ensure that all of the concerns have been addressed.

\subsection{2 $Q$ versus $C$}

The criterion $Q \# C$ is an indication of whether an element meets the requirements of the 1991 NEHRP Recommended Provisions and the 1979 Recomendaciones Provisionales para el Analisis Sismico de Estructuras or the requirements for wind loading defined in Section 2.4.5.

\subsection{3 $D_{E} / C_{E}$ Ratios}

The seriousness of the deficiencies can easily be assessed by listing the $D_{E} / C_{E}$ ratios in descending order, where $D_{E}$ is the unreduced lateral load demand (i.e. demand with $R=1$ ) and $\mathrm{C}_{\mathrm{E}}$ is the member capacity available to resist lateral forces. The element with the largest value is the weakest link in the building. If the element can fail without jeopardizing the building or can be fixed easily, then attention should be focused on the element with the next lower ratio, and so on. 


\subsubsection{Qualitative Issues}

Some of the procedures identify specific deficiencies without any calculation. These can be general concerns (e.g., an adjacent building that is too close) or element concerns. Some will be difficult to remedy, but the evaluation will at least identify the hazard; others simply can be listed as items that are relatively easy to deal with in an upgrade, (e.g., add some braces or strengthen a connection).

\subsubsection{Final Evaluation}

The final evaluation is a statement about the building based on a review of the qualitative and quantitative results of the procedures and the list of deficiencies.

The evaluating engineer should consider the issues carefully, refrain from penalizing the building over fine technical points beyond those contained in the evaluation methodology, and visualize the building in its ultimate condition in earthquake and in windstorm.

\subsection{Final Report}

The report should include the following elements:

1. A description of the building on the data summary sheet in Appendix F.

2. The set of statements (Appendix A, B or C, and Appendices D and E) and a synopsis of the investigation.

3. A list of deficiencies that must be remedied in order to change statement responses from $\mathrm{NC}$ (non-compliant) to $\mathrm{C}$ (compliant).

4. Comments on the relative importance of the deficiencies. 


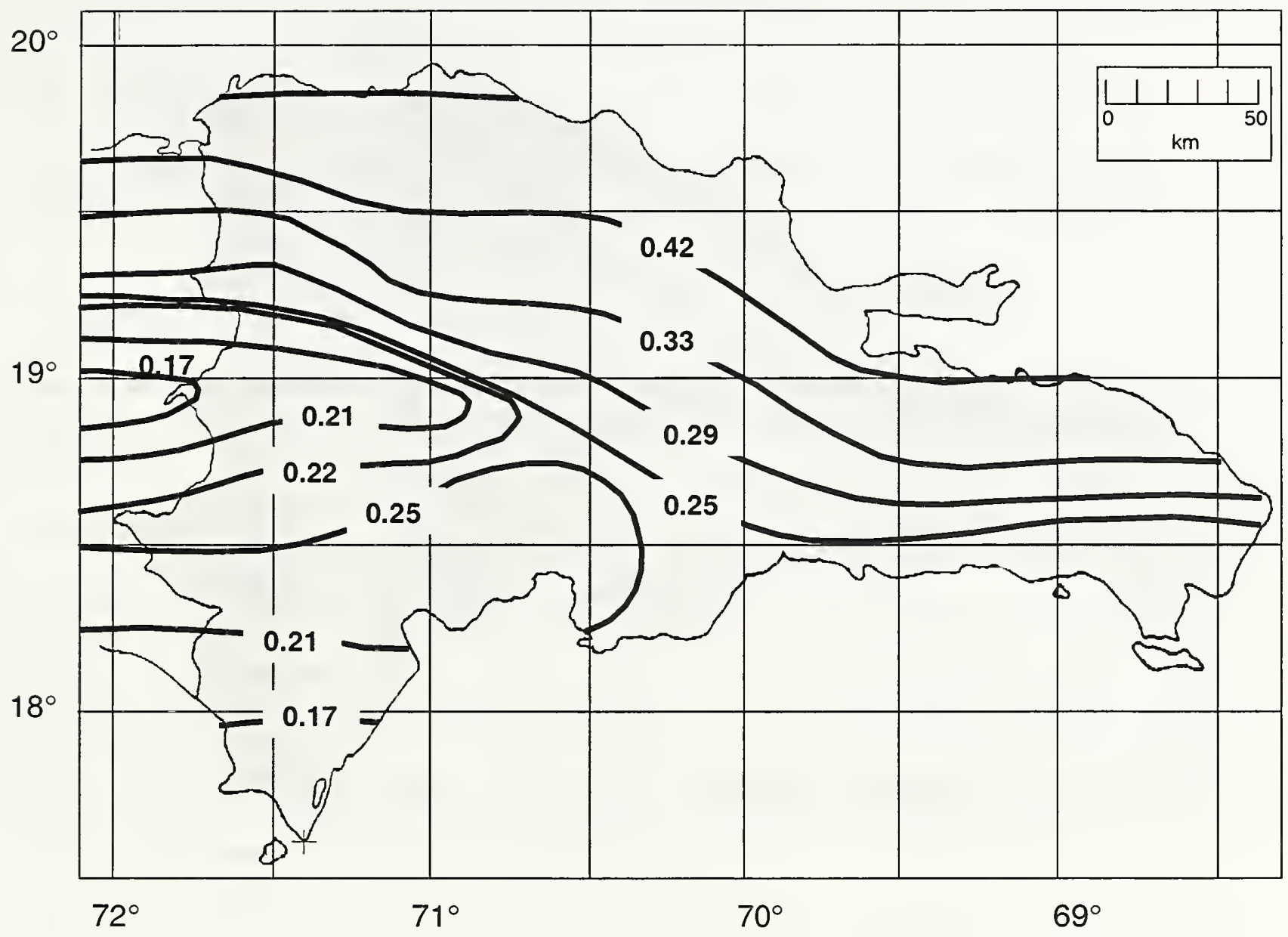

Figure 2.1 - Peak ground acceleration (PGA) contours (50 year return period, $10 \%$ probability of being exceeded) 


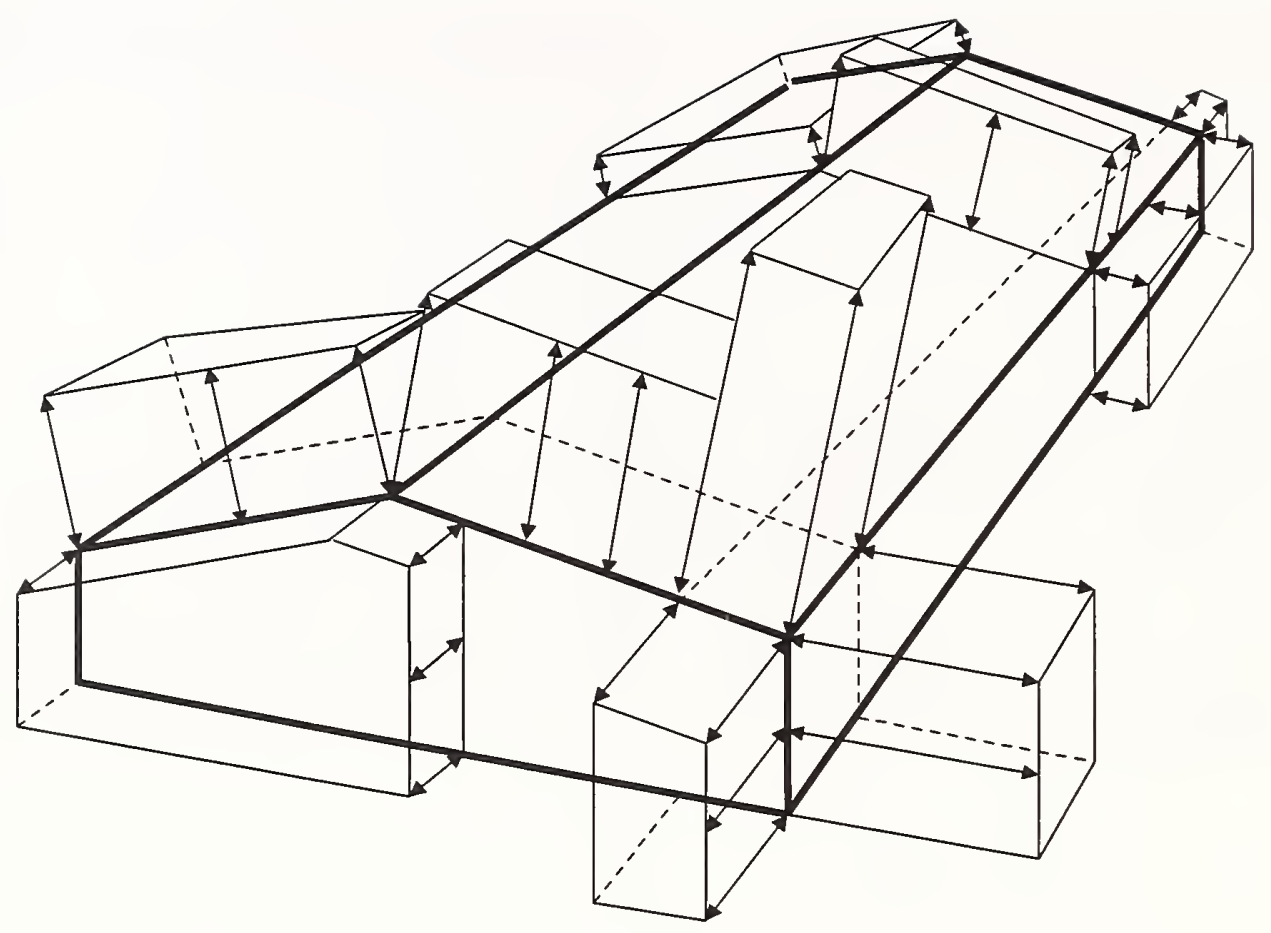

Figure 2.2 - Localized wind pressure distributions 


\section{PROCEDURES AND COMMENTARY FOR BUILDING SYSTEMS}

\subsection{Introduction}

This chapter discusses general requirements that apply to all buildings: load path, adjacent buildings, configuration, redundancy, and the condition of the materials.

\subsection{Load Path}

The structure contains a complete load path for seismic and wind force effects from any horizontal direction that serves to transfer the lateral forces to the foundation.

Commentary:

For proper performance under seismic or wind loads, a lateral force resisting system must exist that forms a load path between the foundation, all diaphragm levels, and all portions of the building. The general path is as follows: earthquake forces, which originate in all the elements of the building, or wind forces which originate on the building surface, are delivered through structural connections to horizontal diaphragms; the diaphragms distribute these forces to vertical resisting components such as shear walls and frames; the vertical elements transfer the forces into the foundations; and the foundation transfers the forces into the supporting soil.

If there is a discontinuity in the load path, the building is unable to resist lateral forces regardless of the strength of the existing elements. Mitigation with elements or connections needed to complete the load path is necessary to achieve the selected performance level. The structural engineer should be watchful for gaps in the load path. Examples would include a shear wall that does not extend to the foundation, a missing shear transfer connection between a diaphragm and vertical elements, a discontinuous chord at a diaphragm notch, a missing collector, or a connection that is incapable of delivering a diaphragm shear to a shear wall or frame.

In cases where there is a structural discontinuity, a load path may exist but it may be a very undesirable one. At a discontinuous shear wall, for example, the diaphragm may transfer the forces to frames not intended to be part of the lateral-force resisting system. While not ideal, it may be possible to show that the load path is acceptable.

A complete load path is a basic requirement for all buildings. The remaining evaluation statements (checklists) in this manual target specific components of the load path and are intended to assist the evaluating engineer in locating potential gaps in the load path. While non-compliant statements further along in the procedure might indicate a potential 
discontinuity or inadequacy in the load path, the identification of a complete load path is a necessary first step before continuing with the evaluation

\subsection{Adjacent Buildings}

\section{An adjacent building must not be located next to the structure being evaluated closer than $4 \%$ of the height.}

Commentary:

Buildings are often built right up to property lines in order to maximize the use of space, and historically buildings have been designed as if the adjacent buildings did not exist. As a result, the buildings may impact each other, or pound, during an earthquake. Pounding can alter the dynamic response of both buildings, and impart additional inertial loads on both structures.

Buildings that are of the same height and have matching floors will exhibit similar dynamic behavior. If the buildings pound, floors will impact other floors, so damage due to pounding usually will be limited to nonstructural components. When the floors of adjacent buildings are at different elevations, floors will impact the columns of the adjacent building and can cause structural damage (see Fig. 3.1). When the buildings are of different heights, the shorter building can act as a buttress for the taller building. The shorter building receives an unexpected load while the taller building suffers from a major stiffness discontinuity that alters its dynamic response (see Fig. 3.2). Since neither building is designed for these conditions, there is a potential for extensive damage and possible collapse.

Buildings that are of the same height and have matching floor levels need not comply with this statement. Non-compliant reparations between buildings that do not have matching floors must be checked using calculated drifts for both buildings.

\subsection{Configuration}

Good design, details, and construction are of secondary value if the building has an odd shape that is not properly considered in the design. Although a building with an irregular configuration may be designed to meet all code requirements, it probably will not perform in an earthquake or a windstorm as well as a building with a regular configuration. Typical configuration deficiencies include an irregular geometry, a weakness in a given story, a concentration of mass, a discontinuity in the lateral force resisting system, or a geometric shape conducive to the development of aerodynamic moments about the center of rigidity of the building or to unusual cross-wind effects.

Vertical irregularities are defined in terms of discontinuities of strength, stiffness, geometry, and mass. These qualities are listed separately, but are related and may 
occur simultaneously. For example, the frame in Figure 3.3 has a tall first story. It can be a weak story, a soft story, or both depending on the relative strength and stiffness of this story and the stories above.

One of the basic goals in the design of a building is efficient use of materials such that all members are stressed about equally and yielding is distributed throughout the building. Distributed yielding dissipates more energy and helps prevent the premature failure of any one element or groups of elements. For example, in moment frames it is desirable to have strong columns relative to the beams to help distribute the formation of plastic hinges throughout the building and prevent the formation of a story mechanism. Code provisions regarding vertical irregularity are intended to achieve this result. Significant irregularities that would cause damage to be concentrated in certain areas require special treatment.

Horizontal irregularities involve the horizontal distribution of lateral forces to the resisting frames or shear walls. Irregularities in the shape of diaphragm itself (i.e., diaphragms that have projecting wings or re-entrant corners) are discussed in Section 3.3.7.

\subsubsection{Weak Story:}

Visual observation or a Quick Check indicates that there are no significant strength discontinuities in any of the vertical elements in the lateral-forceresisting system. The stiffness of the lateral-load-resisting system in any story must not be less than $\mathbf{8 0 \%}$ of the strength in an adjacent story above or below.

Commentary:

A "weak" story is defined as one in which the story strength is less than $80 \%$ of that in the story above. The story strength is the total strength of all the lateral-force-resisting elements sharing the story shear for the direction under consideration. It is the shear capacity of the columns or the shear walls. If the columns are flexure controlled, the shear strength is the shear corresponding to the flexural strength. Weak stories are usually found where vertical discontinuities exist, or where member size or reinforcement has been reduced. It is necessary to calculate the story strengths and compare them. The deficiency that usually makes a story weak is inadequate strength of frame columns. The result of a weak story is a concentration of inelastic activity that may result in the partial or total collapse of the story. The presence of a weak story is particularly serious where a large response modification factor $(R)$ is used.

\subsubsection{SOFT STORY:}

The stiffness of the lateral-force-resisting system in any story is not less than $70 \%$ of the stiffness in an adjacent story above or below, or less than $80 \%$ of the average stiffness of the three stories above or below. 


\section{Commentary:}

This condition commonly occurs in commercial buildings with open fronts at groundfloor storefronts, and hotels or office buildings with particularly tall first stories. Figure 3.3 shows an example of a tall story. Such cases are not necessarily soft stories because the tall columns may have been designed with appropriate stiffness, but they are likely to be soft stories if they have been designed without consideration for interstory drift. Soft stories usually are revealed by an abrupt change in interstory drift (story deflection). Although a comparison of the stiffnesses in adjacent stories is the direct approach, a simple first step might be to plot and compare the interstory drift as indicated in Figure 3.4 if analysis results happen to be available.

The difference between "soft" and "weak" stories is the difference between stiffness and strength. A column may be limber but strong or stiff but weak. A change in column size can affect strength and stiffness, and both need to be considered. The deficiency that usually makes a story weak is in the strength of the columns.

\subsubsection{Geometry:}

There are no significant geometrical irregularities. There must be no change in horizontal dimension of the lateral-force-resisting system of more than $30 \%$ in a story relative to adjacent stories, excluding one-story penthouses.

Commentary:

Geometric irregularities are usually detected in an examination of the story-to-story variation in the dimensions of the lateral-force-resisting system (Fig. 3.5). A building with its upper stories set back from a broader base structure is a common example. Another example is a story in a high-rise that is reduced in width for architectural reasons. It should be noted that the irregularity of concern is in the dimensions of the lateral-force-resisting system, not the dimensions of the envelope of the building, and, as such, it may not be obvious. Geometric irregularities are easily detected in an examination of the story-to-story variation in the dimensions of the lateral systems. The deficiency is in the stiffness of certain portions of the building.

Geometric irregularities affect the dynamic response of the structure, and may lead to unexpected higher mode effects and concentrations of demand.

\subsubsection{Mass}

There is no change of effective mass of more than $50 \%$ from one story to the next, excluding light roofs. 


\section{Commentary:}

Mass irregularities can be detected by comparison of the story weights (Fig. 3.6). The effective mass consists of the dead weight of the structure tributary to each level, plus the actual weights of partitions and equipment at each floor. A roof that is lighter than the floor below need not be considered. The validity of this approximation is dependent upon the vertical distribution of mass and stiffness in the building. Mass irregularities affect the dynamic response of the structure, and may lead to unexpected higher mode effects and concentrations of demand.

\subsubsection{Vertical Discontinuities}

\section{All vertical elements in the lateral-force-resisting system must be continuous to the foundation.}

Commentary:

Vertical discontinuities are usually detected by visual observation. The most common example is a discontinuous shear wall. The shear wall is not continuous to the foundation but stops at an upper level. The shear at this level is transferred through the diaphragm to other resisting elements below. The force transfer can be accomplished either through a strut if the elements are in the same plane (Fig. 3.7) or through a connecting diaphragm if the elements are not in the same plane (Fig. 3.8). In either case, the overturning forces that develop in the wall continue down through the columns that support the wall.

The issue is a local strength and ductility problem below the discontinuous element, not a global story strength or stiffness irregularity. The concern is that the wall may have more shear strength than considered in the design (the code required strength). While the strut or connecting diaphragm may be adequate to transfer the shear forces to adjacent elements, the columns that support the walls are the most critical. It should be noted that moment frames can have the same kinds of discontinuity even though this is rare.

Another common discontinuity is the lack of a column in a lower story where a transfer girder is used to provide for an opening wider than the typical bay. Vertical discontinuities are obvious: a wall or frame that simply stops at an upper story. The primary deficiency is in the strength of the columns that support the wall. The secondary deficiency is in the strength of the connecting strut or diaphragm.

\subsubsection{Earthquake Induced Torsion:}

The lateral-force-resisting elements must form a well balanced system that is not subject to significant torsion. The distance between the story center of rigidity 
and the story center of mass must be less than $20 \%$ of the width of the structure in either major plan dimension.

Commentary:

Whenever there is significant torsion in a building, the concern is for additional demands and lateral drifts imposed on the vertical elements by rotation of the diaphragm. Buildings can be designed to meet code forces including torsion, but buildings with severe torsion are less likely to perform well in earthquakes. It is best to provide a balanced system at the start, rather than design torsion into the system. One concern is for columns that support the diaphragm, especially if the columns are not intended to be part of the lateral-force-resisting system. The columns are forced to drift laterally with the diaphragm which induces lateral forces. Such columns often are not designed to resist these movements.

Another concern is the strength of the vertical elements of the lateral-force-resisting system that will experience additional seismic demands due to torsion.

In the Case A building shown in Figure 3.9, the center of gravity is near the center of the diaphragm while the center of rigidity is also near the centerline but close to wall $A$. Under longitudinal loading, the eccentricity, e1, between the center of gravity (center of earthquake load) and the center of rigidity (center of resistance) causes a torsional moment. The entire earthquake force is resisted directly by wall $A$ and the torsional moment is resisted by a couple consisting of equal and opposite forces in walls $B$ and C. These two walls have displacements in opposite directions and the diaphragm rotates.

Under a transverse loading, if walls $B$ and $C$ have equal rigidity, the building is symmetrical and there is no eccentricity between the centers of gravity and rotation and, therefore, no torsion. Walls $B$ and $C$ resist the earthquake force directly. If walls $B$ and $C$ have unequal rigidity, they still share the load equally but they have different amounts of displacement and this results in rotation of the diaphragm.

In the Case B building sketched in Figure 3.9, the diaphragm is extended to the right. The center of gravity shifts to the right and there is now an eccentricity, e2, for transverse loading; thus, there is torsion. The walls no longer share the force equally, and the diaphragm rotates.

These are very simple cases for analysis and design and if the systems are designed and detailed properly, they should perform well. With the ample proportions suggested by the length of the walls in Figure 3.9 (Case A), stresses will be low and there will be little rotation of the diaphragm. The concern appears when the diaphragm, and consequently the diaphragm stresses, become large; when the stiffness of the walls is reduced; or when the walls have substantial differences in stiffnesses. 
The Case $C$ building shown in Figure 3.10 has a more serious torsional condition than the ones in Figure 3.9. Wall $A$ has much greater rigidity than wall $D$ as indicated by their relative lengths. In the transverse loading, the center of rigidity is close to wall $A$ and there is a significant torsional moment. All four walls are involved in the resistance to the torsional moment. Walls $B, C$, and $D$, although strong enough for design forces, have little rigidity and that allows substantial rotation of the diaphragm. There are two concerns here. First, because of the rotation of the diaphragm, there is a displacement at $E$ and $F$, that induces sidesway moments in the columns that may not have been recognized in the design. Their failure could lead to a collapse. Second, the stability of the building under transverse loading depends on wall $D$. The Case $D$ building in Figure 3.10 is shown with wall $D$ failed. The remaining walls, $A, B$, and $C$, are in the configuration of Figure 3.9 (Case A) and now there is a very large eccentricity that may cause walls $B$ and $C$ to fail. Note that this is an example of a building that lacks redundancy.

Whenever there is significant rotation in the diaphragm, the hazard is in the columns that support the diaphragm, especially if the columns happen not to be part of the lateral-force-resisting system. The tops of the columns are forced to move laterally with respect to the bottoms of the columns at the floor below. Such columns often are designed without regard to these movements. Good practice calls for proper attention to all elements that are not part of the lateral-force-resisting system but that must nevertheless withstand movements induced by lateral forces. Any building with almost any amount of torsion can be designed to meet code forces, but buildings with severe torsion are not likely to perform well in earthquakes.

One deficiency is in the layout and the strengths and stiffnesses of the walls and frames of the lateral-force-resisting system. Another deficiency is in the strength of columns that are not part of the lateral-force-resisting system but are forced to undergo displacements due to the rotation of the diaphragm.

\subsubsection{Wind Induced Torsion}

The lateral-force-resisting elements form a well balanced system that is capable of resisting wind forces acting from any direction and is not subjected to significant torsion. For a non-flexible structure with a reasonably regular shape in plan, the distance, measured along either principal axis of the building plan, between the point of application of the mean load induced by wind normal to that axis and the center of rigidity must be less than $15 \%$ of the width of the structure in either major plan dimension. (For this evaluation a set of structural drawings is necessary).

\section{Commentary:}

An assessment of the capacity of the structure to resist wind-induced torsion is needed for structures capable of resisting wind forces acting from any direction. For torsionally 
flexible structures (torsional frequency of vibration $\mathrm{f}<1 \mathrm{~Hz}$ ), the assessment of the capacity to resist wind-induced torsion requires a dynamic analysis. For a building with an irregular shape in plan, an aerodynamic assessment based on wind tunnel testing or information available in the wind engineering literature is required. For non-flexible structures with a reasonably regular shape in plan, the distance measured along either principal axis of the building plan, between (1) the point of application of the mean load induced by wind normal to that axis and (2) the center of rigidity is less than $0.15 \mathrm{~b}$, where $b$ is the horizontal cross-sectional dimension. For example, for a roughly rectangular building with dimensions in $b$ and $d$, the point of application of the mean load induced by wind normal to the dimensions $b$ and $d$ is located at a distance $b / 2$ and $d / 2$ from the building edges, respectively.

\subsection{Short Captive Columns}

There must be no columns at a level with height/depth ratios less than $50 \%$ of the nominal height/depth ratio of the typical columns at that level for Life Safety and $75 \%$ for Immediate Occupancy.

Commentary:

Short captive columns tend to attract seismic forces because of high stiffness relative to other columns in a story. Significant damage has been observed in parking structure columns adjacent to ramping slabs, even in structures with shear walls. Captive column behavior may also occur in buildings with clearstory windows, or in buildings with partial height masonry infill panels.

If not adequately detailed, the columns may suffer a non-ductile shear failure which may result in partial collapse of the structure.

A captive column that has adequate shear capacity to develop the flexural strength over the clear height must have adequate ductility to prevent sudden non-ductile failure of the vertical support system.

\subsection{Column Bar Splices}

All column bar lap splice lengths must be greater than $35 d_{b}$ for Life Safety and $50 d_{b}$ for Immediate Occupancy, and are enclosed by ties spaced at or less than 8 $d_{b}$.

Commentary:

When located above the floor level, column bar splices are typically in regions of potential plastic hinge formation. Short splices may lead to sudden loss of bond of column bars. This problem may be aggravated by the spalling of concrete cover that 
can occur during large building displacements. Widely spaced ties may result in a spalling of the concrete cover. Splice failures are sudden and non-ductile.

\subsection{Flat Slabs}

The lateral-force-resisting system must not be a frame consisting of columns and a flat slab/plate without beams. Flat slabs/plates classified as secondary components must have continuous bottom bars through the column joints.

Commentary:

The concern is the transfer of the shear and bending forces between the slab and column, which could lead to a punching shear failure. The flexibility of the lateral-forceresisting system will increase as the slab cracks.

Continuity of bottom reinforcement through the column joint will assist in the transfer of forces and provide some resistance to collapse by catenary action in the event of a punching shear failure (Fig. 3.11). Bars can be considered continuous if they have proper lap splices, mechanical couplers, or are developed beyond the support.

Flat slabs not designed to participate in the lateral-force-resisting system may sustain damage due to displacements associated with overall building drift.

\subsection{Deterioration of Concrete}

There must be no visible deterioration of concrete or reinforcing steel in any of the lateral-force-resisting or the vertical elements.

Commentary:

Deteriorated or poor quality concrete and/or corroded steel from water intrusion can cause loss of strength of structural elements. Spalled concrete over reinforcing bars reduces the available surface for bond between the concrete and steel. The deficiency is the reduction in member properties.

\subsection{Post-Tensioning Anchors}

There is no evidence of corrosion or spalling in the vicinity of post-tensioning or end fittings. Coil anchors have not been used. 
Commentary:

Corrosion in post-tensioned anchors can lead to failure of the gravity load system if ground motion causes a release or slip of prestressing strands. Coil anchors (Fig. 3.12) have performed poorly under cyclic load, and are prohibited by current standards.

\subsection{Redundancy}

The number of lines of moment frames in each direction shall be greater than or equal to 2. The number of bays of moment frames in each line shall be greater than or equal to 2 for Life Safety and 3 for Immediate Occupancy.

\section{Commentary}

Redundancy is a fundamental characteristic of lateral force resisting systems with superior seismic performance. Redundancy in the structure will ensure that if an element in the lateral force resisting system fails for any reason, there is another element present that can provide lateral force resistance. Redundancy also provides multiple locations for potential yielding, distributing inelastic activity throughout the structure and improving ductility and energy dissipation. The building should be provided with a redundant system such that the failure of a single member, connection, or component does not adversely affect the lateral stability of the structure. In structures without redundancy, all components must remain operative for the structure to retain its lateral stability. Typical characteristics of redundancy include multiple lines of resistance to distribute the lateral forced uniformly throughout the structure, and multiple bays in each line of resistance to reduce the shear and axial demands on any one element (Fig. 3.13).

A distinction should be made between redundancy and adequacy. For the purpose of this manual, redundancy is intended to mean simply "more than one." That is not to say that for large buildings two elements is adequate, or for small buildings one is not enough. When redundancy is not present in the structure, analysis which demonstrates the adequacy of the lateral force elements is required.

The evaluating engineer should check whether stability depends on a single element. If there are such concerns, they should be reported in the final evaluation. For example, if a frame has only a single diagonal brace in the second story and that brace fails, the frame would lose all capacity and that could overwhelm the remaining frames and lead to collapse of the building.

Another critical element could be a welded joint in reinforcing steel in a chord of a tilt-up building or a collector connection to a shear wall. Such a defect can result when a relatively minor item does not receive a level of care in its design, detailing, and construction that is commensurate with its importance to the building. 


\subsection{Interfering Walls}

All infill walls placed in moment frames must be isolated from structural elements.

Commentary:

When an infill wall is connected to a moment frame, the wall becomes an unintended part of the lateral-force-resisting system and it takes loads that can cause it to fail. The deficiency is an inappropriate connection of the wall to the frame. Typically these walls are not designed and detailed to participate in the lateral-force-resisting system and may be subject to significant damage.

Interfering walls should be checked for forces induced by the frame. In particular, damage to these walls can lead to falling hazards near means of egress. The frames should be checked for forces induced by contact with the walls, particularly if the walls are not full height, or do not completely infill the bay.

\subsection{Shearing Stress Check}

The shear stress in the concrete columns must be less than $0.7 \mathrm{MPa}\left(7 \mathrm{kgf} / \mathrm{cm}^{2}\right)$ or $\sqrt{f_{c}^{\prime}} / 6 \mathrm{MPa}$. The shear stress in the concrete shear walls must be less than $1.0 \mathrm{MPa}\left(10 \mathrm{kgf} / \mathrm{cm}^{2}\right)$ or $\sqrt{f^{\prime}}{ }_{c} / 4 \mathrm{MPa}$, if the total cross sectional area of the walls in a story is less than $3 \%$ of the floor area. If greater than $3 \%$, no shearing stress check is needed.

Commentary:

The shear stress check provides a quick assessment of the overall level of demand on the structure. The concern is the overall strength of the building. Past earthquakes have shown that buildings that had a total wall cross sectional area in a story greater than $3 \%$ of the floor area performed well.

\subsection{Axial Stress Check}

The axial stress due to gravity loads in columns subjected to overturning forces must be less than $0.10 f_{c}^{\prime}$. Alternatively, the axial stress due to overturning forces alone must be less than 0.3. $f_{c}^{\prime}$.

Commentary:

Columns that carry a substantial amount of gravity load may have limited additional capacity to resist lateral forces. When axial forces due to overturning moments caused 
by the lateral loads are added, the columns may crush in a nonductile manner due to excessive axial compression.

The alternative calculation of overturning stresses due to seismic or wind forces alone is intended to provide a means of screening out frames with high gravity loads, but are known to have small seismic overturning forces.

When both demands are large, the combined effects of gravity and lateral forces must be calculated to demonstrate compliance.

\subsection{Concrete Columns}

All longitudinal column steel must be doweled into the foundation and the dowels must be able to develop the tensile capacity of the column.

Commentary:

Concrete columns that are part of the lateral-force-resisting system must be connected for the transfer of uplift and shear forces to the foundation (Fig. 3.14). The absence of a substantial connection between the columns and the foundation may allow the column to uplift or slide off the bearing supports which will limit the ability of the columns to support vertical loads or resist lateral forces.

\subsection{Prestressed Frame Elements}

The lateral-load-resisting frames must not include any prestressed or posttensioned elements.

Commentary:

Frame components that have prestressed or post-tensioned elements may not behave in a ductile manner. The concern is in the strength of the frames during inelastic straining. Check the capacity of the members and joints using all of the mild steel reinforcing that is available and bonded prestressing when appropriate. The $R$ value used for evaluation of performance under seismic effects should reflect the ductility and damping of the system. Where better information is not available, multiply the $R$ value selected on the basis of mild reinforcement by 0.75 to account for the effect of prestressing.

\subsection{No Shear Failures}

The shear capacity of the frame columns must be able to develop the moment capacity at the top and bottom of the columns. 
Commentary:

If the shear capacity of a column is reached before the moment capacity, there is a potential for a sudden brittle failure of the column, leading to collapse. The required shear capacity is the shear associated with the probable flexural moment strength, $M_{p r}$. This is the maximum moment a beam or column can develop. This moment capacity is calculated with two conditions intended to capture the maximum capacity: (1) the tension bars are at their yield strength which is assumed, since it is not usually known, to be 1.25 times the specified minimum yield; and (2) $\phi=1.0$, (i.e., there is no capacity reduction as required for design).

As indicated in Figure 3.15, $V_{e}=2 M_{p r} / L$ where $L$ is the length of the member. This is a maximum possible shear demand. Note that the shear capacity of a member is affected by the axial load. Shear capacity should be based on the most critical axial load. The deficiency is inadequate shear capacity in the columns or beams.

\subsection{Strong Column/Weak Beam}

\section{The sum of the moment capacity of the columns must be $\mathbf{2 0} \%$ greater than that of the beams at frame joints}

Commentary:

When columns are not strong enough to force hinging in the beams, column hinging can lead to story mechanisms and a concentration of inelastic activity at a single level. Excessive story drifts may result in an instability of the frame due to P- $\Delta$ effects. Good post-elastic behavior consists of yielding distributed throughout the frame. A story mechanism will limit forces in the levels above, preventing the upper levels from yielding. Joints at the roof level need not be considered.

If it can be demonstrated that non-compliant columns are strong enough to resist calculated demands with sufficient overstrength, acceptable behavior can be expected.

Alternative procedure checks for the formation of a story mechanism. The story strength is the sum of the shear capacities of all the columns as limited by the controlling action. If the columns are shear critical, a shear mechanism forms at the shear capacity of the columns. If the columns are controlled by flexure, a flexural mechanism forms at a shear corresponding to the flexural capacity.

\subsection{Beam Bars}

At least two longitudinal top and two longitudinal bottom bars must extend continuously throughout the length of each frame beam. At least $25 \%$ of the 
longitudinal bars provided at the joints for either positive or negative moment must be continuous throughout the members.

Commentary:

The requirement for two continuous bars is a collapse prevention measure. In the event of complete beam failure, continuous bars will prevent total collapse of the supported floor, holding the beam in place by catenary action.

Previous construction techniques used bent-up longitudinal bars as reinforcement. These bars transitioned from bottom to top reinforcement at the gravity load inflection point. Some amount of continuous top and bottom reinforcement is desired because moments due to lateral forces can shift the location of the inflection point.

Because non-compliant beams are vulnerable to collapse, the beams are required to resist demands at an elastic level. Continuous slab reinforcement adjacent to the beam may be considered as continuous top reinforcement.

\subsection{Beam Bar Splices}

The lap splices for longitudinal beam reinforcing must be located within the center half of the member length and shall not be located within the vicinity of potential plastic hinge locations.

Commentary:

Lap splices located at the end of beams and in the vicinity of potential plastic hinges may not be able to develop the full moment capacity of the beam as the concrete degrades during multiple cycles.

Typical short compression laps for bottom steel located within the beam-column joints may not be sufficient to develop positive yield moments and this can lead to hinging at levels below the yield strength of the beams.

\subsection{Column-Tie Spacing}

Frame columns must have ties spaced at or less than $d / 4$ throughout their length and at or less than $8 d_{b}$ at all potential plastic hinge regions.

Commentary:

Widely spaced ties will reduce the ductility of the column, and it may not be able to maintain full moment capacity through several cycles. Columns with widely spaced ties have limited shear capacity and non-ductile shear failures may result. 


\subsection{Stirrup Spacing}

All beams must have stirrups spaced at or less than $d / 2$ throughout their length. At potential hinge locations stirrups must be spaced at or less than the minimum $8 d_{b}$ or $d / 4$.

Commentary:

Without closely spaced stirrups, the beams may be unable to maintain the yield level moments under repeated cycles.

\subsection{Joint Reinforcing}

Beam-column joints must have ties spaced at or less than $\mathbf{8 d}$.

Commentary:

Beam-column joints without shear reinforcement may not be able to develop the strength of the connected members, and this can lead to sudden brittle failure of the joint. Exterior columns are especially vulnerable because the confinement of the joint is limited to three sides (along the exterior) or two sides (at a corner).

\subsection{Joint Eccentricity}

There must be no eccentricities larger than $20 \%$ of the smallest column plan dimension between girder and column centerlines.

Commentary:

Joint eccentricities can result in high torsional demands on the joint area, which will cause high shear stresses.

\subsection{Stirrup and Tie Hooks}

The beam stirrups and column ties must be anchored into the member cores with hooks of $135^{\circ}$ or more.

Commentary:

To be fully effective, stirrups and ties must be anchored into the confined core of the member. $90^{\circ}$ hooks that are anchored within the concrete cover are unreliable if the cover spalls during plastic hinging. The amount of shear resistance and confinement will be reduced if the ties are not well anchored. 


\subsection{Diaphragm Continuity}

The diaphragm must not be composed of split-level floors.

Commentary:

Split level floors and roofs, or diaphragms interrupted by expansion joints, create discontinuities in the diaphragm. This condition is common in ramped parking structures. It is a common problem unless special details are used, or lateral-forceresisting elements are provided at the vertical offset of the diaphragm or on both sides of the expansion joints. Such a discontinuity may cause the diaphragm to function as a cantilever element or three-sided diaphragm. If the diaphragm is not supported on at least three sides by lateral-force-resisting elements, torsional forces in the diaphragm may cause it to become unstable. In both the cantilever and three-sided cases, increased lateral deflection in the discontinuous diaphragm may cause increased damage to, or collapse of, the supporting elements.

If the load path is incomplete, mitigation with elements or connections to complete the load path is necessary.

\subsection{Plan Irregularities}

There must be tensile capacity to develop the strength of the diaphragm at reentrant corners or other locations of the plan irregularities.

Commentary:

Diaphragms with plan irregularities such as extending wings, plan insets, or E-, T-, X-, $\mathrm{L}-$, or C-shaped configurations have re-entrant corners where large tensile and compressive forces can develop (Fig. 3.16). The diaphragm may not have sufficient strength at these re-entrant corners to resist the tensile forces. Local damage may occur (Fig. 3.17).

\subsection{Diaphragm Reinforcement at Openings}

There must be reinforcing around all diaphragm openings larger than $50 \%$ of the building width in either major plan dimension. This statement applies to the Immediate Occupancy performance level only.

Commentary:

Openings in diaphragms increase shear stresses and induce secondary moments in the diaphragm segments adjacent to the opening. Tension and compression forces 
are generated along the edges of these segments by the secondary moments, and must be resisted by chord elements in the subdiaphragms around the openings.

Openings that are small relative to the diaphragm dimensions may have only a negligible impact. Openings that are large relative to the diaphragm dimensions can substantially reduce the stiffness of the diaphragm and induce large forces around the openings (Fig. 3.18).

\subsection{Lateral Load at Pile Caps}

Pile caps must have top reinforcement and piles must be anchored to the pile caps.

Commentary:

Pile foundations may have been designed considering downward gravity loads only. A potential problem is a lack of top reinforcement in the pile cap and a lack of a positive connection between the piles and the pile cap. The piles may be socketed into the cap without any connection to resist tension.

Lateral forces may induce uplift at the foundation which must be delivered into the piles for overturning stability. The absence of top reinforcement means the pile cap cannot distribute the uplift forces to the piles. The absence of pile tension connections means that the forces cannot be transferred to the piles.

\subsection{Concrete Wall Cracks}

All existing diagonal cracks in wall elements must be less than $1.0 \mathrm{~mm}$, must not be concentrated in one location, and must not form an $X$ pattern.

Commentary:

Small cracks in concrete elements have little effect on strength. A significant reduction in strength is usually the result of large displacements or crushing of concrete. Only when the cracks are large enough to prevent aggregate interlock or have the potential for buckling of the reinforcing steel does the adequacy of the concrete capacity become a concern.

Crack width is commonly used as a convenient indicator of damage to a wall, but it should be noted that recent studies list other factors, such as location, orientation, number, distribution and pattern of the cracks to be equally important in measuring the extent of damage present in the shear walls. All these factors should be considered when evaluating the reduced capacity of a cracked element. 


\subsection{Complete Frames}

Steel or concrete frames classified as secondary components must form a complete vertical load carrying system.

Commentary:

If the frame does not form a complete vertical load carrying system, the walls will be required to provide vertical support as bearing walls (see Fig. 3.19). A frame is incomplete if there are no columns cast into the wall, there are no columns adjacent to the wall, and beams frame into the wall, support solely by the wall.

During an earthquake or windstorm, shear walls that might become damaged, could lose their ability to support vertical loads. Loss of vertical support may lead to partial collapse.

Compliance can be demonstrated if the wall is judged adequate for combined vertical and seismic or wind forces.

\subsection{Reinforcing Steel}

The ratio of reinforcing steel area to gross concrete area must be greater than 0.0015 in the vertical direction and 0.0025 in the horizontal direction. The spacing of reinforcing steel must be equal to or less than $450 \mathrm{~mm}$.

Commentary:

If the walls do not have sufficient reinforcing steel, they will have limited capacity in resisting seismic forces. The wall will also behave in a nonductile manner for inelastic forces.

\subsection{Diaphragm Openings at the Shear Walls}

Diaphragm openings immediately adjacent to the shear walls must be less than $25 \%$ of the wall length for Life Safety and $15 \%$ of the wall length for Immediate Occupancy.

\section{Commentary:}

The large openings at shear walls significantly limit the ability of the diaphragm to transfer lateral forces to the wall (see Fig. 3.20). The opening reduces the length for shear transfer from $L$ to $A+B$. This can have a compounding effect if the opening is near one end of the wall and divides the diaphragm into small segments with limited stiffness that are ineffective in transferring shear to the wall. This might have the net 
effect of a much larger opening. Large openings may also limit the ability of the diaphragm to provide out-of-plane support for the wall.

The presence of drag struts (see Sect. 1.4.2) developed into the diaphragm beyond the wall will help mitigate this effect.

\subsection{Transfer to Shear Walls}

Diaphragms must be reinforced and connected for transfer of loads to the shear walls, and should be able to develop the shear strength of the walls.

Commentary:

The floor or roof diaphragms must be connected to the shear walls to provide a complete load path for the transfer of diaphragm shear forces to the walls. Where the wall does not extend the full depth of the diaphragm, this connection may include collectors or drag struts. Collectors and drag struts must be continuous across intersecting framing members, and must be adequately connected to the wall to deliver high tension and compression forces at a concentrated location.

In the case of frame buildings with infill walls, the performance under lateral loads is dependent upon the interaction between the frame and infill walls, and the behavior is more like that of a shear-wall building. The load path between the diaphragms and the infill panels is most likely through the frame elements, which may also act as drag struts and collectors. In this case, the evaluation statement is addressing the connection between the diaphragm and the frame elements.

If the connection is non-existent, mitigation is necessary with elements or connection needed to transfer diaphragm shear to the shear walls.

\subsection{Foundation Dowels}

Walls must be doweled into the foundation.

Commentary:

The absence of an adequate connection between the shear walls and the foundation is a gap in the load path that will limit the ability of the shear walls to resist lateral forces.

If the connection is non-existent, mitigation is necessary with elements or connections needed to anchor the walls to the foundation. 


\subsection{Deflection Compatibility}

Secondary components must have the shear capacity to develop the flexural strength of the elements and must have ductile detailing.

Commentary:

Frame components, especially columns, that are not specifically designed to participate in the lateral-force-resisting system will still undergo displacements associated with overall inter-story drift. If the columns are located some distance away from the lateralforce-resisting elements, the added deflections due to semi-rigid floor diaphragms will increase the drifts. Stiff columns, designed for potentially high gravity loads, may develop significant bending moments due to the imposed drifts. The moment-axial force interaction may lead to a nonductile failure of the columns and a collapse of the building.

\subsection{Coupling Beams}

The stirrups in all coupling beams over means of egress must be spaced at or less than $\mathrm{d} / 2$ and must be anchored into the core with hooks of $135^{\circ}$ or more.

Commentary:

Coupling beams with sufficient strength and stiffness can increase the lateral stiffness of the system significantly beyond the stiffnesses of the independent walls. When the walls deflect laterally, large moments and shears are induced in the coupling beams as they resist the imposed deformations. Coupling beams also link the coupled walls for overturning resistance (see Fig. 3.21).

Coupling beam reinforcement is often inadequate for the demands that can be induced by the movement of the coupled walls. Seismic forces may damage and degrade the coupling beams so severely that the system degenerates into a pair of independent walls. This changes the distribution of overturning forces which may result in potential stability problems for the independent walls. The boundary reinforcement may also be inadequate for flexural demands if the walls act independently.

If the coupling beams are lightly reinforced, their degradation could result in falling debris that is a potential life-safety hazard, especially at locations of egress.

\subsection{Overturning}

All shear walls must have aspect ratios less than 4 to 1 . Wall piers need not be considered. 
Commentary:

Tall, slender shear walls may have limited overturning resistance. Displacements at the top of the building will be greater than anticipated if overturning forces are not properly resisted.

Often sufficient resistance can be found in immediately adjacent bays, if a load path is present to rely on the adjacent column dead load to counteract the overturning forces.

\subsection{Confinement Reinforcing}

For shear walls with aspect ratios greater than 2.0, the boundary elements must be confined with spirals or ties with spacing less than $8 d_{b}$.

Commentary:

Fully effective shear walls require boundary elements to be properly confined with closely spaced ties (see Fig. 3.22). Degradation of the concrete in the vicinity of the boundary elements can result in buckling of rebars in compression and failure of lap splices in tension. Non-ductile failure of the boundary elements will lead to reduced capacity to resist overturning forces.

\subsection{Reinforcing at Openings}

There must be added trim reinforcement abound all wall openings.

Commentary:

Conventional trim reinforcement is adequate only for small openings (see Fig. 3.23). Large openings will cause significant shear and flexural stress in the adjacent piers and spandrels. Inadequate reinforcing steel around these openings will lead to strength deficiencies, nonductile performance and degradation of the wall.

\subsection{Wall Thickness}

Thickness of bearing walls must not be less than $1 / 25$ the minimum unsupported height or length, nor less than $100 \mathrm{~mm}$.

Commentary:

Slender bearing walls may have limited capacity for vertical loads and higher potential for damage due to out-of-plane forces and magnified moments. Note that this condition is considered for immediate occupancy performance. 


\subsection{Masonry Units}

There must be no visible deterioration of masonry units.

Commentary:

Deteriorated or poor quality masonry elements can result in significant reductions in the strength of structural elements. Damaged or deteriorated masonry may not be readily observable.

\subsection{Masonry Joints}

The mortar must not be easily scraped away from the joints by hand with a metal tool, and there must be no area of eroded mortar.

Commentary:

Older buildings constructed with lime mortar may have surface repointing but still have deteriorated mortar in the main part of the joint. One test is to tap a small hole with a nail in the repointing and, if it breaks through, powdery lime mortar shows on the nail. If it does not break through after aggressive blows, the wall probably is repointed full depth. This can also be seen by looking behind exterior trim or wall fixtures where the new repointing did not reach. Mortar that is severely eroded or can easily be scraped away has been found to have low shear strength, which results in low wall strength. Destructive or in-place shear tests are required to measure the strength of the bond between the brick and mortar in order to determine the shear capacity of the walls.

\subsection{Cracks in Infill Walls}

There must be no existing diagonal cracks in infill walls that extend throughout a panel, are greater than $3 \mathrm{~mm}$, or have out-of-plane offsets in the bed joint greater than $3 \mathrm{~mm}$.

Commentary:

Diagonal wall cracks, especially along the masonry joints, may affect the interaction of the masonry units, leading to a reduction of strength and stiffness. The cracks may indicate distress in the wall from past seismic or windstorm events, foundation settlement, or other causes.

Offsets in the bed joint along the masonry joints may affect the interaction of the masonry units in resisting out-of-plane forces. The offsets may indicate distress in the wall from past seismic or windstorm events, or just poor construction. 
Crack width is commonly used as a convenient indicator of damage to a wall, but it should be noted that recent studies list other factors, such as location, orientation, number, distribution and pattern of the cracks to be equally important in measuring the extent of damage present in the shear walls.

\subsection{Cracks in Boundary Columns}

There must be no existing diagonal cracks wider than $3 \mathrm{~mm}$ in concrete columns that encase masonry infill.

Commentary:

Small cracks in concrete elements have little effect on strength. A significant reduction in strength is usually the result of large displacements or crushing of concrete. Only when the cracks are large enough to prevent aggregate interlock or have potential for buckling of the reinforcing steel does the adequacy of the concrete element capacity become a concern.

Columns are required to resist diagonal compression strut forces that develop in infill wall panels. Vertical components induce axial force in the columns. The eccentricity between horizontal components and the beams is resisted by the columns. Extensive cracking in the columns may indicate locations of possible weakness. Such columns may not be able to function in conjunction with the infill panel as expected.

\subsection{Shear Stress Check}

The shear stress in the reinforced masonry shear walls must be less than $0.5 \mathrm{MPa}\left(5 \mathrm{kgf} / \mathrm{cm}^{2}\right)$.

Commentary:

Shear stress check provides a quick assessment of the overall level of demand on the structure. The concern is the overall strength of the building.

\subsection{Shear Stress Check in URM Walls}

The shear stress in the unreinforced masonry shear walls must be less than $0.2 \mathrm{MPa}\left(2 \mathrm{kgf} / \mathrm{cm}^{2}\right)$ for clay units and $0.5 \mathrm{MPa}\left(5 \mathrm{kgf} / \mathrm{cm}^{2}\right)$ for concrete units.

Commentary:

The shear stress check provides a quick assessment of the overall level of demand on the structure. The concern is the overall strength of the building. 


\subsection{Wall Connection}

Masonry must be in full contact with frame.

Commentary:

Performance of frame buildings with masonry infill walls is dependent upon the interaction between the frame and infill panels. In-plane lateral force resistance is provided by a compression strut developing in the infill panel that extends diagonally between corners of the frame. If gaps exist between the frame and infill, this strut cannot be developed (see Fig. 3.24). If the infill panels separate from the frame due to out-of-plane forces, the strength and stiffness of the system will be determined by the properties of the bare frame, which may not be detailed to resist the in-plane forces due to the lateral loads. Severe damage or partial collapse due to excessive drift and P. delta effects may occur.

A positive connection is needed to anchor the infill panel for out-of-plane forces. In this case, a positive connection can consist of a fully grouted bed joint in full contact with the frame, or complete encasement of the frame by the brick masonry.

If the connection is non-existent, mitigation is necessary with adequate connection to the frame.

\subsection{Proportions of Infill Walls}

The height-to-thickness ratio of the infill walls at each story must be less than 14 .

Commentary:

Slender masonry infill walls with large height-to-thickness rations have a potential for damage due to out-of-plane forces. Failure of these walls will result in falling hazards and degradation of the strength and stiffness of the lateral-force-resisting system.

The out-of-plane stability of infill walls is dependent on many factors including flexural strength of the wall and confinement provided by the surrounding frame. If the infill wall is unreinforced, the flexural strength is limited by the flexural tension capacity of the material. The surrounding frame will provide confinement, induce infill thrust forces, and develop arching action against out-of-plane forces. The height-to-thickness limit in the evaluation statement is based on arching action models that will exceed any plausible lateral force levels in moderate to high seismic or windstorm regions.

\subsection{Solid Infill Walls}

The infill walls must not be of cavity construction. 
Commentary:

When infill walls are of cavity construction, the inner and outer wythes will act independently due to a lack of composite action, increasing the potential for damage from out-of-plane forces. Failure of these walls out-of-plane will result in falling hazards and degradation of the strength and stiffness of the lateral-force-resisting system.

\subsection{Infill Walls}

The infill walls must be continuous to the soffits of the frame beams and to the columns to either side.

Commentary:

Discontinuous infill walls occur when full bay windows or ventilation openings are provided between the top of the infill and the bottom soffit of the frame beam. The portion of the column above the infill is a short captive column which may attract large shear forces due to increased stiffness relative to other columns (Fig. 3.24). Partial infill walls will also develop compression struts with horizontal components that are highly eccentric to the beam-column joints. If not adequately detailed, concrete columns may suffer a non-ductile shear failure which may result in partial collapse of the structure. 


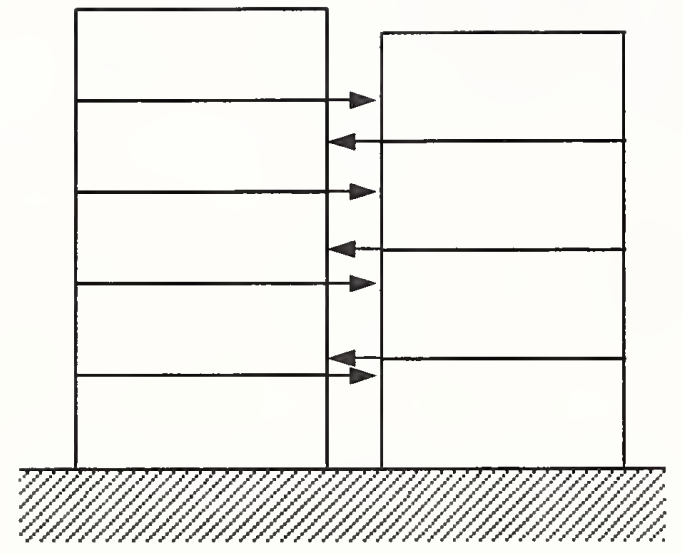

Figure 3.1 - Unmatching floors

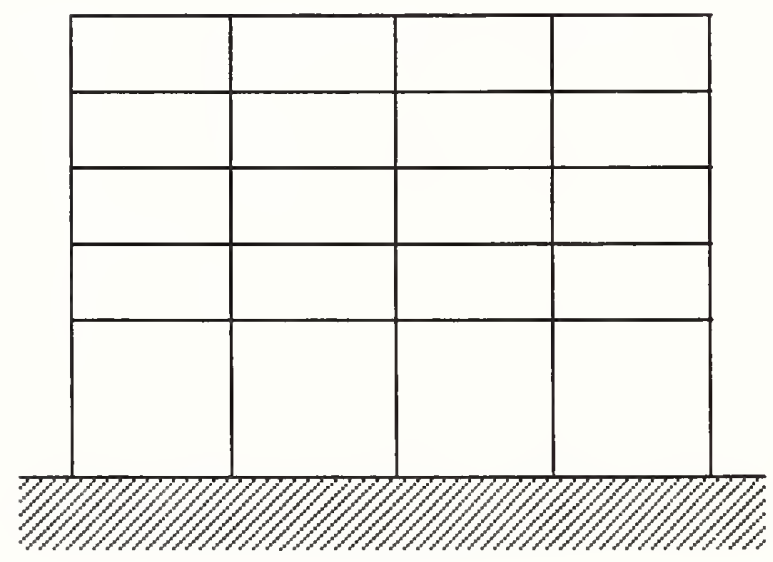

Figure 3.3 - Tall story

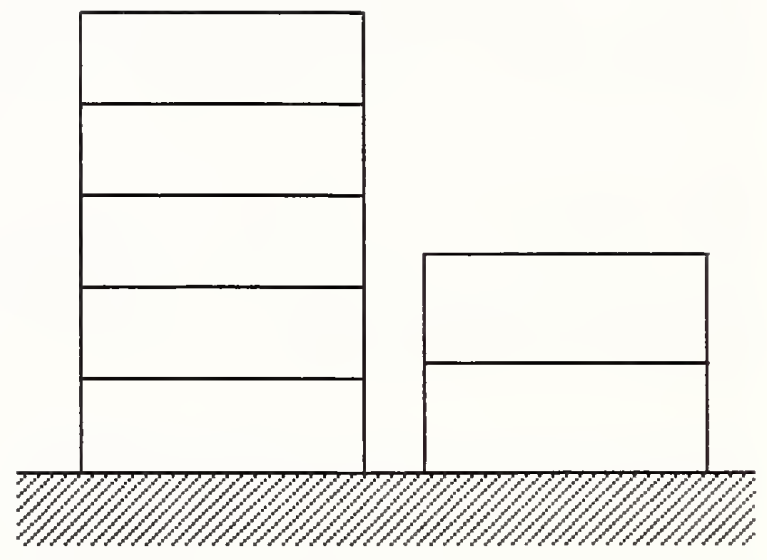

Figure 3.2 - Buildings of different height

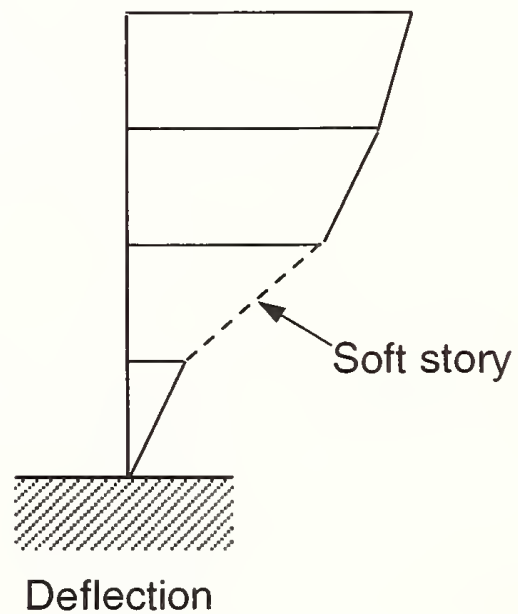

Figure 3.4 - Soft story 

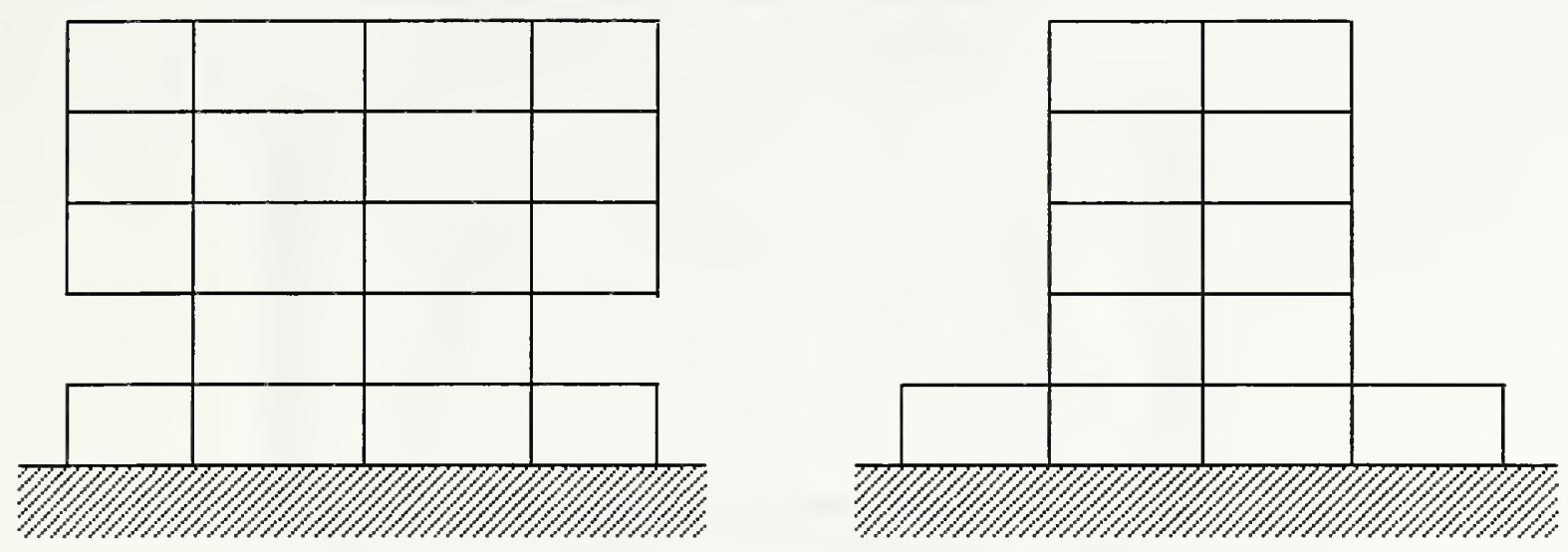

Figure 3.5 - Geometric irregularities

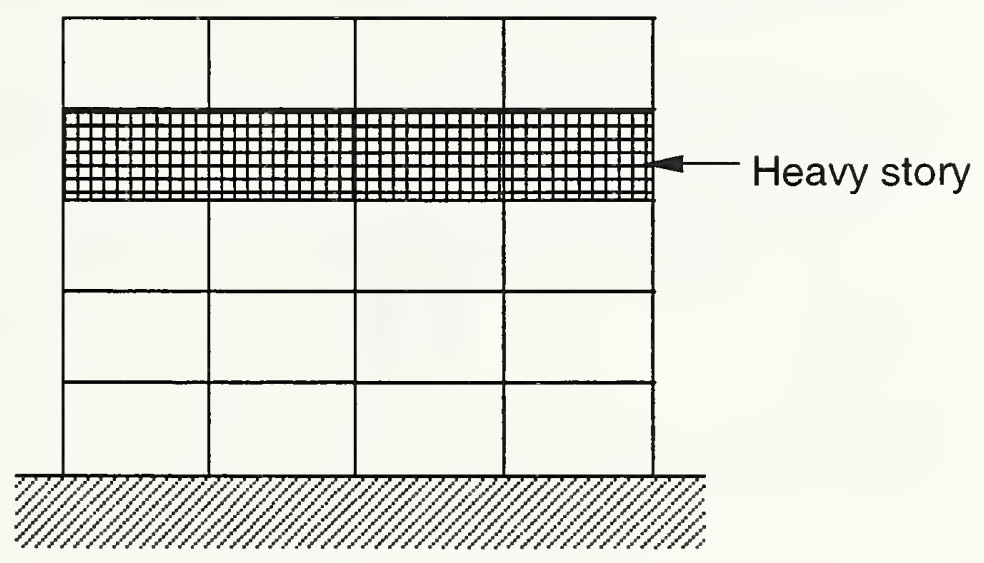

Figure 3.6 - Heavy story

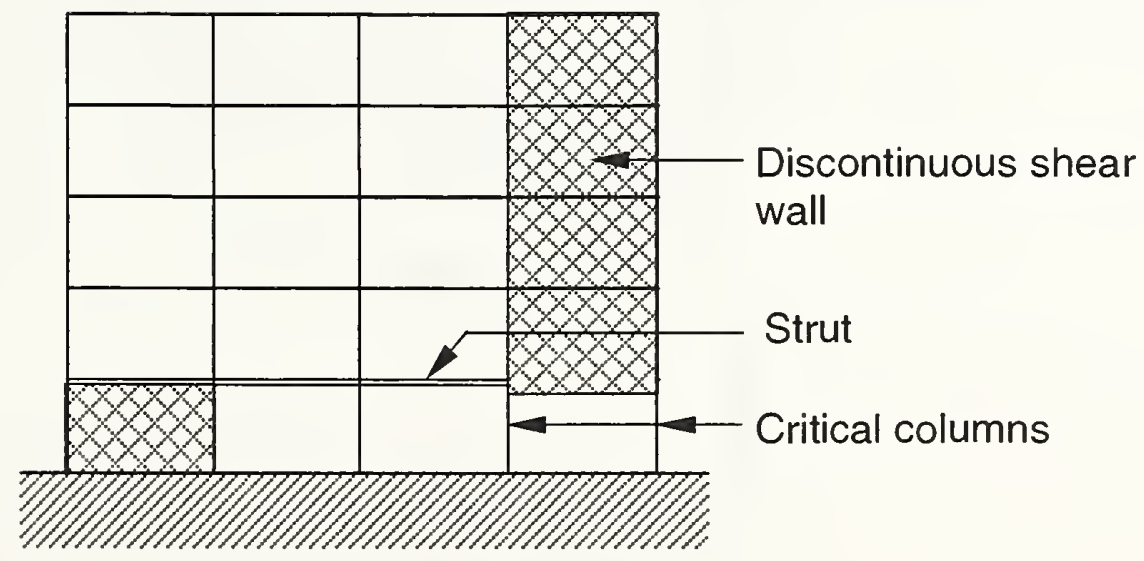

Figure 3.7 - Vertical discontinuity in-plane 


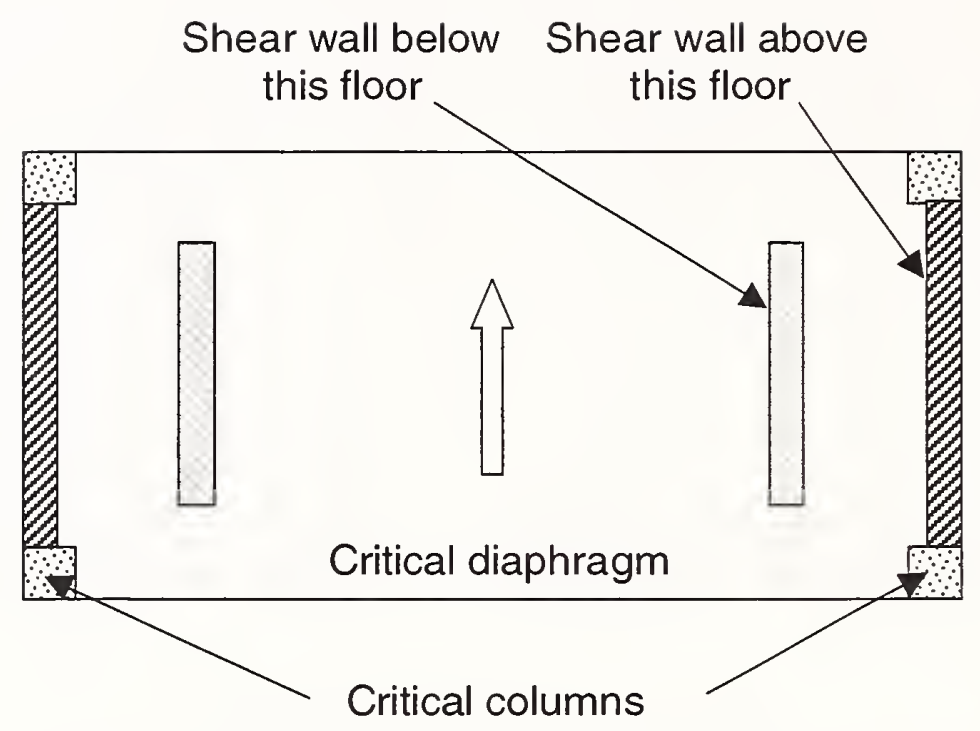

Figure 3.8 - Vertical discontinuity out-of-plane
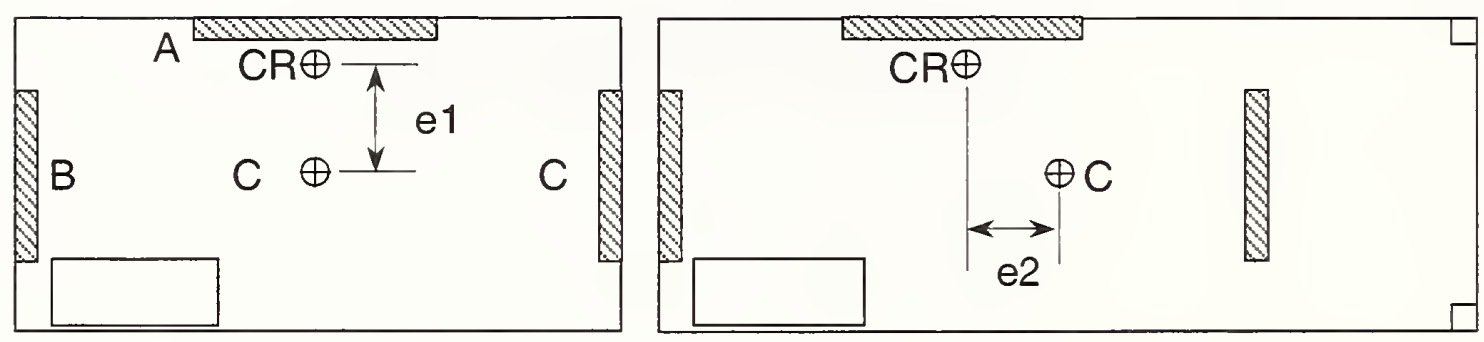

Figure 3.9 - Torsion: Cases A and B
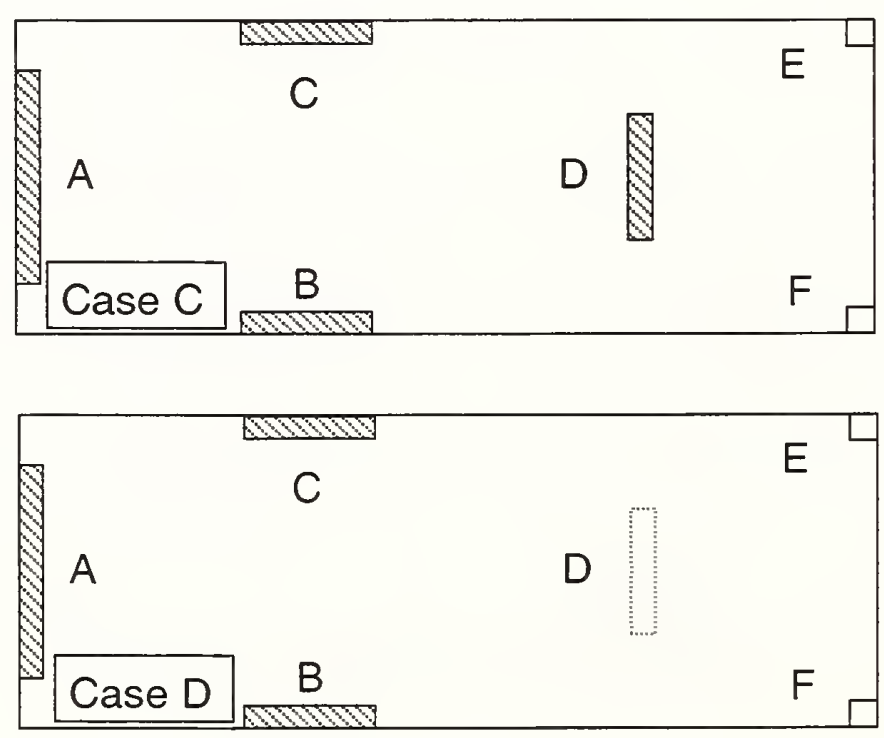

Figure 3.10 - Torsion: Cases C and D 


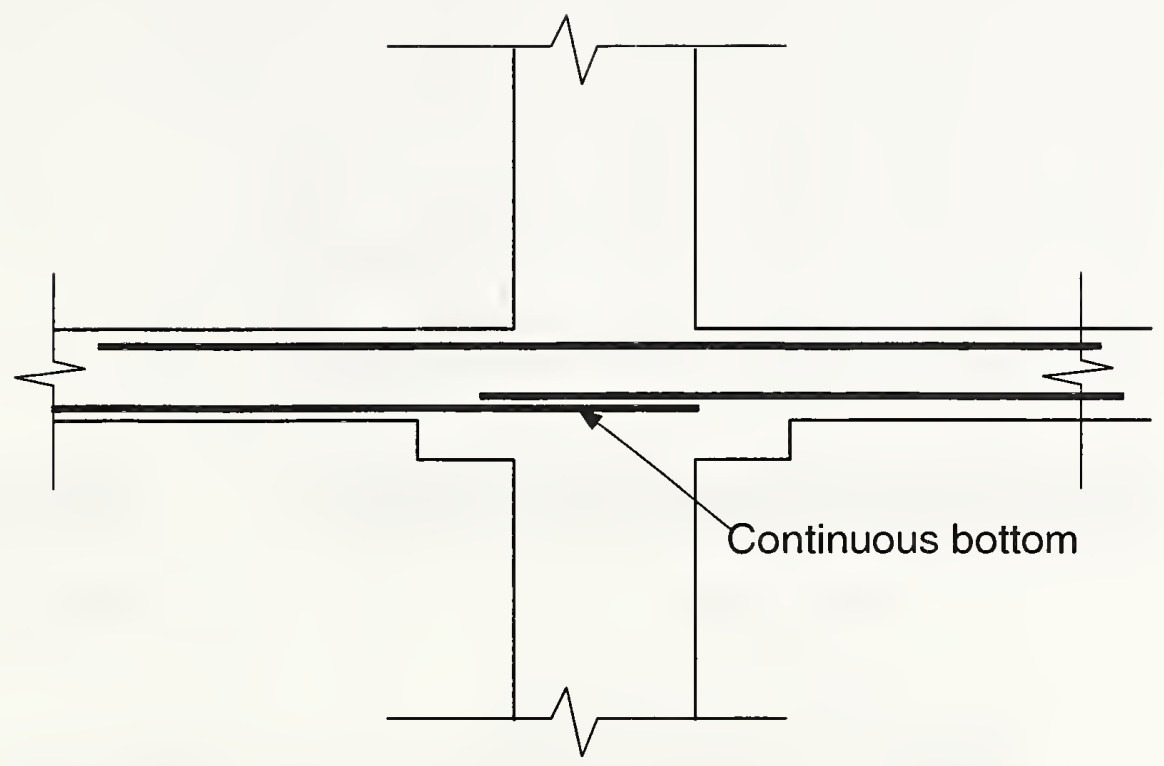

Figure 3.11 - Continuous bottom steel

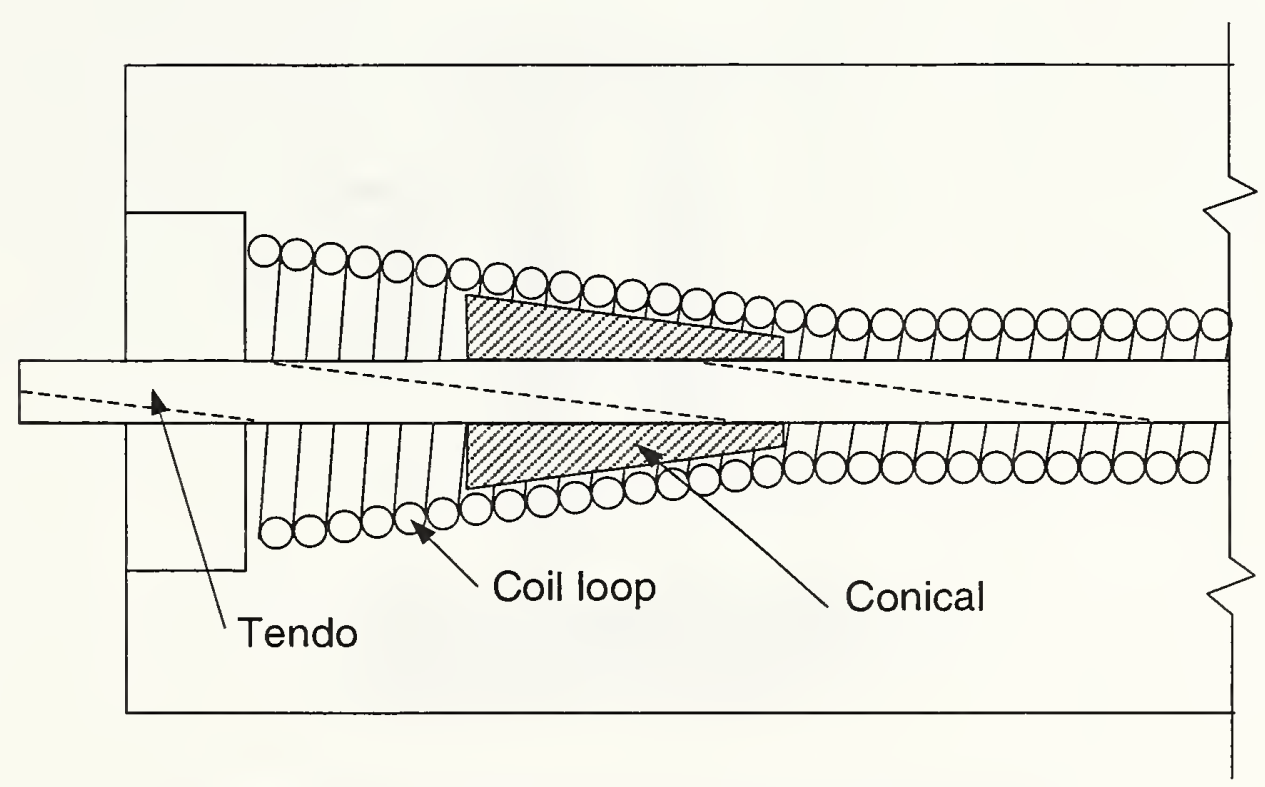

Figure 3.12 - Coil anchor 


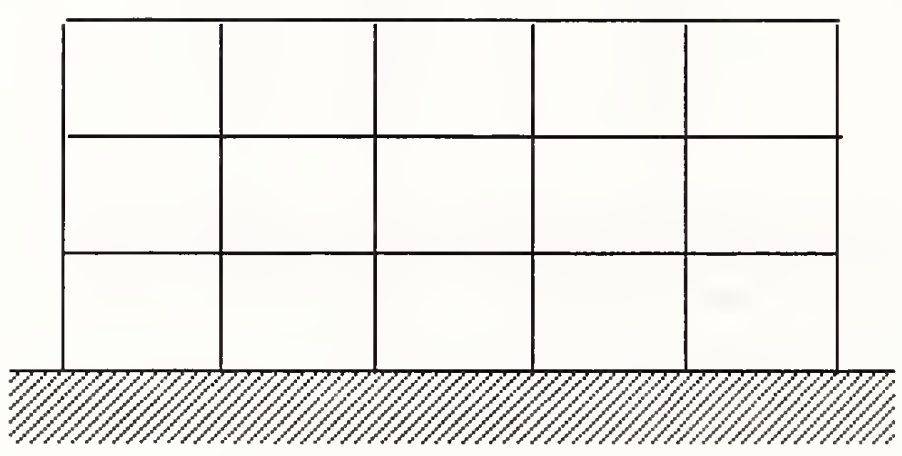

Redundant

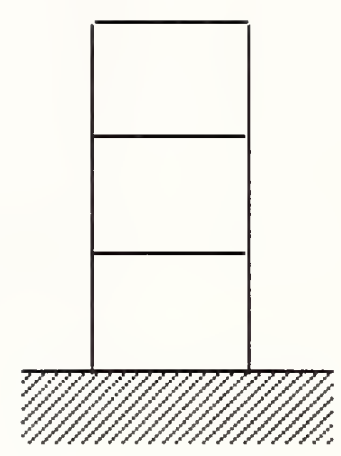

Nonredundant

Figure 3.13 - Redundancy along a line of moment frame

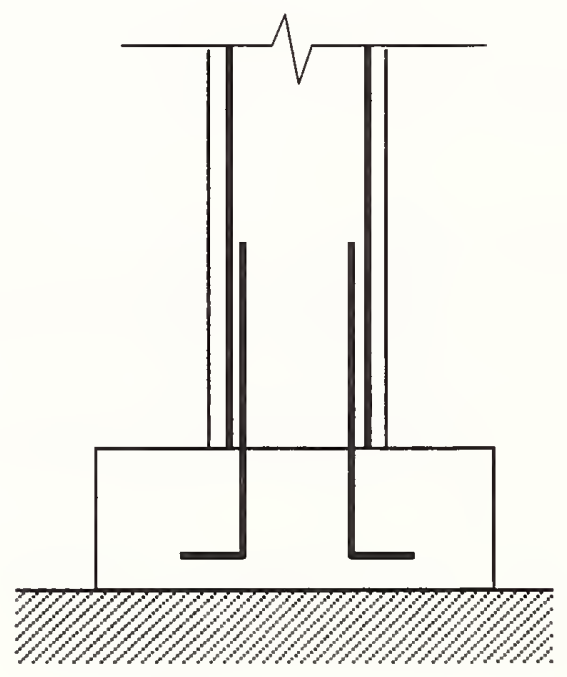

Figure 3.14 - Column doweled into foundation 


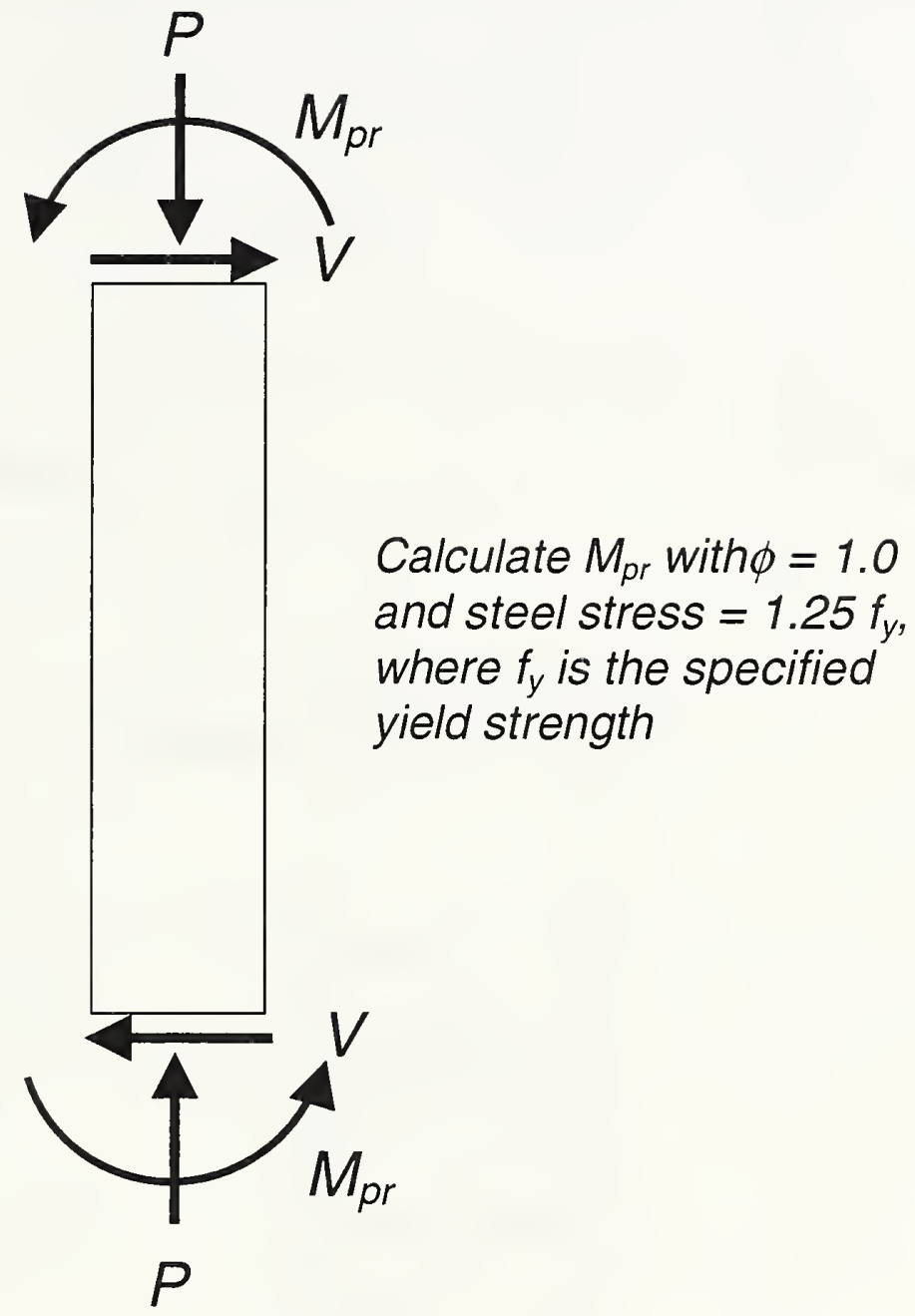

Figure $3.15-M_{p r}$ and $V_{e}$ 

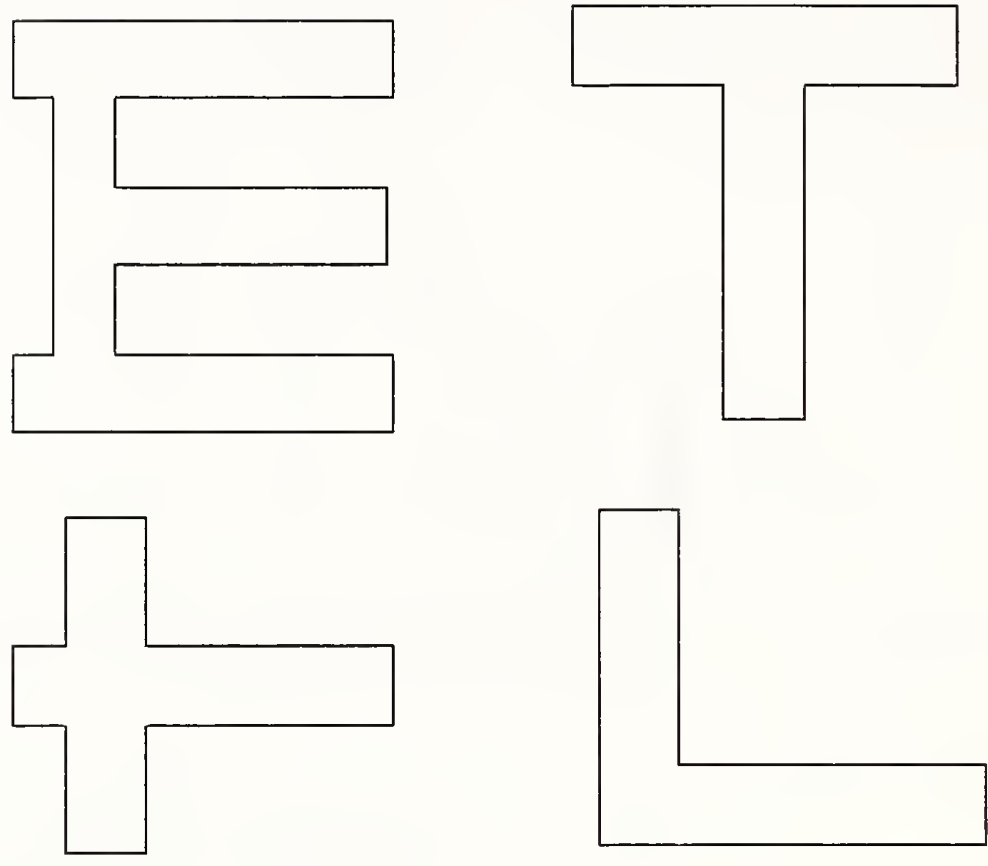

Figure 3.16 - Plan irregularities

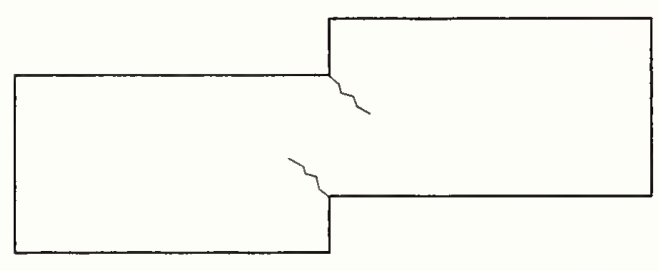

Re-entrant corners
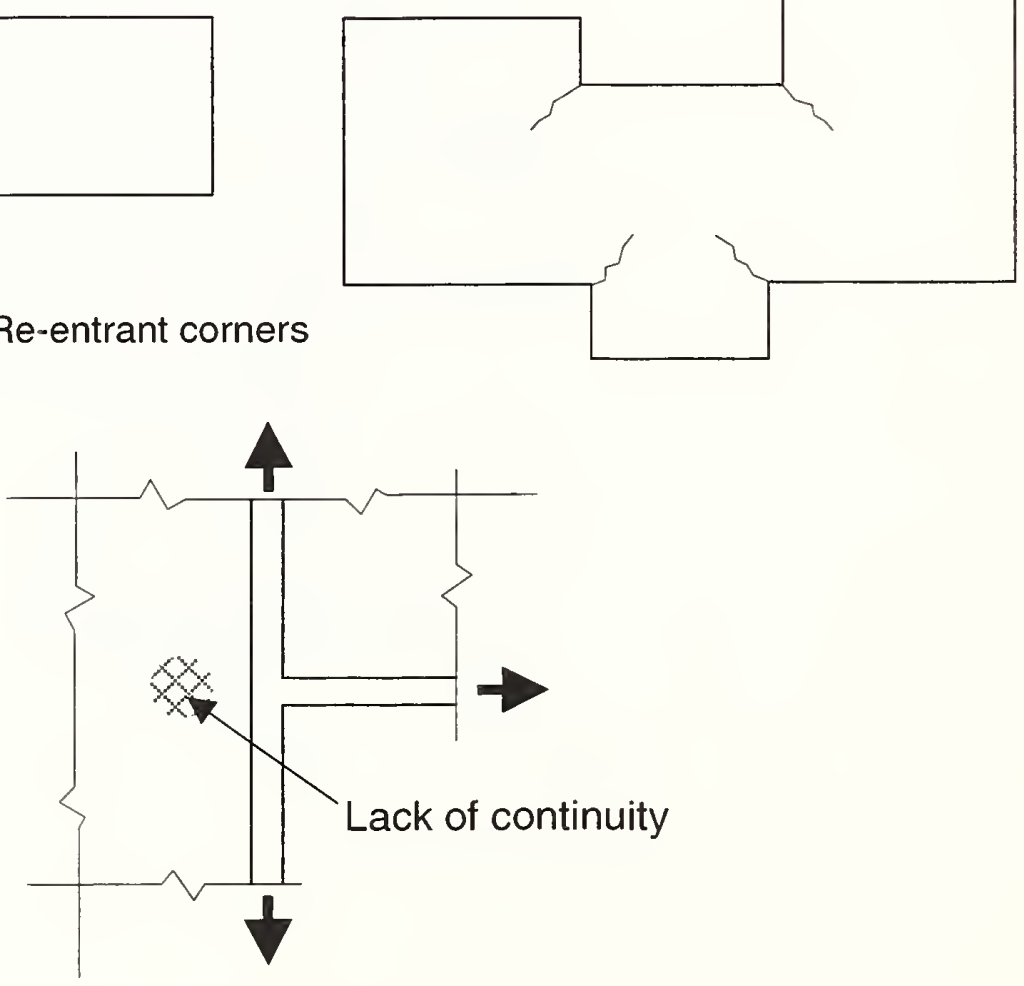

Figure 3.17 - Re-entrant corners 


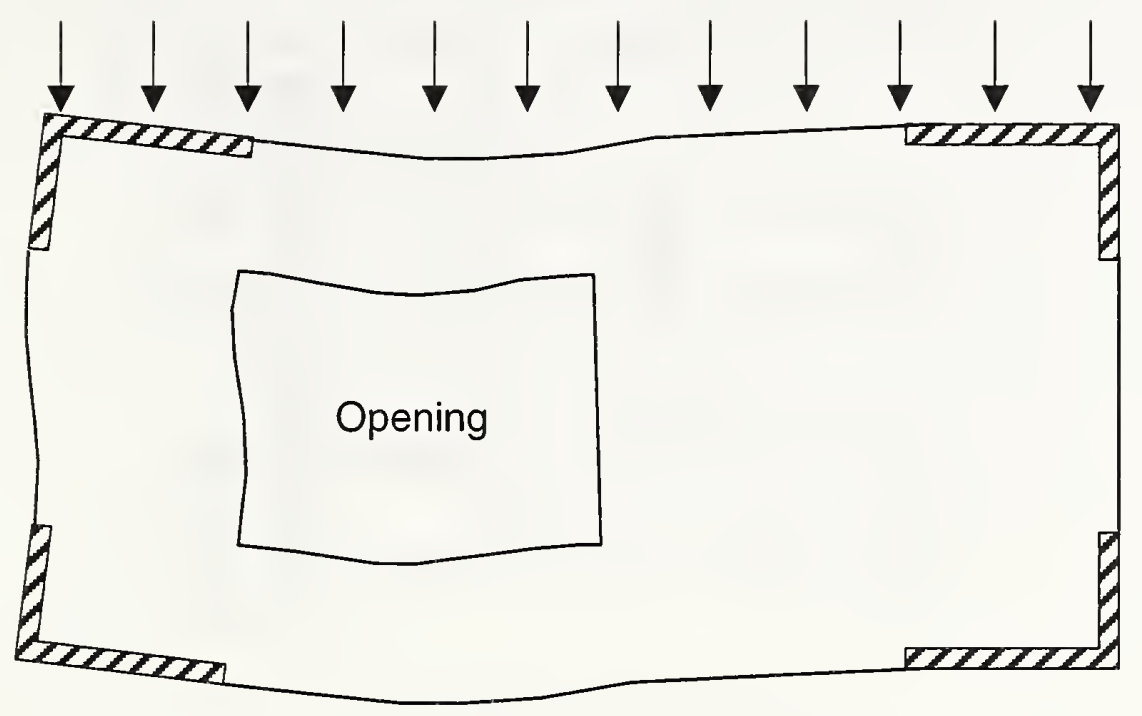

Figure 3.18 - Diaphragm opening

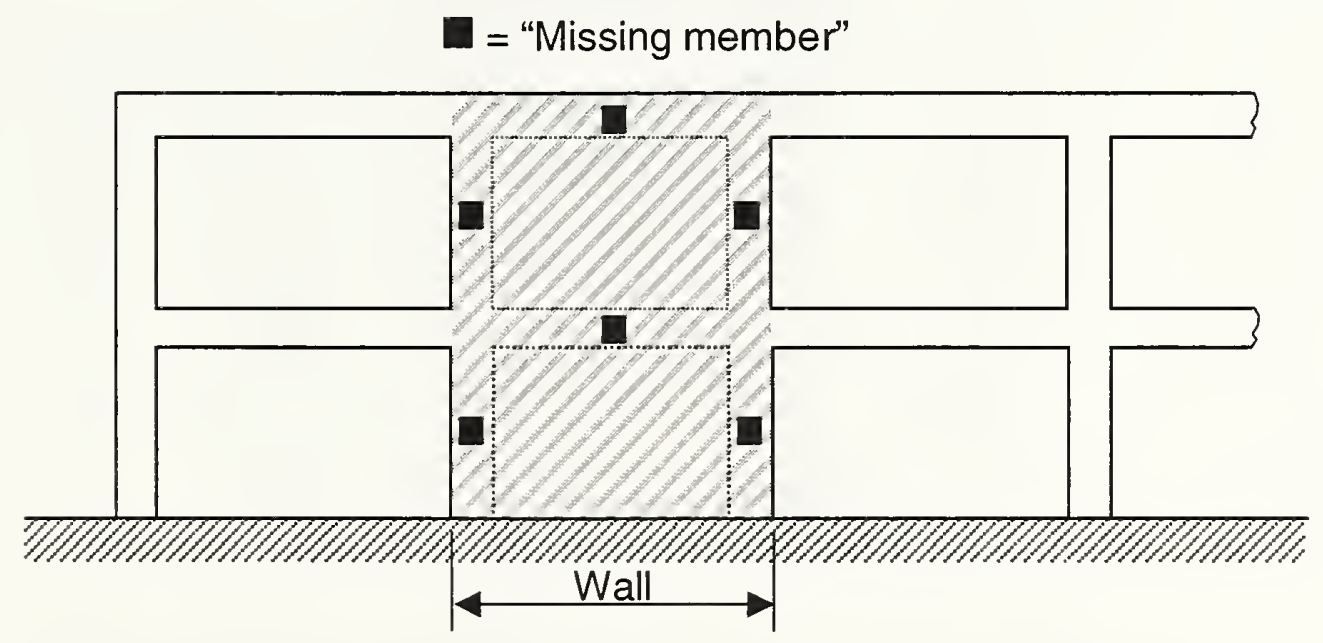

Figure 3.19 - Incomplete frame 


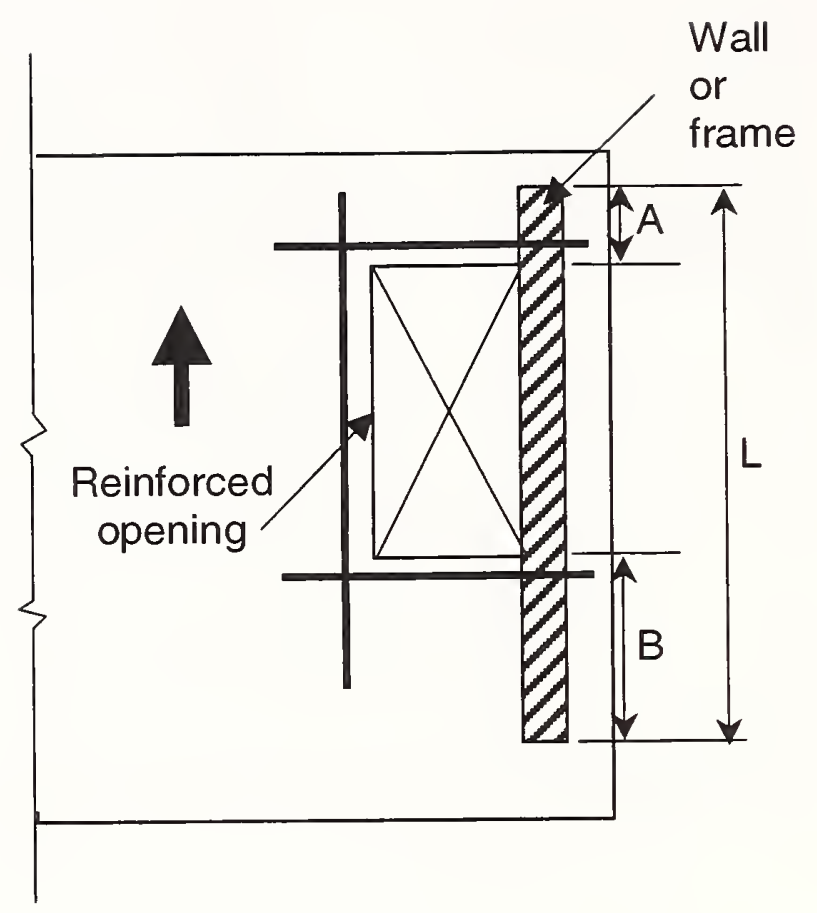

Figure 3.20 - Diaphragm opening at exterior wall

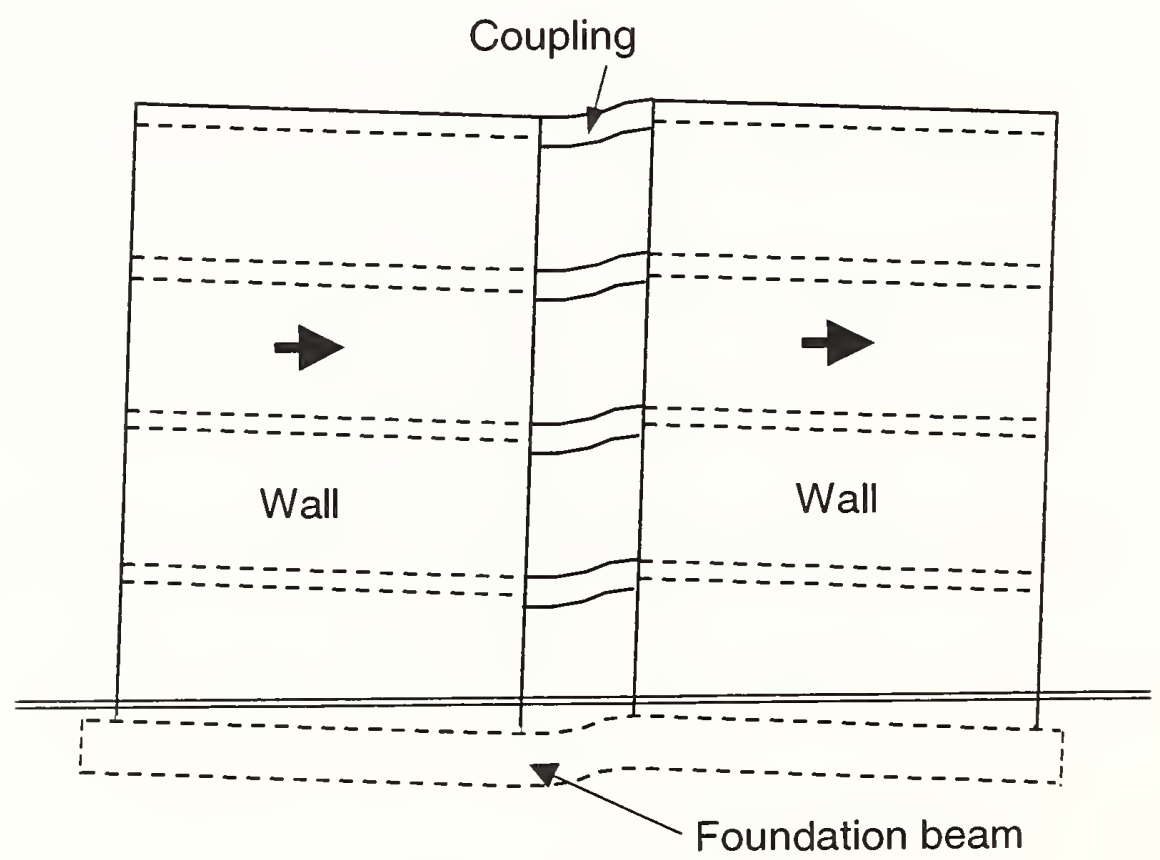

Figure 3.21 - Coupled walls 


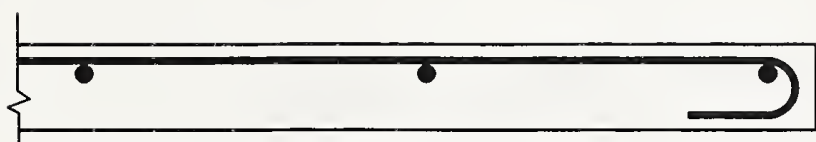

Edge Bar

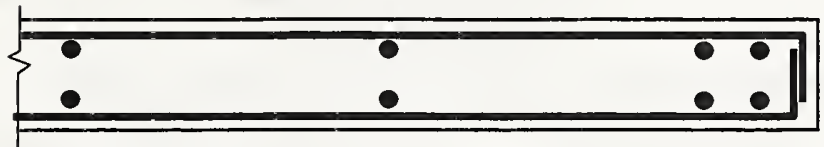

Bar group

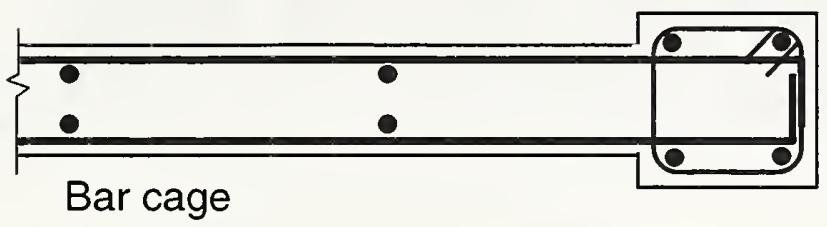

Figure 3.22 - Boundary elements

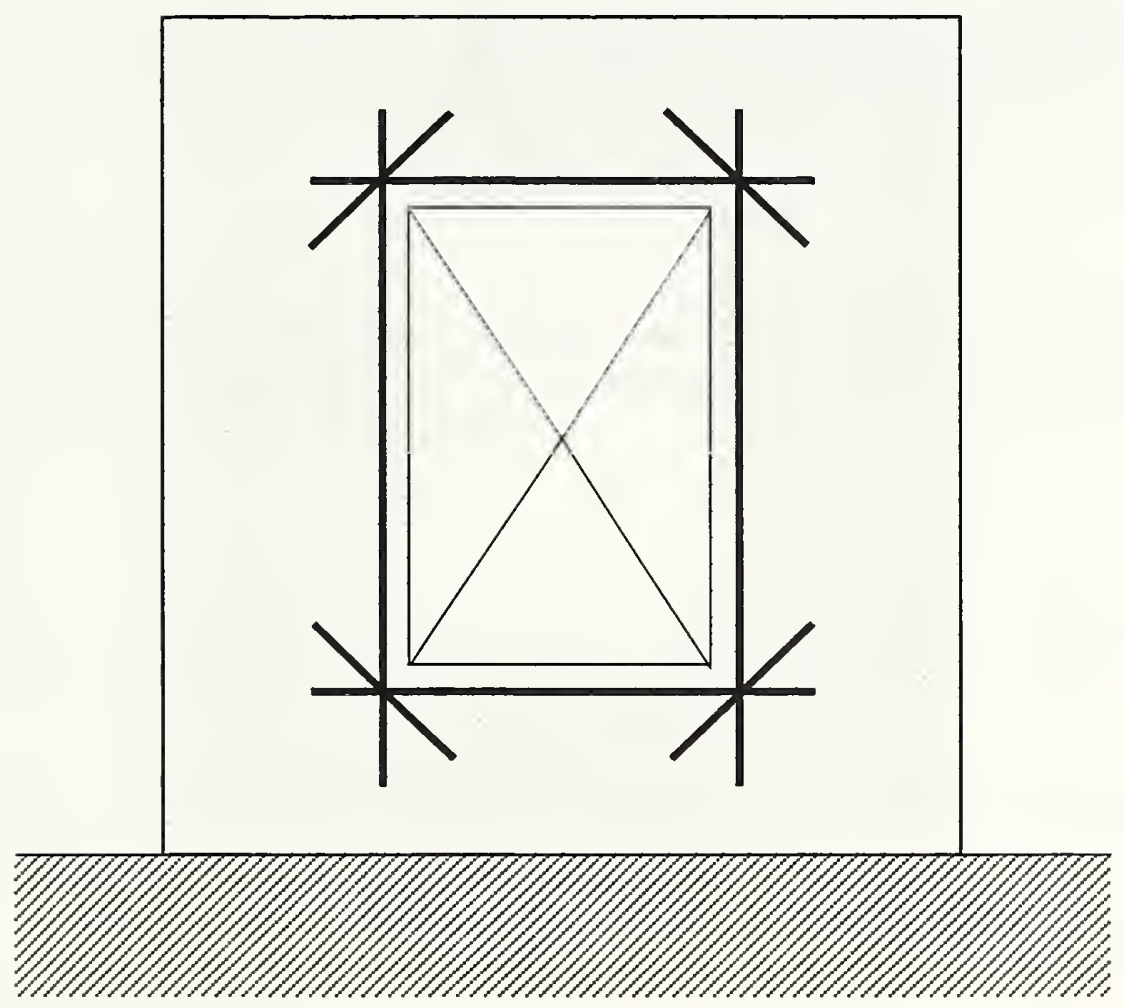

Figure 3.23 - Conventional trim steel 


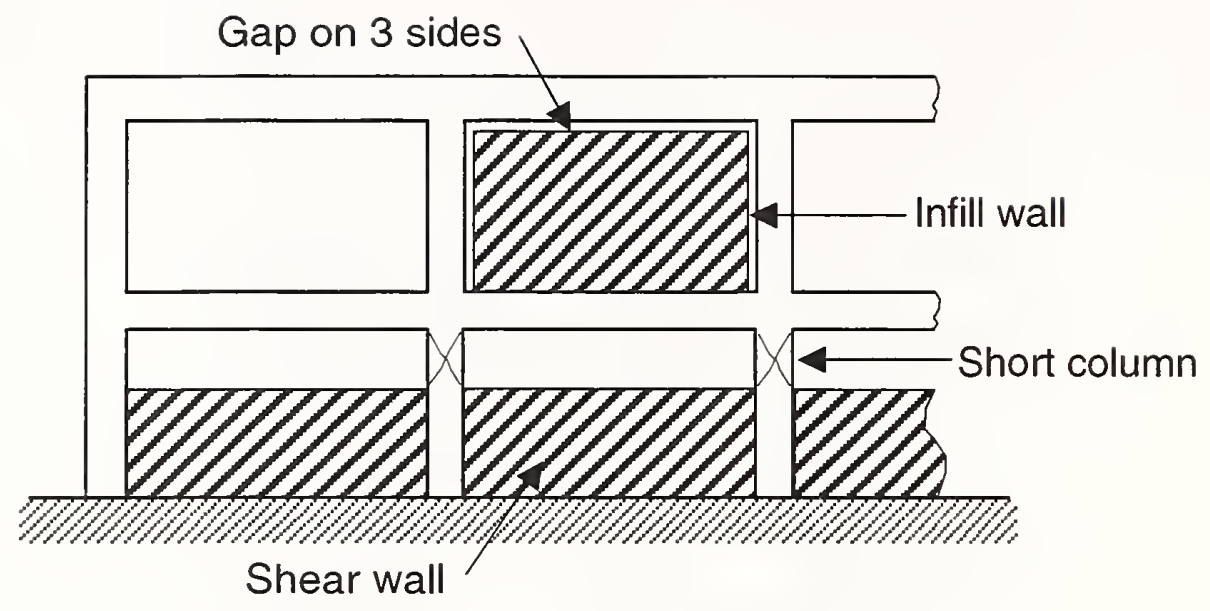

Figure 3.24 - Infill wall 


\section{PROCEDURES AND COMMENTARY FOR GEOLOGIC SITE HAZARDS AND FOUNDATIONS}

\subsection{Introduction}

A seismic evaluation of an existing building should include an examination of the foundation, an assessment of the capability of the soil beneath the foundation to withstand the forces applied during an earthquake, and consideration of nearby geologic hazards that may affect the stability of the building during an earthquake.

This chapter discusses general requirements that apply to foundations and supporting soils: geologic site hazards, condition of foundations and capacity of foundations.

\subsection{Geologic Site Hazards}

Certain geologic and local site conditions can lead to structural damage in the event of an earthquake. Large foundation movements due to any number of causes can severely damage otherwise seismic resistant building. Potential causes of significant foundation movement include settlement or lateral spreading due to liquefaction, slope failure, or surface ruptures. An evaluation of the building should include consideration for these effects and the impact they might have on the superstructure.

\subsubsection{Liquefaction}

Liquefaction-susceptible, saturated, loose granular soils that could jeopardize the building's seismic performance must not exist in the foundation soils at depths within $15 \mathrm{~m}$ under the building.

Commentary:

Soils susceptible to liquefaction may lose all vertical load bearing capacity during an earthquake. Loss of vertical support for the foundation will cause large differential settlements and induce large forces in the building superstructure

These forces will be concurrent with all existing gravity loads and seismic forces during the earthquake.

\subsubsection{Slope Failure}

The building site must be sufficiently remote from potential earthquake-induced slope failures or rock falls to be unaffected by such failures, or must be capable of accommodating any predicted movements without failure. 
Commentary:

Steep slopes are susceptible to slides during an earthquake. Slope failures are possible in rock or other on non-liquefiable soils on slopes that normally exceed $6 \%$. Slopes that exhibit signs of prior landslides require the most attention.

The concern for buildings on the uphill side of slopes is lateral spreading of the downhill footings. The concern for buildings on the downhill side is impact by sliding soil and debris.

\subsubsection{Surface Fault Rupture}

Surface fault rupture and surface displacement at the building site are not anticipated.

Commentary:

In the near field of active faults, there is a potential for large fissures and differential movement to occur in the surface soils. Foundations of buildings located above these ruptures will be subjected to large differential movements that will induce large forces in the building superstructure.

These forces will be concurrent with all existing gravity loads and seismic forces during the earthquake

\subsection{Condition of Foundation}

Foundation elements are usually below grade and concealed from view. Evaluations, however, should still include consideration of the foundation and the condition of the elements. Often signs of foundation performance are visible on the surface in the form of existing differential settlement, sloping floors, out-of-plumb walls, and cracking or distress in visible portions of the footings.

\subsubsection{Foundation Performance}

There must be no evidence of excessive foundation movement such as settlement or heave that would affect the integrity or strength of the structure.

Commentary:

The integrity and strength of foundation elements may be reduced by cracking, yielding, tipping or buckling of the foundation. Such weakening may be critical in the event of an earthquake. 
Lower level walls, partitions, grade beams, visible footings, pile caps, and similar elements should be visually examined for cracking, yielding, buckling, and out-of-level conditions. Any such signs should be identified and further evaluated.

\subsection{Capacity of Foundations}

Building foundation elements normally have a capacity at least two times the gravity loads. If there are no signs of foundation distress due to settlement, erosion, corrosion or other reasons, the foundations are likely to have adequate vertical capacity if the total gravity and seismic overturning loads do not exceed the allowable static capacity by more than a factor of two.

Foundations are considered to have adequate lateral capacity for seismic resistance if the allowable horizontal capacity of the foundation system exceeds the calculated seismic base shear of the buildings

\subsubsection{Pole Foundations}

Pole foundations shall have minimum embedment of $1.5 \mathrm{~m}$.

Commentary:

Pole buildings are structures supported by poles or posts, usually found on rocky and hillside sites. Seismic resistance for a pole structure depends on the embedment depth of the poles and the resistance to active and passive soil pressures.

\subsubsection{Overturning}

The ratio of the effective horizontal dimension, at the foundation level of the lateral-force-resisting system, to the building height (base/height) must be greater than 0.4 .

Commentary:

The concentration of seismic overturning forces in foundation elements may exceed the capacity of the soil, the foundation structure, or both

\subsubsection{Ties Between Foundation Elements}

The foundation shall have ties adequate to resist seismic forces where footings, piles, and piers are not restrained by beams, slabs, or soils classified as Type 1 or 2. 


\section{Commentary:}

Ties between discrete foundation elements, such as pile caps and pole footings, are required when the seismic ground motions are likely to cause significant lateral spreading of the foundations. Ties may consist of tie beams, grade beams or slabs. If the foundations are restrained laterally by competent soils or rock, ties are not required.

\subsubsection{Sloping Sites}

The grade difference from one side of the building to another must not exceed one-half the story height at the location of embedment.

Commentary:

The transfer of seismic force is more difficult when a permanent horizontal force is present. 


\section{PROCEDURES AND COMMENTARY FOR NONSTRUCTURAL COMPONENTS}

\subsection{Introduction}

This chapter discusses the performance of nonstructural components during earthquakes and windstorm. "Nonstructural" is the name given by design professionals to those architectural, mechanical and electrical components that are delineated on the construction documents. Special consideration is warranted for nonstructural components in essential facilities (e.g., hospitals, police and fire stations) and other facilities that must remain operational after an earthquake or a windstorm.

For nonstructural component evaluation, the key issue is generally whether the component is braced or anchored. This is generally immediately visible. Because some critical components, such as connections and framing, will often be concealed, in some cases, it will be necessary to remove materials in order to conduct the evaluation.

Several different types of nonstructural deficiencies may be identified by the evaluator, such as the non-existence of anchorage or bracing, which is clearly non-complying. In other cases, where some bracing or anchorage is provided, or material is deteriorated or corroded, further evaluation and judgment is necessary to ascertain the extent of the deficiency and the consequences of failure. Some simple calculations of weights, dimensional ratios and forces are used in the evaluation.

\subsection{Unreinforced Masonry}

Unreinforced masonry or hollow clay tile partitions must be braced at a spacing of equal to or less than $2.5 \mathrm{~m}$.

Commentary:

Hollow clay tile units are brittle and subject to shattering. Unreinforced masonry units may have cracks, loose blocks, or weak mortar. Bracing is needed to prevent portions of the unreinforced masonry from dislodging due to out-of-plane seismic forces. Door openings often create localized weaknesses due to inadequate support for the block masonry or clay tile at the head and at the sides of the opening.

If bracing is non-existent, mitigation with elements or connections needed to brace the partitions is necessary. 


\subsection{Ceiling Systems}

\subsubsection{Integrated Ceilings}

Integrated suspended ceilings at exitways and corridors or weighing more than $10 \mathrm{~kg} / \mathrm{m}^{2}$ must be laterally restrained with a minimum of 4 diagonal wires or rigid members attached to the structure above at a spacing of equal to or less than $4 \mathrm{~m}$.

Commentary:

Without bracing, integrated ceiling systems are susceptible to vertical and lateral movement which can damage fire sprinkler piping and other elements that penetrate the ceiling grid. Lightweight suspended ceilings may not pose a life safety hazard unless special conditions apply in the judgment of the evaluating engineer, such as a large area of ceiling, poor quality construction, vulnerable occupancy, or egress route.

If bracing is non-existent, mitigation with elements or connections needed to brace the ceilings is necessary.

\subsubsection{Support}

The integrated suspended ceiling system must not be used to laterally support the tops of gypsum board, masonry, or hollow clay tile partitions.

Commentary:

Integrated suspended ceilings braced with diagonal wires will move laterally when subjected to seismic forces. The ability of the gypsum board, masonry or hollow clay tile partitions to accommodate such movement without collapse should be considered by the evaluator.

\subsubsection{Suspended Lath and Plaster}

Ceilings consisting of suspended lath and plaster shall be anchored for every 1 square meter of area.

Commentary:

Suspended plaster ceilings may behave like structural diaphragms and resist in-plane seismic forces. If the strength of the plaster is exceeded, cracking and spalling of portions of the ceiling are possible. Large areas of suspended plaster may separate from the suspension system and fall if not properly fastened. The interconnection of 
the plaster to the lath and lath to the support framing should also be specifically assessed.

If anchorage is non-existent, mitigation with elements or connections needed to brace the ceilings is necessary

\subsection{Light Fixtures}

\subsubsection{Independent Support}

Light fixtures in suspended grid ceilings must be supported independently of the ceiling suspension system by a minimum of two wires at diagonally opposite corners of the fixtures.

Commentary:

With lay-in fluorescent lighting systems, ceiling movement can cause fixtures to separate and fall from suspension systems. These fixtures perform satisfactorily when they are supported separately from the ceiling system or have back-up support that is independent of the ceiling system. If the fixtures are independently supported by methods other than that described, the evaluator should exercise judgment as to its efficacy.

If independent support is non-existent, mitigation is necessary.

\subsubsection{Emergency Lighting}

Emergency lighting must be anchored or braced to prevent falling or swaying during an earthquake.

Commentary:

Emergency lighting should be provided with positive anchorage and/or bracing to prevent falling hazards and to enhance the reliability of post-earthquake performance.

If bracing or anchorage is non-existent, mitigation is necessary.

\subsection{Cladding and Glazing}

\subsubsection{Cladding Anchors}

Cladding components weighing more than $50 \mathrm{~kg} / \mathrm{m}^{2}$ must be anchored to the exterior wall framing at a spacing equal to or less than $2 \mathrm{~m}$. 
Commentary:

Exterior cladding components, which are often heavy, can fail if their connections to the building frames have insufficient strength and/or ductility. The evaluator should assess the consequences of failure, in particular the location of the panels in relation to building occupants and passers-by. If anchorage is non-existent, mitigation is necessary.

\subsubsection{Bearing Connections}

Where bearing connections are required, there must be a minimum of two bearing connections for each wall panel.

Commentary:

A single bearing connection can result in a dangerous lack of redundancy. The adequacy of single point bearing connections should be evaluated for resistance to inplane overturning forces including all eccentricities. Small panels such as some column covers may have a single bearing connection, and still provide adequate safety against failure.

If connections are non-existent, mitigation is necessary.

\subsubsection{Deterioration}

There must be no evidence of deterioration or corroding in any of the connection elements.

Commentary:

Corrosion can reduce the strength of connections and lead to deterioration of the adjoining materials. The extent of corrosion and its impact on the wall cladding and structure should be considered in the evaluation.

\subsubsection{Glazing}

Glazing in curtain walls and individual panes over $1.5 \mathrm{~m}^{2}$ in area, located up to a height of $4 \mathrm{~m}$ above an exterior walking surface, must be laminated, annealed or heat strengthened safety glass that will remain in the frame when cracked. 
Commentary:

Glazing may shatter and fall due to lack of provision for building drift or racking. If it is safety glazing with racking capability it may shatter or crack in a manner that is unlikely to cause injury, and it may remain in the frame to provide a temporary weather barrier. Giass generally fails in earthquakes because of deformation of the frame and lack of space between the glass and frame to allow for independent movement. Special attention should be given to glazing over or close to entrance and exit ways. This requirement is also applicable to windstorms, in which glazing failure can be due either to excessive wind pressure or more commonly, to wind-borne missiles. It is desirable that glazing satisfy the provisions of the ASCE 7-98 Standard for hurricane-prone regions.

\subsection{Parapets, Cornices and Appendages}

\subsubsection{URM Parapets}

There must be no laterally unsupported unreinforced masonry parapets or cornices above the highest anchorage level with height-to-thickness ratios greater than 2.

Commentary:

URM parapets present a major falling hazard and potential life-safety threat. If anchorage is non-existent, mitigation is necessary.

\subsubsection{Canopies}

Canopies located at building exits must be anchored at a spacing of $3 \mathrm{~m}$ or less.

Commentary:

Inadequately supported canopies present a life safety hazard. A common form of failure is pullout of shallow anchors from building walls. If anchorage is non-existent, mitigation is necessary.

\subsubsection{Wind Load Effects}

Parapets, overhangs, and appendages must withstand aerodynamic forces induced by winds with speeds specified in the applicable building code provisions (the 1980 Provisionales). 
Commentary:

The total pressure coefficient $C$ for parapets and appendages should be assumed to be equal to 1.75. Overhangs should be analyzed for upward pressures with a pressure coefficient $C=3.5$ for roofs with slope equal to or less than $10^{\circ}$, and $C=2.5$ for roofs with slope greater than $10^{\circ}$. Definition of $\mathrm{C}$ is given in the 1980 Provisionales.

\subsection{Masonry Chimneys}

\subsubsection{URM}

No unreinforced masonry chimney must extend above the roof surface more than twice the least dimension of the chimney.

Commentary:

Unreinforced masonry chimneys are highly vulnerable to damage in earthquakes. Typically, chimneys extending above the roof more than twice the least dimension of the chimney crack just above the roof line and become dislodged. Chimneys may fall through the roof or on a public or private walkway creating a life-safety hazard. Experience has shown that the costs of rehabilitating masonry chimneys can sometimes exceed the costs of damage repair.

\subsubsection{Masonry}

Masonry chimneys must be anchored to the floor and roof.

Commentary:

Refer to Commentary of Section 5.6.1

\subsection{Stairs}

\subsubsection{URM Walls}

Walls around stair enclosures must not consist of unbraced hollow clay tile or unreinforced concrete masonry. 
Commentary:

Hollow tile or unreinforced masonry walls may fail and block stairs and corridors. Postearthquake evacuation efforts can be severely hampered as a result. If bracing is nonexistent, mitigation is necessary.

\subsection{Elevators}

\subsubsection{Support System}

All elements of the elevator system must be anchored.

Commentary:

The successful performance of an elevator system requires that the various elements of the system remain in place, undamaged and capable of operating after inspection. As a minimum, all equipment, including hoistway doors, brackets, controllers, and motors must he anchored.

\subsubsection{Shaft Walls}

All elevator shaft walls must be anchored and reinforced to prevent toppling into the shaft during strong shaking.

Commentary:

Elevator shaft walls are often unreinforced masonry construction using hollow clay tiles or concrete masonry blocks. In the event of strong shaking, these walls may experience significant damage due to in-plane forces and fall into the shaft.

\subsubsection{Brackets}

The brackets that tie the counterweight rail to the building structure must have spacing of $3 \mathrm{~m}$ or less.

Commentary:

The brackets that support the rails must be properly spaced and designed to be effective. It is common for brackets to be properly spaced but improperly designed. The evaluator should be particularly aware of the eccentricities that often occur within the standard bracket systems most commonly used. 


\subsection{Roofs, Glazing and Cladding}

All elements and connections of the roof and the roof wind-force resisting system must be capable of resisting the wind forces inherent in the applicable building code provisions.

Glazing and cladding must withstand aerodynamic forces induced by wind as specified in applicable building code provisions.

Commentary:

Roof pressure should be calculated in accordance with the 1980 Provisionales. Wind loads on roofs and cladding are non-uniformly distributed. For example, Fig. 2.2 shows that wind pressures are greater at roof corners and edges, and edges of walls. For details of pressure distribution, see applicable building code provisions. 


\section{GLOSSARY}

Appendage: An architectural component such as a canopy, ornamental balcony, or statuary.

Base shear: Total calculated lateral force or shear at the base.

Boundary members: Portions along wall and diaphragm edges strengthened by longitudinal and transverse reinforcement and/or structural steel members.

Collector (Drag strut, Diaphragm strut): A member that transfers lateral forces from the diaphragm of the structure to vertical elements of the lateral-force-resisting system. A collector can be a part of slab with special reinforcement.

Diaphragm: A horizontal structural member, such as floor and roof slab, that transmits seismic or wind forces to the vertical resisting elements.

Drag strut (Collector, Diaphragm strut): A diaphragm or shear wall boundary element parallel to the applied load that collects and transfers diaphragm shear forces to the vertical resisting elements. A drag strut often is an extension of a boundary element that transfers forces into the diaphragm or shear wall.

Immediate occupancy: A performance level whereby building sustains very limited damage to both structural and nonstructural components during the design earthquake and windstorm. The basic vertical and lateral-force-resisting systems retain nearly all of their pre-earthquake or pre-windstorm strength and stiffness.

Life safety: A performance level whereby a building sustains significant damage to both structural and nonstructural components during a design earthquake and windstorm, but remains stable and has reserve capacity. Injuries may occur, but the level of risk for life-threatening injury and entrapment is low.

Lateral-force resisting system: That portion of the structure composed of members proportioned to resist forces related to earthquake or wind effects.

P-Delta effect: The secondary effect on shears and moments of frame members due to the action of the vertical loads induced by displacement of the building frame resulting from the design loads.

Shear wall: A wall, bearing or nonbearing, capable of resisting lateral forces acting in the plane of the wall.

Story shear force: Portion of the lateral force carried by each story of the building. 


\section{REFERENCES}

DNRS, 1979, Recomendaciones Provisionales para el Análisis Sísmico de Estructuras, Departamento de Normas, Reglamentos y Sistemas Secretaría de Estado de Obras Públicas y Comunicaciones, República Dominicana.

DNRS, 1980, Recomendaciones Provisionales para el Análisis por Viento de Estructuras, Departamento de Normas, Reglamentos y Sistemas, Secretaría de Estado de Obras Públicas y Comunicaciones, República Dominicana.

FEMA, 1992a, NEHRP Recommended Provisions for the Development of Seismic Regulations for New Buildings, U.S. Federal Emergency Management Agency (Report No. FEMA 222), Washington, D.C.

FEMA, 1992b, NEHRP Handbook for the Seismic Evaluation of Existing Buildings, U.S. Federal Emergency Management Agency (Report No. FEMA 178), Washington, D.C.

FEMA, 1998, Handbook for the Seismic Evaluation of Buildings - A Prestandard, U.S. Federal Emergency Management Agency (Report No. FEMA 310), Washington, D.C.

FEMA, 2000, Prestandard and Commentary for the Seismic Rehabilitation of Buildings, U.S. Federal Emergency Management Agency (Report No. FEMA 356), Washington, D.C. 


\section{APPENDIX A}

\section{EVALUATION STATEMENTS FOR CONCRETE MOMENT FRAME BUILDINGS}

These buildings consist of a frame assembly of cast-in-place concrete beams and columns. Floor and roof framing consists of cast-in-place concrete slabs, concrete beams, one-way joists, two-way waffle joists, or flat slabs. Lateral forces are resisted by concrete moment frames that develop their stiffness through monolithic beam-column connections. In older construction, the moment frames may consist of the column strips of two-way flat slab systems. Modern frames in regions of high seismicity have joint reinforcing, closely spaced ties, and special detailing to provide ductile performance. This detailing is not present in older construction. Foundations consist of concrete spread footings or deep pile foundations.

Each of the evaluation statements on this checklist should be marked compliant $(C)$, non-compliant (NC), or not applicable (N/A). Compliant statements identify issues that are acceptable according to the criteria of this manual, while non-compliant statements identify issues that require further investigation. Certain statements may not apply to the buildings being evaluated. For non-compliant evaluation statements, the evaluating engineer may choose to conduct further investigation

For guidance in the investigation, refer to the manual section indicated in parentheses at the end of the statement.

\section{BASIC STRUCTURAL CHECK LIST}

This Basic Structural Checklist must be completed for both Life Safety and Immediate Occupancy evaluations.

\section{Building System}

C NC N/A LOAD PATH: The structure contains a complete load path for seismic force effects from any horizontal direction that serves to transfer the inertial forces from the mass to the foundation. (NOTE: Write a brief description of this linkage for each principal direction.)(Sec. 3.1)

C NC N/A ADJACENT BUILDINGS: An adjacent building must not be located next to the structure being evaluated closer than $4 \%$ of the height for Life Safety and Immediate Occupancy. (Sec. 3.2) 
C NC N/A WEAK STORY: The strength of the lateral-load-resisting system in any story must not be less than $80 \%$ of the strength in an adjacent story above or below. (Sec. 3.3.1)

C NC N/A SOFT STORY: The stiffness of the lateral-load-resisting system in any story is not less than $70 \%$ of the stiffness in an adjacent story above or below, or less than $80 \%$ of the average stiffness of the three stories above or below. (Sec. 3.3.2)

C NC N/A GEOMETRY: There must be no changes in horizontal dimension of the lateral-force-resisting system of more than $30 \%$ in a story relative to adjacent stories, excluding one-story penthouses. (Sec. 3.3.3)

C NC N/A MASS: There is no change of effective mass of more than $50 \%$ from one story to the next, excluding light roofs.

(Sec. 3.3.4)

C NC N/A VERTICAL DISCONTINUITIES: All vertical elements in the lateral-force-resisting system must be continuous to the foundation. (Sec. 3.3.5)

C NC N/A EARTHQUAKE INDUCED TORSION: The distance between the story center of rigidity and the story center of mass must be less than $20 \%$ of the width of the structure in either major plan dimension. (Sec. 3.3.6)

C NC N/A WIND INDUCED TORSION: The lateral-force-resisting elements form a well balanced system that is capable of resisting wind forces acting from any direction and is not subjected to significant torsion. For a non-flexible structure with a reasonably regular shape in plan, the distance, measured along either principal axis of the building plan, between the point of application of the mean load induced by wind normal to that axis and the center of rigidity must be less than $15 \%$ of the width of the structure in either major plan dimension. (For this evaluation a set of structural drawings is necessary.) (Sec. 3.3.7)

C NC N/A SHORT CAPTIVE COLUMNS: There must be no columns at a level with height/depth ratios less than $50 \%$ of the nominal height/depth ratio of the typical columns at that level. (Sec. 3.4)

C NC N/A COLUMN-BAR SPLICES: All column bar lap splice lengths shall be greater than $35 d_{b}$ and shall be enclosed by ties spaced at or less than $8 d_{b}$. (Sec. 3.5) 
C NC N/A FLAT SLABS: The lateral-force-resisting system must not be a frame consisting of columns and a flat slab/plate without beams. Flat slabs/plates classified as secondary components must have continuous bottom bars through the column joints. (Sec. 3.6)

C NC N/A DETERIORATION OF CONCRETE: There must be no visible deterioration of concrete or reinforcing steel in any of the lateralforce-resisting or the vertical elements. (Sec. 3.7)

C NC N/A POST-TENSIONING ANCHORS: There must be no evidence of corrosion or spalling in the vicinity of post-tensioning or end fittings. Coil anchors have not been used. (Sec. 3.8)

\section{Lateral Force Resisting System}

C NC N/A REDUNDANCY: The number of lines of moment frames in each principal direction must be greater than or equal to 2 . The number of bays of moment frames in each line must be greater than or equal to 2 for Life Safety and 3 for Immediate Occupancy (Sec. 3.9).

C NC N/A INTERFERING WALLS: All concrete and masonry infill walls placed in the moment frames are isolated from the structural elements. (Sec. 3.10)

C NC N/A SHEARING STRESS CHECK: The shear stress in the concrete columns must be less than $0.7 \mathrm{MPa}\left(7 \mathrm{kgf} / \mathrm{cm}^{2}\right)$ or $\sqrt{f^{\prime}{ }_{c}} / 6 \mathrm{MPa}$. (Sec. 3.11)

C NC N/A AXIAL STRESS CHECK: The axial stress due to gravity loads in columns subjected to overturning forces shall be less than $0.10 f_{c}^{\prime}$. (Sec. 3.12)

\section{Connections}

C NC N/A CONCRETE COLUMNS: All longitudinal column steel must be doweled into the foundation and the dowels must be able to develop the tensile capacity of the column. (Sec. 3.13) 


\section{Additional Structural Check list for Concrete Moment Frame Buildings for Immediate Occupancy}

This Additional Structural Checklist must be completed when the structure is evaluated for immediate occupancy. The Basic Structural Checklist must be completed prior to completing this checklist.

\section{Lateral Force Resisting System}

C NC N/A FLAT SLAB FRAMES: The lateral-force-resisting system must not be a frame consisting of columns and a flat slab/plate without beams. (Sec.3.6)

C NC N/A PRESTRESSED FRAME ELEMENTS: The lateral-force-resisting frames shall not include any prestressed or post-tensioned elements. (Sec.3.14)

C NC N/A SHORT CAPTIVE COLUMNS: There must be no columns at a level with height/depth ratios less than $75 \%$ of the nominal height/depth ratio of the typical columns at that level. (Sec. 3.4)

C NC N/A NO SHEAR FAILURES: The shear capacity of the frame columns must be able to develop the moment capacity at the top and the bottom of the columns. (Sec. 3.15)

C NC N/A STRONG COLUMN/WEAK BEAM: The sum of the moment capacity of the columns must be $20 \%$ greater than that of the beams at frame joints. (Sec. 3.16)

C NC N/A BEAM BARS: At least two longitudinal top and two longitudinal bottom bars must extend continuously throughout the length of each frame beam. At least $25 \%$ of the longitudinal bars provided at the joints for either positive or negative moment must be continuous throughout the length of the members. (Sec. 3.17)

C NC N/A COLUMN-BAR SPLICES: All column bar lap splice lengths must be greater than $50 \mathrm{~d}_{\mathrm{b}}$ for Immediate Occupancy and must be enclosed by ties spaced at or less than $8 \mathrm{~d}_{\mathrm{b}}$. (Sec. 3.5)

C NC N/A BEAM-BAR SPLICES: The lap splices for longitudinal beam reinforcing must not be located within the center half of the member length and shall not be located within the vicinity of potential plastic hinge locations. (Sec. 3.18) 
C NC N/A COLUMN-TIE SPACING: Frame columns must have ties spaced at or less than $d / 4$ throughout their length and at or less than $8 d_{b}$ at all potential plastic hinge locations. (Sec. 3.19)

C NC N/A STIRRUP SPACING: All beams must have stirrups spaced at or less than $\mathrm{d} / 2$ throughout their length. At potential plastic hinge locations stirrups must be spaced at or less than the minimum of $8 d_{b}$ or $d / 4$. (Sec. 3.20)

C NC N/A JOINT REINFORCING: Beam-column joints must have ties spaced at or less than $8 d_{b}$. (Sec. 3.21)

C NC N/A JOINT ECCENTRICITY: There must be no eccentricities larger than $20 \%$ of the smallest column plan dimension between girder and column centerlines. (Sec. 3.22)

C NC N/A STIRRUP AND TIE HOOKS: The beam stirrups and column ties must be anchored into the member cores with hooks of $135^{\circ}$ or more. (Sec. 3.23)

C NC N/A FLAT SLABS: Flat slabs/plates must not be permitted as primary components. (Sec. 3.6)

\section{Diaphragms}

C NC N/A DIAPHRAGM CONTINUITY: The diaphragms must not be composed of split-level floors. (Sec. 3.24)

C NC N/A PLAN IRREGULARITIES: There must be tensile capacity to develop the strength of the diaphragm at re-entrant corners or other locations of plan irregularities. (Sec. 3.25)

C NC N/A DIAPHRAGM REINFORCEMENT AT OPENINGS: There must be reinforcing around all diaphragm openings larger than $50 \%$ of the building width in either major plan dimension. (Sec. 3.26)

\section{Connections}

C NC N/A LATERAL LOAD AT PILE CAPS: Pile caps must have top reinforcement and piles must be anchored to the pile caps. (Sec. 3.27) 


\section{APPENDIX B}

\section{EVALUATION STATEMENTS FOR CONCRETE SHEAR WALL BUILDINGS WITH STIFF DIAPHRAGMS}

These buildings have floor and roof framing that consists of cast-in-place concrete slabs, concrete beams, one-way joists, two-way waffle joists, or flat slabs. Floors are supported on concrete columns or bearing walls. Lateral forces are resisted by cast-inplace concrete shear walls. In older construction, shear walls are lightly reinforced, but often extend throughout the building. In more recent construction, shear walls occur in isolated locations and are more heavily reinforced with boundary elements and closely spaced ties to provide ductile performance. The diaphragms consist of concrete slabs and are stiff relative to the walls. Foundations consist of concrete spread footings or deep pile foundations.

Each of the evaluation statements on this checklist should be marked compliant (C), non-compliant (NC), or not applicable (N/A). Compliant statements identify issues that are acceptable according to the criteria of thismanual, while non-compliant statements identify issues that require further investigation. Certain statements may not apply to the buildings being evaluated. For non-compliant evaluation statements, the design professional may choose to conduct further investigation.

For guidance in the investigation, refer to the manual section indicated in parentheses at the end of the statement.

\section{BASIC STRUCTURAL CHECKLIST}

This Basic Structural checklist must be completed for both Life Safety and Immediate Occupancy evaluation.

\section{Building System}

C NC N/A LOAD PATH: The structure contains a complete load path for seismic force effects from any horizontal direction that serves to transfer the inertial forces from the mass to the foundation. (NOTE: Write a brief description of this linkage for each principal direction.) (Sec. 3.1)

C NC N/A WEAK STORY: The strength of the lateral-force-resisting system in any story must not be less than $80 \%$ of the strength in an adjacent story, above or below. (Sec. 3.3.1) 
C NC N/A SOFT STORY: The stiffness of the lateral-force-resisting system in any story must not he less than $70 \%$ of the stiffness in an adjacent story above or below, or less than $80 \%$ of the average stiffness of the three stories above or below. (Sec. 3.3.2)

C NC N/A GEOMETRY: There must be no changes in horizontal dimension of the lateral-force-resisting system of more than $30 \%$ in a story relative to adjacent stories, excluding one-story penthouses. (Sec. 3.3.3)

C NC N/A MASS: There must be no change in effective mass more than $50 \%$ from one story to the next, excluding light roof. (Sec. 3.3.4)

C NC N/A VERTICAL DISCONTINUITIES: All vertical elements in the lateral-force-resisting system must be continuous to the foundation. (Sec. 3.3.5)

C NC N/A EARTHQUAKE INDUCED TORSION: The distance between the story center of mass and the story center of rigidity must be less than $20 \%$ of the building width in either plan dimension. (Sec. 3.3.6)

C NC N/A

WIND INDUCED TORSION: The lateral-force-resisting elements form a well balanced system that is capable of resisting wind forces acting from any direction and is not subjected to significant torsion. For a non-flexible structure with a reasonably regular shape in plan, the distance, measured along either principal axis of the building plan, between the point of application of the mean load induced by wind normal to that axis and the center of rigidity must be less than $15 \%$ of the width of the structure in either major plan dimension. (For this evaluation a set of structural drawings is necessary.) (Sec. 3.3.7)

C NC N/A DETERIORATION OF CONCRETE: There must be no visible deterioration of concrete or reinforcing steel in any of the vertical- or lateral-force-resisting elements. (Sec. 3.7)

C NC N/A POST-TENSIONING ANCHORS: There must be no evidence of corrosion or spalling in the vicinity of post-tensioning or end fittings. Coil anchors have not been used. (Sec. 3.8)

C NC N/A CONCRETE WALL CRACKS: All existing diagonal cracks in wall elements must be less than $1.0 \mathrm{~mm}$, must not be concentrated in one location, and must not form an X pattern. (Sec. 3.28) 


\section{Lateral Force Resisting System}

C NC N/A COMPLETE FRAMES: Steel or concrete frames classified as secondary components must form a complete vertical load carrying system. (Sec. 3.29)

C NC N/A REDUNDANCY: The number of lines of shear walls in each principal direction must be greater than or equal to 2. (Sec. 3.9)

C NC N/A SHEAR STRESS CHECK: The shear stress in the concrete shear walls must be less than $1.0 \mathrm{MPa}\left(10 \mathrm{kgf} / \mathrm{cm}^{2}\right)$ or $\sqrt{\mathrm{f}_{\mathrm{c}}} / 4 \mathrm{MPa}$, if the total cross sectional area of the walls in a story is less than $3 \%$ of the floor area. If greater than $3 \%$, no shearing stress check is needed. (Sec. 3.11)

C NC N/A REINFORCING STEEL: The ratio of reinforcing steel area to gross concrete area must be greater than 0.0015 in the vertical direction and 0.0025 in the horizontal direction. The spacing of reinforcing steel must be equal to or less than $450 \mathrm{~mm}$.

(Sec. 3.30)

C NC N/A DIAPHRAGM OPENINGS AT THE SHEAR WALLS:

Diaphragm openings immediately adjacent to the shear walls must be less than $25 \%$ of the wall length. (Sec. 3.31)

\section{Connections}

C NC N/A TRANSFER TO SHEAR WALLS: Diaphragms must be reinforced and connected for transfer of loads to the shear walls (Sec. 3.32)

C NC N/A FOUNDATION DOWELS: Walls must be doweled into the foundation. (Sec. 3.33) 


\section{Additional Structural Checklist for Concrete Shear Wall Buildings With Stiff Diaphragms for Immediate Occupancy}

This Additional Structural Checklist must be completed when the structure is evaluated for immediate occupancy. The Basic Structural Checklist must be completed prior to completing this checklist.

\section{Lateral Force Resisting System}

C NC N/A DEFLECTION COMPATIBILITY: Secondary components must have the shear capacity to develop the flexural strength of the elements and must have ductile detailing. (Sec. 3.34)

C NC N/A FLAT SLABS: Flat slabs/plates must not be permitted as primary components. (Sec. 3.6)

C NC N/A COUPLING BEAMS: The stirrups in all coupling beams over means of egress must be spaced at or less than $\mathrm{d} / 2$ and must be anchored into the core with hooks of $135^{\circ}$ or more. (Sec. 3.35)

C NC N/A OVERTURNING: All shear walls must have aspect ratios less than 4 to 1. Wall piers need not be considered. (Sec. 3.36)

C NC N/A CONFINEMENT REINFORCING: For shear walls with aspect ratios greater than 2.0 , the boundary elements must be confined with spirals or ties with spacing less than $8 d_{b}$. (Sec. 3.37)

C NC N/A REINFORCING AT OPENINGS: There must be added trim reinforcement around all wall openings. (Sec. 3.38)

C NC N/A WALL THICKNESS: Thickness of bearing walls must not be less than 1/25 the minimum unsupported height or length, nor less than $100 \mathrm{~mm}$. (Sec. 3.39)

\section{Diaphragms}

C NC N/A DIAPHRAGM CONTINUITY: The diaphragms must not be composed of split-level floors. (Sec. 3.24)

C NC N/A DIAPHRAGM OPENINGS AT SHEAR WALLS: Diaphragm openings immediately adjacent to the shear walls must be less than $15 \%$ of the wall length. (Sec. 3.31) 
C NC N/A PLAN IRREGULARITIES: There must be tensile capacity to develop the strength of the diaphragm at re-entrant corners or other locations of plan irregularities. (Sec. 3.25)

C NC N/A DIAPHRAGM REINFORCEMENT AT OPENINGS: There must be reinforcing around all diaphragm openings larger than $50 \%$ of the building width in either major plan dimension. (Sec. 3.26)

\section{Connections}

C NC N/A LATERAL LOAD AT PILE CAPS: Pile caps must have top reinforcement and piles must be anchored to the pile caps. (Sec. 3.27)

C NC N/A TRANSFER TO SHEAR WALLS: Diaphragm connection to shear walls must be able to develop the lesser of the shear strength of the wall or diaphragm. (Sec. 3.32) 


\section{APPENDIX C}

\section{EVALUATION STATEMENTS FOR CONCRETE MOMENT FRAMES WITH INFILL MASONRY SHEAR WALLS AND STIFF DIAPHRAGMS}

This is an older type of building construction that consists of a frame assembly of castin-place concrete beams and columns. The floors and roof consist of cast-in-place concrete slabs. Walls consist of infill panels constructed of solid clay brick, concrete block, or hollow clay tile masonry. The performance of this type of construction depends on the interaction between the frame and infill panels. The combined behavior is more like a shear wall structure than a frame structure. Solidly infill masonry panels form diagonal compression struts between the intersections of the frame members. If the walls are offset from the frame and do not fully engage the frame members, the diagonal compression struts will not develop. The strength of the infill panel is limited by the shear capacity of the masonry bed joint or the compression capacity of the strut. The post-cracking strength is determined by an analysis of a moment frame that is partially restrained by the cracked infill. The shear strength of the concrete columns, after cracking of the infill, may limit the semiductile behavior of the system. The diaphragms consist of concrete floors and are stiff relative to the walls.

Each of the evaluation statements on this checklist should be marked compliant (C), non-compliant (NC), or not applicable (N/A). Compliant statements identify issues that are acceptable according to the criteria of this manual, while non-compliant statements identify issues that require further investigation. Certain statements may not apply to the buildings being evaluated. For non-compliant evaluation statements, the design professional may choose to conduct further investigation.

For guidance in the investigation, refer to the manual section indicated in parentheses at the end of the statement.

\section{BASIC STRUCTURAL CHECK LIST}

This Basic Structural Checklist must be completed for both Life Safety and Immediate Occupancy evaluations.

\section{Building System}

C NC N/A LOAD PATH: The structure must contain one complete load path for seismic force effects from any horizontal direction that serves to transfer the inertial forces from the mass to the foundation (Note: Write a brief description of this linkage for each principal direction.) (Sec. 3.1) 
C NC N/A WEAK STORY: The strength of the lateral-force-resisting system in any story must not be less than $80 \%$ of the strength in an adjacent story above or below. (Sec. 3.3.1)

C NC N/A SOFT STORY: The stiffness of the lateral-force-resisting system in any story shall not be less than $70 \%$ of the stiffness in an adjacent story above or below, or less than $80 \%$ of the average stiffness of the three stories above or below. (Sec. 3.3.2)

C NC N/A GEOMETRY: There must be no changes in horizontal dimension of the lateral-force-resisting system of more than $30 \%$ in a story relative to adjacent stories, excluding one-story penthouses. (Sec. 3.3.3)

C NC N/A MASS: There must be no change in effective mass more than $50 \%$ from one story to the next. (Sec. 3.3.4)

C NC N/A VERTICAL DISCONTINUITIES: All vertical elements in the lateral -force-resisting system must be continuous to the foundation. (Sec. 3.3.5)

C NC N/A EARTHQUAKE INDUCED TORSION: The distance between the story center of mass and the story center of rigidity must be less than $20 \%$ of the building width in either plan dimension.

(Sec. 3.3.6)

C NC N/A WIND INDUCED TORSION: The lateral-force-resisting elements form a well balanced system that is capable of resisting wind forces acting from any direction and is not subjected to significant torsion. For a non-flexible structure with a reasonably regular shape in plan, the distance, measured along either principal axis of the building plan, between the point of application of the mean load induced by wind normal to that axis and the center of rigidity must be less than $15 \%$ of the width of the structure in either major plan dimension. (For this evaluation a set of structural drawings is necessary.) (Sec. 3.3.7)

C NC N/A DETERIORATION OF CONCRETE: There must be no visible deterioration of concrete or reinforcing steel in any of the verticalor lateral-force-resisting elements. (Sec. 3.7)

C NC N/A MASONRY UNITS: There must be no visible deterioration of masonry units. (Sec. 3.40) 
C NC N/A MASONRY JOINTS: The mortar must not be easily scraped away from the joints by hand with a metal tool, and there must be no areas of eroded mortar. (Sec. 3.41)

C NC N/A CRACKS IN INFILL WALLS: There must be no existing diagonal cracks in infill walls that extend throughout a panel, are greater than $3 \mathrm{~mm}$, or have out-of-plane offsets in the bed joint greater than $3 \mathrm{~mm}$. (Sec. 3.42)

C NC N/A CRACKS IN BOUNDARY COLUMNS: There must be no existing diagonal cracks wider than $3 \mathrm{~mm}$ in concrete columns that encase masonry infills. (Sec. 3.43)

\section{Lateral Force Resisting System}

C NC N/A REDUNDANCY: The number of lines of shear walls in each principal direction must be greater than or equal to 2. (Sec. 3.9)

C NC N/A SHEAR STRESS CHECK: The shear stress in the reinforced masonry shear walls. calculated must be less than $0.5 \mathrm{MPa}$ $\left(5 \mathrm{kgf} / \mathrm{cm}^{2}\right)$. (Sec. 3.44)

C NC N/A SHEAR STRESS CHECK: The shear stress in the unreinforced masonry shear walls must be less than $0.2 \mathrm{MPa}\left(2 \mathrm{kgf} / \mathrm{cm}^{2}\right)$ for clay units and $0.5 \mathrm{MPa}\left(5 \mathrm{kgf} / \mathrm{cm}^{2}\right)$ for concrete units. (Sec. 3.45)

C NC N/A WALL CONNECTIONS: Masonry must be in full contact with frame. (Sec. 3.46)

\section{Connections}

C NC N/A TRANSFER TO SHEAR WALLS: Diaphragms must be reinforced and connected for transfer of loads to the shear walls. (Sec. 3.32)

C NC N/A CONCRETE COLUMNS: All concrete columns must be doweled into the foundation. (Sec. 3.13) 


\section{Additional Structural Checklist for Concrete Frames With Infill Masonry Shear Walls and Stiff Diaphragms}

This Additional Structural Checklist must be completed when the structure is evaluated for immediate occupancy. The Basic Structural Checklist must be completed prior to completing this Additional Structural Checklist.

\section{Lateral Force Resisting System}

C NC N/A DEFLECTION COMPATIBILITY: Secondary components must have the shear capacity to develop the flexural strength of the elements and must have ductile detailing. (Sec. 3.34)

C NC N/A FLAT SLABS: Flat slabs/plates must not be permitted as primary lateral-force-resisting components. (Sec. 3.6)

C NC N/A REINFORCING AT OPENINGS: All wall openings that interrupt reinforcement must have trim reinforcing on all sides.

(Sec. 3.38)

C NC N/A PROPORTIONS OF INFILL WALLS: The height-to-thickness ratio of the infill walls at each story must be less than 14 . (Sec. 3.47)

C NC N/A SOLID INFILL WALLS: The infill walls must not be of cavity construction. (Sec. 3.48)

C NC N/A INFILL WALLS: The infill walls must be continuous to the soffits of the frame beams and to the columns to either side. (Sec. 3.49)

\section{Diaphragms}

C NC N/A DIAPHRAGM CONTINUITY: The diaphragms must not be composed of split-level floors. (Sec. 3.24)

C NC N/A DIAPHRAGM OPENINGS AT SHEAR WALLS: Diaphragm openings immediately adjacent to the shear walls must be less than $15 \%$ of the wall length. (Sec. 3.31)

C NC N/A PLAN IRREGULARITIES: There must be tensile capacity to develop the strength of the diaphragm at re-entrant corners or other locations of plan irregularities. (Sec. 3.25) 
C NC N/A DIAPHRAGM REINFORCEMENT AT OPENINGS: There must be reinforcing around all diaphragm openings larger than $50 \%$ of the building width in either major plan dimension. (Sec. 3.26)

\section{Connections}

C NC N/A LATERAL LOAD AT PILE CAPS: Pile caps must have top reinforcement and piles must be anchored to the pile caps. (Sec. 3.27) 


\section{APPENDIX D \\ EVALUATION STATEMENTS FOR GEOLOGIC SITE HAZARDS AND FOUNDATIONS}

Evaluation of any nearby geologic hazards that my affect the stability of the foundation and the capacity of soil beneath the foundation must be carried out to assess their impact on the building evaluated.

Each of the evaluation statements on this checklist shall be marked compliant (C), non-compliant (NC), or not applicable (N/A). Compliant statements identify issues that are acceptable according to the criteria of this manual, while non-compliant statements identify issues that require further investigation. Certain statements may not apply to the buildings being evaluated. For non-compliant evaluation statements, the design professional may choose to conduct further investigation.

For guidance in the investigation, refer to the manual section indicated in parentheses at the end of the statement.

\section{Geologic Site Hazards}

The following statements shall be completed for buildings in regions of high or moderate seismicity.

C NC N/A LIQUEFACTION: Liquefaction-susceptible, saturated, loose granular soils that could jeopardize the building's seismic performance must not exist in the foundation soils at depths within $15 \mathrm{~m}$ under the building. (Sec. 4.1.1)

C NC N/A SLOPE FAILURE: The building site must be sufficiently remote from potential earthquake-induced slope failures or rockfalls to be unaffected by such failures, or must be capable of accommodating any predicted movements without failure. (Sec. 4.1.2)

C NC N/A SURFACE FAULT RUPTURE: Surface fault rupture and surface displacement at the building site is not anticipated. (Sec. 4.1.3) 


\section{Condition of Foundations}

C NC N/A FOUNDATION PERFORMANCE: There must be no evidence of excessive foundation movement such as settlement or heave that would affect the integrity or strength of the structure. (Sec. 4.2.1)

\section{Capacity of Foundations}

C NC N/A POLE FOUNDATIONS: Pole foundations must have a minimum embedment depth of $1.5 \mathrm{~m}$. (Sec. 4.3.1)

C NC N/A OVERTURNING: The ratio of the effective horizontal dimension, at the foundation level of the lateral-force-resisting system to the building height (base/height) must be greater than 0.4.(Sec. 4.3.2)

C NC N/A TIES BETWEEN FOUNDATION ELEMENTS: The foundation must have ties adequate to resist seismic forces where footings, piles, and piers are not restrained by beams, slabs, or soils classified as Type 1 or 2 . (Sec. 4.3.3)

C NC N/A SLOPING SITES: The grade difference from one side of the building to another must not exceed one-half the story height at the location of embedment. (Sec. 4.3.4) 


\section{APPENDIX E \\ EVALUATION STATEMENTS FOR NONSTRUCTURAL COMPONENTS}

Nonstructural components include architectural, mechanical and electrical components that are not part of load-carrying structural members. Investigation of nonstructural components can be very time consuming because they usually are not well detailed on plans and because they often are concealed. It is essential, however, to investigate these items because their seismic support may have been given little attention in the past and they are potentially dangerous. Of particular importance in nonstructural component evaluation efforts are site visits to identify the present status of nonstructural items.

Each of the evaluation statements on this checklist shall be marked compliant (C), noncompliant (NC), or not applicable (N/A). Compliant statements identify issues that are acceptable according to the criteria of this manual, while non-compliant statements identify issues that require further investigation. Certain statements may not apply to the buildings being evaluated. For non-compliant evaluation statements, the design professional may choose to conduct further investigation.

For guidance in the investigation, refer to the manual section indicated in parentheses at the end of each evaluation statement.

\section{Partitions}

C NC N/A UNREINFORCED MASONRY: Unreinforced masonry or hollow clay tile partitions must be braced at a spacing of equal to or less than $2.5 \mathrm{~m}$. (Sec 5.1.1)

\section{Ceiling Systems}

C NC N/A INTEGRATED CEILINGS: Integrated suspended ceilings at exits and corridors or weighing more than $10 \mathrm{MPa}\left(\mathrm{kgf} / \mathrm{m}^{2}\right)$ must be laterally restrained with a minimum of 4 diagonal wires or rigid members attached to the structure above at a spacing of equal to or less than $4 \mathrm{~m}$. (Sec. 5.2.1)

C NC N/A SUPPORT: The integrated suspended ceiling system must not be used to laterally support the tops of gypsum board, masonry, or hollow clay tile partitions. (Sec. 5.2.2)

C NC N/A SUSPENDED LATH AND PLASTER: Ceilings consisting of suspended lath and plaster or gypsum board must be attached for each $1 \mathrm{~m}^{2}$ of area. (Sec. 5.2.3) 


\section{Light Fixtures}

C NC N/A INDEPENDENT SUPPORT: Light fixtures in suspended grid ceilings must be supported independently of the ceiling suspension system by a minimum of two wires at diagonally opposite corners of the fixtures. (Sec. 5.3.I)

C NC N/A EMERGENCY LIGHTING: Emergency lighting must he anchored or braced to prevent falling or swaying during an earthquake or windstorm. (Sec. 5.3.2)

\section{Cladding and Glazing}

C NC N/A CLADDING ANCHORS: Cladding components weighing more than $50 \mathrm{~kg} / \mathrm{m}^{2}$ must be anchored to the exterior wall framing at a spacing equal to or less than $2 \mathrm{~m}$. (Sec. 5.4.I)

C NC N/A BEARING CONNECTIONS: Where bearing connections are required, there must be a minimum of two bearing connections for each wall panel. (Sec.5.4.2)

C NC N/A DETERIORATION: There must be no evidence of deterioration or corroding in any of the connection elements. (Sec. 5.4.3)

C NC N/A GLAZING (seismic): Glazing in curtain walls and individual panes over $1.5 \mathrm{~m}^{2}$ in area, located up to a height of $4 \mathrm{~m}$ above an exterior walking surface, must be laminated, annealed or heat strengthened safety glass that will remain in the frame when cracked (Sec 5.4.4).

C NC N/A GLAZING and CLADDING (wind): Glazing and cladding must withstand aerodynamic forces induced by wind as specified in applicable building code provisions (See 5.9)

\section{Parapets, Cornices, and Appendages}

C NC N/A URM PARAPETS: There must be no laterally unsupported unreinforced masonry parapets or cornices above the highest anchorage level with height-to-thickness ratios greater than 2 . (Sec. 5.5.1) 
C NC N/A CANOPIES: Canopies located at building exits must be anchored at a spacing $3 \mathrm{~m}$ or less. (Sec. 5.5.2)

C NC N/A WIND LOAD EFFECTS: Parapets, overhangs, and appendages must withstand aerodynamic forces induced by winds with as specified in applicable building code provisions. (Sec. 5.5.3)

\section{Masonry Chimneys}

C NC N/A URM: Unreinforced masonry chimney must not extend above the roof surface more than twice the least dimension of the chimney. (Sec. 5.6.1)

C NC N/A MASONRY: Masonry chimneys must be anchored to the floor and roof. (Sec 5.6.2)

\section{Stairs}

C NC N/A URM WALLS: Walls around stair enclosures must not consist of unbraced hollow clay tile or unreinforced masonry. (Sec. 5.7.1)

\section{Elevators}

C NC N/A SUPPORT SYSTEM: All elements of the elevator system must be anchored. (Sec 5.8.1)

C NC N/A SHAFT WALLS: All elevator shaft walls must be anchored and reinforced to prevent toppling into the shaft during strong shaking. (Sec. 5.8.2)

C NC N/A BRACKETS: The brackets that tie the counterweight rail to the building structure must have a spacing of $3 \mathrm{~m}$ or less. (Sec. 5.8.3)

\section{Roofs}

C NC N/A ROOFS: All elements and connections of the roof and the roof wind-force resisting system must be capable of resisting the wind force inherent in applicable building code provisions. (Sec 5.9) 


\section{APPENDIX F}

\section{DATA SUMMARY SHEET}

Building Designation:

Location:

Date of Evaluation:

\section{BUILDING DATA.}

Year built: $\quad$ Year(s) remodeled:

Area, (sq. m.)

Length:

No. of stories above ground:

No. of stories below ground:

Original Design Code:

\section{CONSTRUCTION DATA}

Gravity Load Structural System:

Exterior Transverse Walls:

$\%$ Opening:

Exterior Longitudinal Walls:

$\%$ Opening:

Roof framing and Materials:

Intermediate floor framing:

Ground floor:

Basement:

Columns:

Foundation:

General condition of structure:

Evidence of settling.

\section{LATERAL FORCE RESISTING SYSTEM}

Transverse:

Longitudinal:

Ground acceleration (50 yr/10\%):

Design wind speed (Zone):

Site soil profile type: Site soil coefficient:

Description of terrain: Open Suburban Urban 
$\underline{\text { Required Checklists: }}$

Basic structural checklist

Yes No

Supplemental structural checklist

Geologic site hazards and foundation checklist

Nonstructural checklist

\section{Further Evaluation Requirements:}

\section{REMARKS:}




\section{APPENDIX G EXAMPLES}

Example 1: Concrete Frame Building (Hospital Regional, Santiago, DR)

Example 2: Concrete Shear Wall Building (Fire Station, Santiago, DR) 


\section{Example 1}

Concrete Frame Building

Hospital Regional Universitario

Santiago, Dominican Republic

\section{Building Description}

This regional hospital is a six-story reinforced concrete structure. According to the drawings, the building was designed using $\mathrm{ACl}$ 318-71, and constructed in 1978.

The building has three wings, which are connected to a central service core. There are construction joints between the central core and each wing. The structural framing of the wing is comprised of post-tensioned flat slab without drop panels and columns. Shear reinforcement is provided at each column location.

It should be noted that slabs without beams are not permitted in regions of moderate and high seismic risk or for structures assigned to high seismic performance. This building is located in a moderate-to-high seismic risk region, and is in the category of high seismic performance. This hospital is an essential facility for postearthquake recovery.

For evaluation purpose, this building is categorized as Ordinary Reinforced concrete Frames $(\mathrm{R}=3.0)$.

\section{Lateral force Resisting System}

In the longitudinal direction, the primary lateral-force resisting system consists of the concrete slab-column frames. In the transverse direction, there are four shear walls as indicated: two at the end of the building and two at the stairwell (see floor plan). 


\section{DATA SUMMARY SHEET}

Building Designation: Hospital Regional Universitario

Location: Sangiago, Dominican Republic

Date of Evaluation: 11/28/2001

\section{BUILDING DATA.}

Year built:1978 Year(s) remodeled:n/a Original Design Code: AC/ 318-71, BOCA year?

Area, (sq. m.) see plan Length: see plan Width: see plan

No. of stories below ground: $1 \quad$ No. of stories above ground: 6

\section{CONSTRUCTION DATA}

Gravity Load Structural System: Concrete moment frame

Exterior Transverse Walls: Precast concrete panels/louvers $\quad \%$ Opening: 50

Exterior Longitudinal Walls: Precase concrete panels/louvers $\quad \%$ Opening: 50

Roof framing and Materials: Post-tensioned concrete slab

Intermediate floor framing: Post-tensioned concrete slab

Ground floor: Post-tensioned concrete slab

Basement: Reinforced concrete slab

Columns: Reinforced concrete

Foundation: Concrete mat foundation

General condition of structure: Fair

Evidence of settling. None

\section{LATERAL FORCE RESISTING SYSTEM}

Transverse: Slab-column frames with shear walls

Longitudinal: Slab-column frames

Ground acceleration (50 yr/10\%): $0.4 \mathrm{~g}$

Design wind speed (Zone): Zone 2

Site soil profile type: $\underline{3}$

Site soil coefficient:: $\underline{1.5}$

Description of terrain: Open

Suburban Urban $\underline{X}$ 
$\underline{\text { Required Checklists: }}$

Basic structural checklist

$\underline{\text { Yes }} \quad \underline{\text { No }}$

Supplemental structural checklist

$\mathrm{X}$

Geologic site hazards and foundation checklist

$x$

Nonstructural checklist

$x$

$x$

\section{Further Evaluation Requirements:}

Post-tension anchors need to be checked for corrosion.

REMARKS:

Compressive strength of concrete $=280 \mathrm{kgf} / \mathrm{cm}^{2}$

Reinforcement: ASTM A-615, Grade 60 


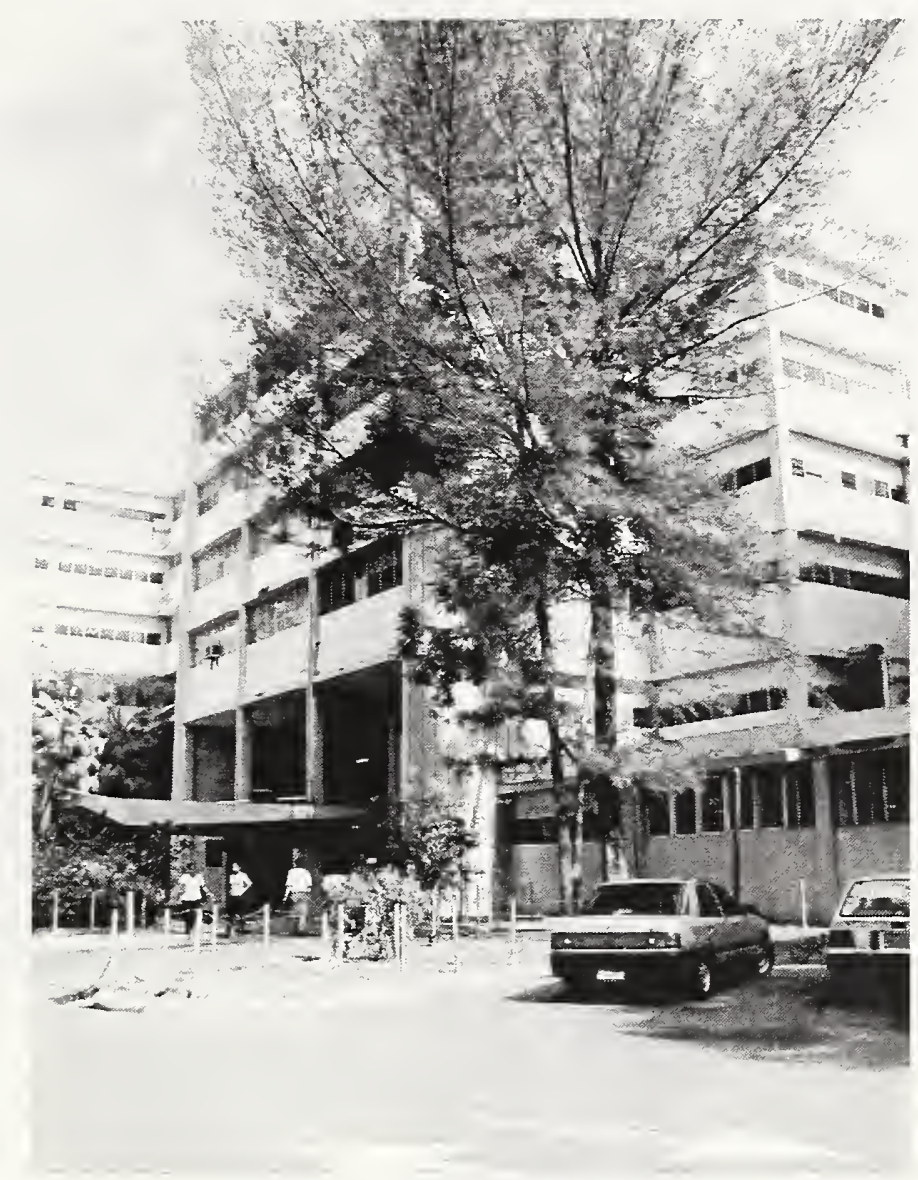

View from the rear of Hospital

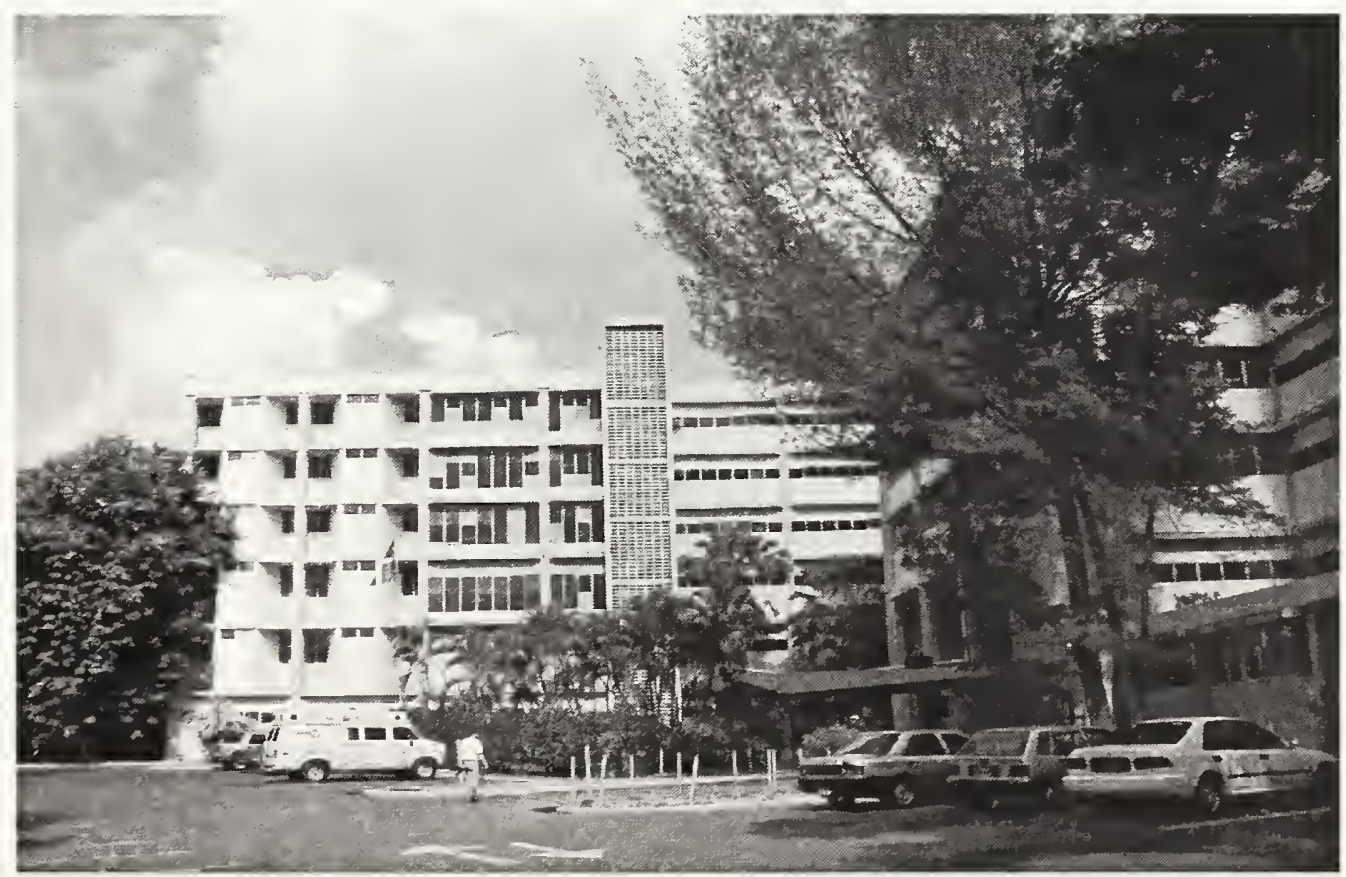

South Wing of Hospital 


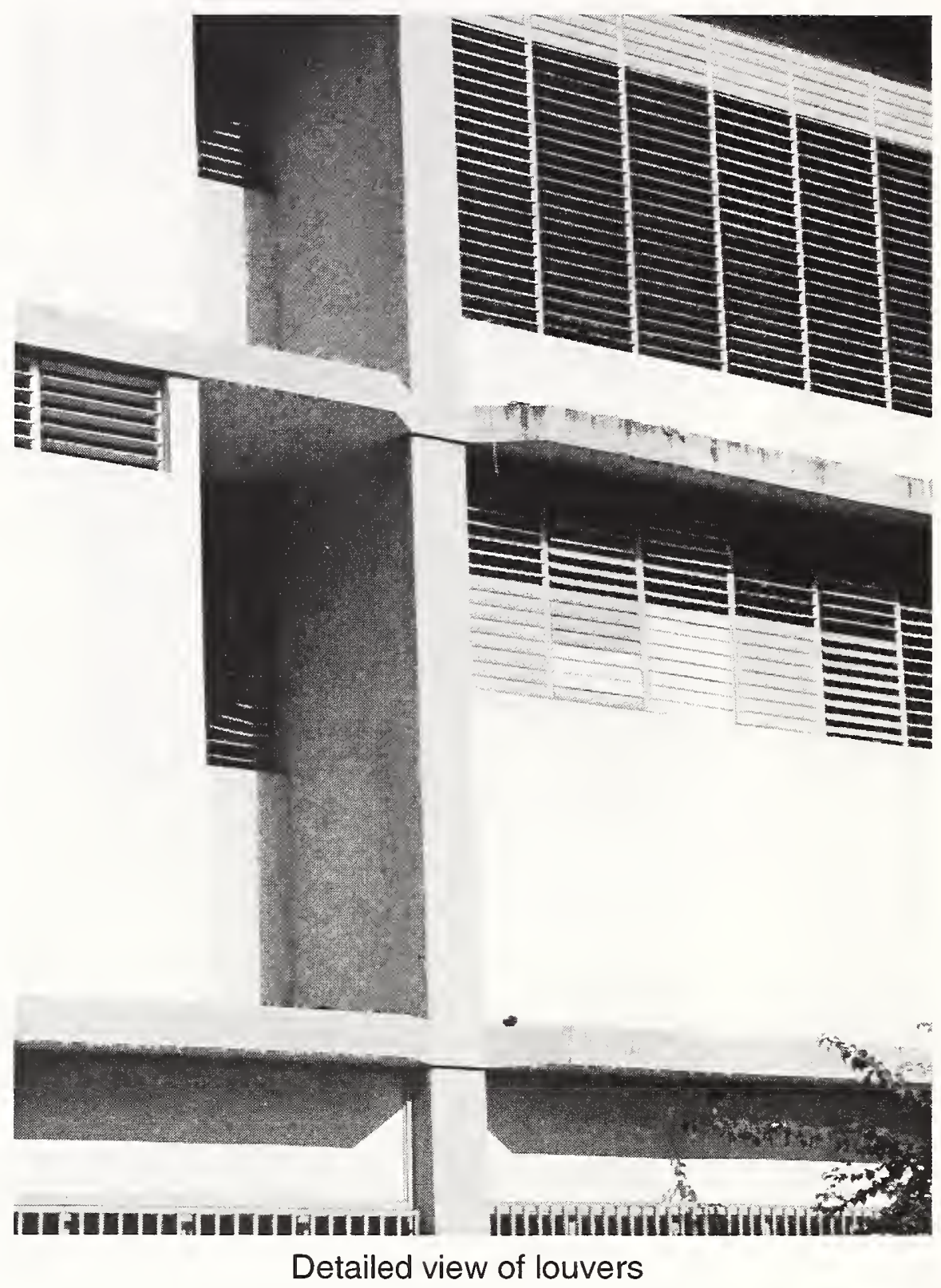



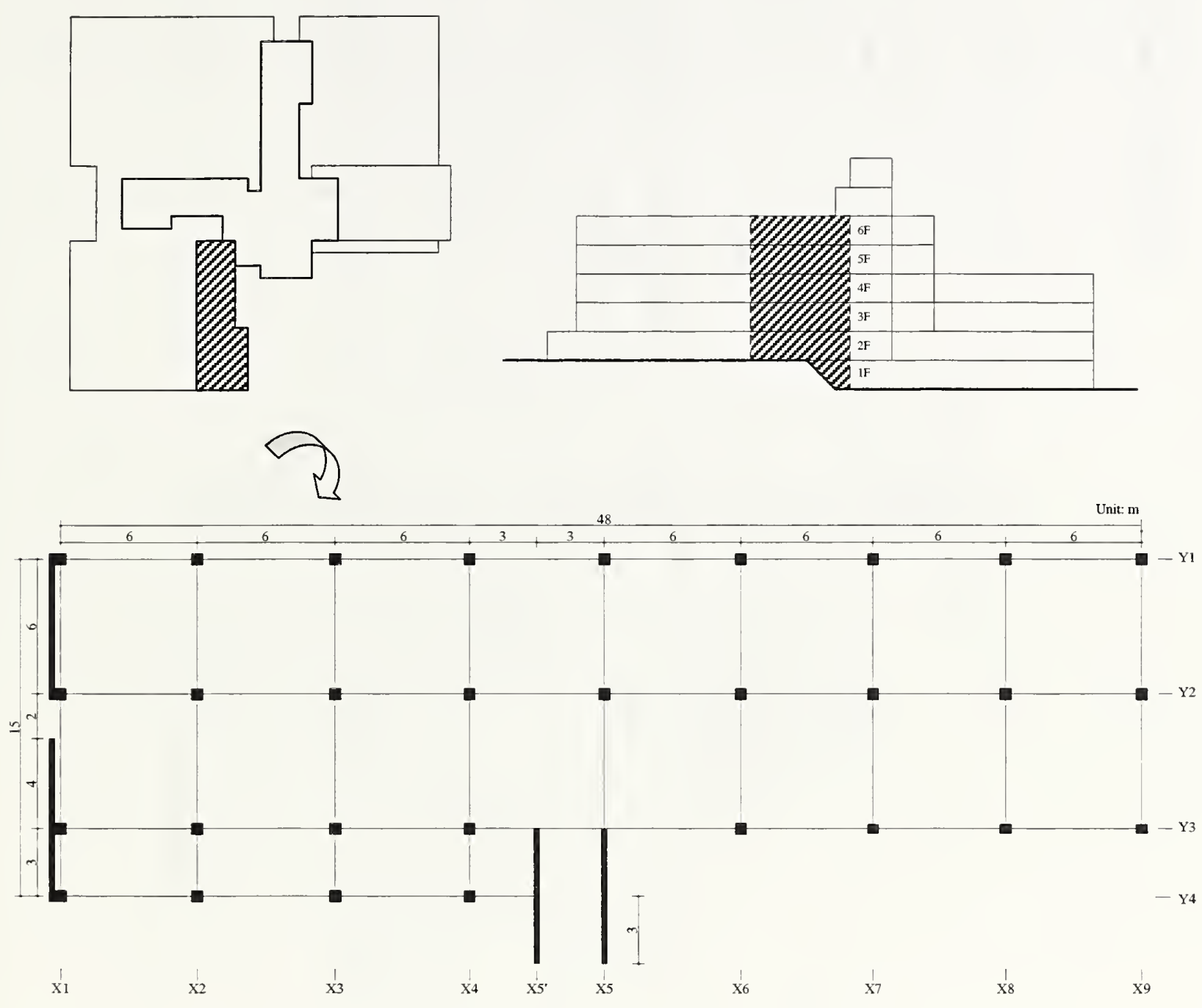

Figure G1 - Floor Plan of One Wing 


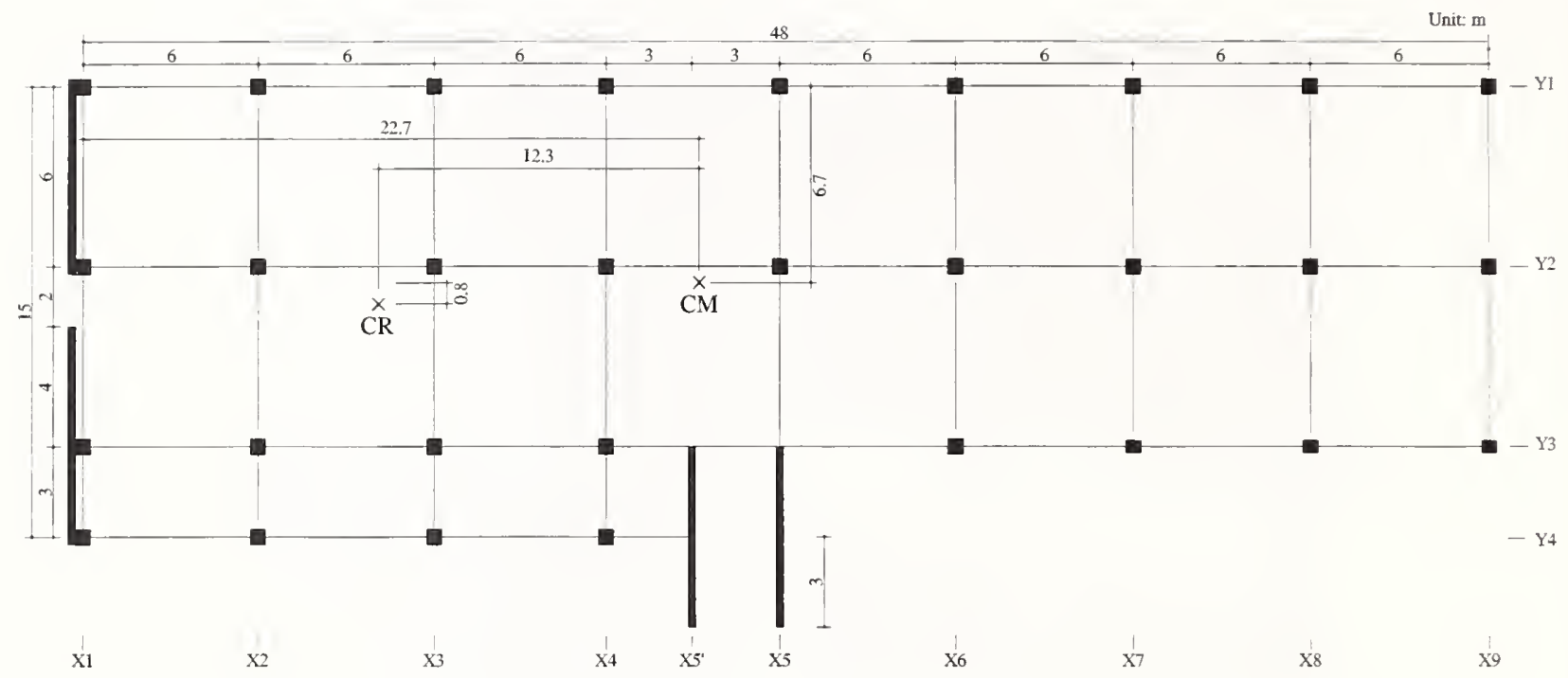

Figure G2 - Locations of Center of mass and Center of Rigidity 


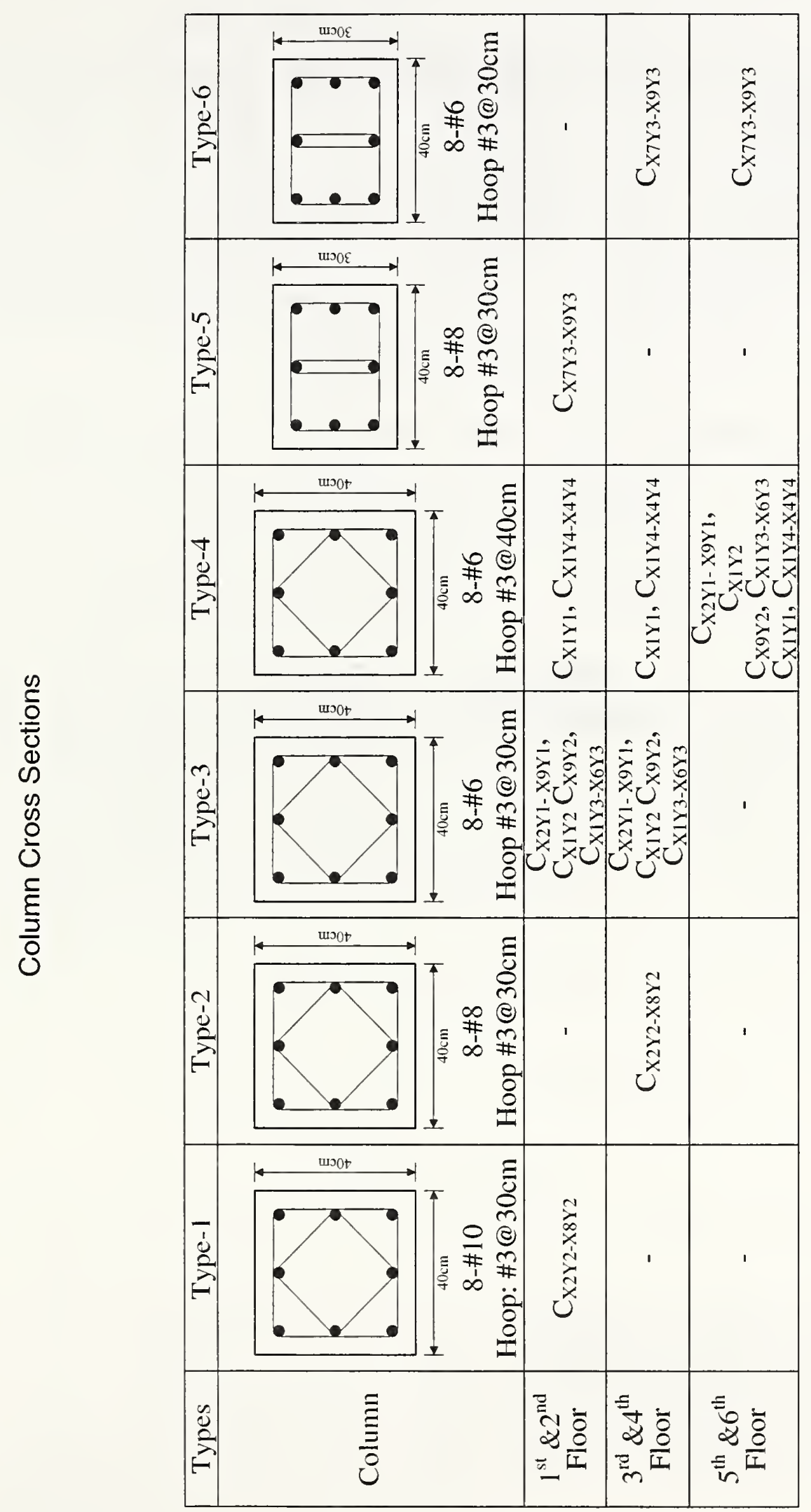


Wall Cross Section

\begin{tabular}{|c|c|}
\hline Types & Type-1 \\
\hline & \\
Wall & \\
&
\end{tabular}

\begin{tabular}{|c|c|}
\hline Vertical Bar & D10@ $25 \mathrm{~cm}$ \\
\hline Horizontal Bar & D10@25cm \\
\hline
\end{tabular}




\begin{tabular}{c|c|c|c}
\hline Floor & Floor Area $\left(\mathrm{m}^{2}\right)$ & Mass $(\mathrm{kg})$ & $\mathrm{W}_{\mathrm{j}}(\mathrm{kg})$ \\
\hline 6 & 657 & 657,000 & 657,000 \\
\hline 5 & 657 & 657,000 & 1314,000 \\
\hline 4 & 657 & 657,000 & 1971,000 \\
\hline 3 & 657 & 657,000 & 2628,000 \\
\hline 2 & 657 & 657,000 & 3285,000 \\
\hline 1(basement) & - & - & - \\
\hline
\end{tabular}

\section{Story Shear Force}

$$
\begin{gathered}
V=\frac{Z U S C}{R_{d}} \times W=[1 * 1.3 * 1.5 * 0.635 / 3] * 3285,000 \mathrm{~kg}=\underline{0.41} * 3285,000 \mathrm{~kg}=1346,850 \mathrm{~kg} \\
(\mathrm{Z}=1.0, \mathrm{~S}=1.5, \mathrm{U}=1.3, \mathrm{C}=0.635, \underline{\mathrm{Rd}=3.0}) \\
\bar{V}_{j}=0.75 \times V_{j}=0.9 \times \frac{n+j}{n+1}\left(\frac{W_{j}}{W}\right) V \quad \text { Equation }(2-4)
\end{gathered}
$$

\begin{tabular}{c|c|c|c|c|c}
\hline story & $\mathrm{W}(\mathrm{kg})$ & $\mathrm{W}_{\mathrm{j}}(\mathrm{kg})$ & $(\mathrm{n}+\mathrm{j}) /(\mathrm{n}+1)$ & $\mathrm{W}_{\mathrm{j}} / \mathrm{W}$ & $\bar{V}_{j}(\mathrm{~kg})$ \\
\hline 6 & 657,000 & 657,000 & 1.67 & 0.2 & 404,860 \\
\hline 5 & 657,000 & 1314,000 & 1.5 & 0.4 & 727,300 \\
\hline 4 & 657,000 & 1971,000 & 1.34 & 0.6 & 974,580 \\
\hline 3 & 657,000 & 2628,000 & 1.17 & 0.8 & 1134,590 \\
\hline 2 & 657,000 & 3285,000 & 1 & 1 & 1212,170 \\
\hline 1(basement) & - & - & - & - & - \\
\hline
\end{tabular}

\section{Shear stress in Columns}

$$
v_{\mathrm{arg}}=\frac{1}{m}\left(\frac{n_{c}}{n_{c}-n_{f}}\right)\left(\frac{\bar{V}_{j}}{A_{c}}\right) \quad \text { Equation }(2-5)
$$

Longitudinal direction

\begin{tabular}{c|c|c|c|c|c|c}
\hline \multirow{2}{*}{ Story } & \multirow{2}{*}{$\bar{V}_{j}(\mathrm{~kg})$} & $\mathrm{n}_{\mathrm{c}} /\left(\mathrm{n}_{\mathrm{c}}-\mathrm{n}_{\mathrm{f}}\right)$ & \multirow{2}{*}{$\mathrm{A}_{\mathrm{C}}\left(\mathrm{cm}^{2}\right)$} & $\begin{array}{c}v_{\text {arg }} \\
\left(\mathrm{kg} / \mathrm{cm}^{2}\right)\end{array}$ & $\begin{array}{c}v_{\text {arg }} \\
(\mathrm{MPa})\end{array}$ & $<0.7 \mathrm{MPa}$ \\
\hline 6 & 404,860 & 1.154 & 46800 & 9.98 & 0.98 & NG \\
\hline 5 & 727,300 & 1.154 & 46800 & 17.93 & 1.76 & NG \\
\hline 4 & 974,580 & 1.154 & 46800 & 24.03 & 2.07 & NG \\
\hline 3 & 1134,590 & 1.154 & 46800 & 27.98 & 2.75 & NG \\
\hline 2 & 1212,170 & 1.154 & 46800 & 29.89 & 2.93 & NG \\
\hline 1(basement) & - & - & - & - & - & \\
\hline
\end{tabular}


Transverse direction

\begin{tabular}{|c|c|c|c|c|c|c|}
\hline \multirow[b]{2}{*}{ Story } & \multirow[b]{2}{*}{$\bar{V}_{j}(\mathrm{~kg})$} & \multirow[b]{2}{*}{$\mathrm{n}_{\mathrm{c}} /\left(\mathrm{n}_{\mathrm{c}}-\mathrm{n}_{\mathrm{f}}\right)$} & \multirow[b]{2}{*}{$\begin{array}{c}\mathrm{A}_{\mathrm{C}}\left(\mathrm{cm}^{2}\right) \\
{\left[+\mathrm{A}_{\mathrm{W}}\right]}\end{array}$} & \multicolumn{3}{|c|}{$\mathrm{m}=1$} \\
\hline & & & & $\begin{array}{c}v_{\arg } \\
\left(\mathrm{kg} / \mathrm{cm}^{2}\right)\end{array}$ & $\begin{array}{c}v_{\text {arg }} \\
(\mathrm{MPa})\end{array}$ & $<0.7 \mathrm{MPa}$ \\
\hline 6 & 404,860 & 1.43 & 96800 & 5.98 & 5.90 & $\mathrm{OK}$ \\
\hline 5 & 727,300 & 1.43 & 96800 & 10.74 & 1.05 & $\mathrm{NG}$ \\
\hline 4 & 974,580 & 1.43 & 96800 & 14.40 & 1.41 & $\mathrm{NG}$ \\
\hline 3 & 1134,590 & 1.43 & 96800 & 16.76 & 1.65 & $\mathrm{NG}$ \\
\hline 2 & 1212,170 & 1.43 & 96800 & 17.91 & 1.76 & $\mathrm{NG}$ \\
\hline 1(basement) & - & - & - & - & - & \\
\hline
\end{tabular}




\section{EVALUATION STATEMENTS FOR CONCRETE MOMENT FRAME BUILDINGS}

\section{BASIC STRUCTURAL CHECK LIST}

This Basic Structural Checklist must be completed for both Life Safety and Immediate Occupancy evaluations.

\section{Building System}

C NC N/A LOAD PATH: The structure contains a complete load path for seismic force effects from any horizontal direction that serves to transfer the inertial forces from the mass to the foundation. (NOTE: Write a brief description of this linkage for each principal direction.) (Sec. 3.1)

The structure contains a complete load path.

C NC N/A ADJACENT BUILDINGS: An adjacent building must not be located next to the structure being evaluated closer than $4 \%$ of the height for Life Safety and Immediate Occupancy. (Sec. 3.2)

There are no adjacent buildings.

C NC N/A WEAK STORY: The strength of the lateral-load-resisting system in any story must not be less than $80 \%$ of the strength in an adjacent story above or below. (Sec. 3.3.1)

There are no significant discontinuities in any of the vertical elements.

$\underline{C}$ NC N/A SOFT STORY: The stiffness of the lateral-load-resisting system in any story is not less than $70 \%$ of the stiffness in an adjacent story above or below, or less than $80 \%$ of the average stiffness of the three stories above or below. (Sec. 3.3.2)

There are no significant discontinuities in any of the vertical elements.

C NC N/A GEOMETRY: There must be no changes in horizontal dimension of the lateral-force-resisting system of more than $30 \%$ in a story 
relative to adjacent stories, excluding one-story penthouses. (Sec. 3.3.3)

The building (each wing) is rectangular.

C NC N/A MASS: There is no change of effective mass of more than 50 $\%$ from one story to the next, excluding light roofs. (Sec. 3.3.4)

The building is uniform along the height.

C NC N/A VERTICAL DISCONTINUITIES: All vertical elements in the lateral-force-resisting system must be continuous to the foundation. (Sec. 3.3.5)

All frames and shear walls are continuous to the foundation.

C NC N/A EARTHQUAKE INDUCED TORSION: The distance between the story center of rigidity and the story center of mass must be less than $20 \%$ of the width of the structure in either major plan dimension. (Sec. 3.3.6)

$0.2 \times 48 m<12.3 m \quad$ (See Fig. G2)

C NC N/A WIND INDUCED TORSION: The lateral-force-resisting elements form a well balanced system that is capable of resisting wind forces acting from any direction and is not subjected to significant torsion. For a non-flexible structure with a reasonably regular shape in plan, the distance, measured along either principal axis of the building plan, between the point of application of the mean load induced by wind normal to that axis and the center of rigidity must be less than $15 \%$ of the width of the structure in either major plan dimension. (For this evaluation a set of structural drawings is necessary.) (Sec. 3.3.7)

$$
18-12.3=5.7 m<0.15 \times 48 m
$$

C NC N/A SHORT CAPTIVE COLUMNS: There must be no columns at a level with height/depth ratios less than $50 \%$ of the nominal height/depth ratio of the typical columns at that level. (Sec. 3.4)

There are no short captive columns.

C NC N/A COLUMN-BAR SPLICES: All column bar lap splice lengths shall be greater than $35 d_{b}$ and shall be enclosed by ties spaced at or less than $8 d_{b}$. (Sec. 3.5) 
Column bar splice lengths are less than 35 bar diameters.

C NC N/A FLAT SLABS: Flat slabs/plates classified as secondary components must have continuous bottom bars through the column joints. (Sec. 3.6)

Flat slab is not allowed as primary lateral-force-resisting members.

C NC N/A DETERIORATION OF CONCRETE: There must be no visible deterioration of concrete or reinforcing steel in any of the lateralforce-resisting or the vertical elements. (Sec. 3.7)

There is no visible sign of deterioration.

C NC N/A POST-TENSIONING ANCHORS: There must be no evidence of corrosion or spalling in the vicinity of post-tensioning or end fittings. Coil anchors have not been used. (Sec. 3.8)

There is no visible sign of deterioration of post-tensioning anchors.

\section{Lateral Force Resisting System}

C NC N/A REDUNDANCY: The number of lines of moment frames in each principal direction must be greater than or equal to 2 . The number of bays of moment frames in each line must be greater than or equal to 2 for Life Safety and 3 for Immediate Occupancy. (Sec. 3.9)

There are more than one line of shear walls.

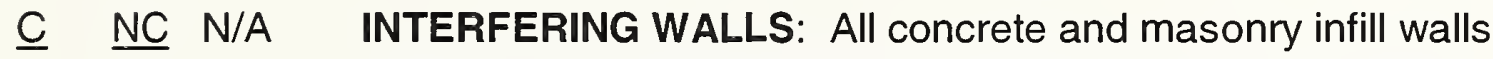
placed in the moment frames are isolated from the structural elements. (Sec. 3.10)

There are no interfering walls.

C NC N/A SHEARING STRESS CHECK: The shear stress in the concrete columns must be less than $0.7 \mathrm{MPa}\left(7 \mathrm{kgf} / \mathrm{cm}^{2}\right)$ or $\sqrt{f^{\prime}{ }_{c}} / 6 \mathrm{MPa}$. (Sec. 3.11)

Column shear stresses are greater than 0.7 MPa (See computations.) 
C NC N/A AXIAL STRESS CHECK: The axial stress due to gravity loads in columns subjected to overturning forces shall be less than $0.10 f_{c}^{\prime}$. (Sec. 3.12)

Column axial stress $=5.5 . \mathrm{MPa}\left(56 \mathrm{kgf} / \mathrm{cm}^{2}\right)$ Allowed $=0.1 \times 280=28 \mathrm{kgf} / \mathrm{cm}^{2}$

\section{Connections}

C NC N/A CONCRETE COLUMNS: All longitudinal column steel must be doweled into the foundation and the dowels must be able to develop the tensile capacity of the column. (Sec. 3.13)

The development lengths of column bars are not known. Therefore, this statement cannot be checked. 


\section{Additional Structural Check list for Concrete Moment Frame Buildings for Immediate Occupancy}

This Additional Structural Checklist must be completed when the structure is evaluated for immediate occupancy. The Basic Structural Checklist must be completed prior to completing this checklist.

\section{Lateral Force Resisting System}

C NC N/A FLAT SLAB FRAMES: The lateral-force-resisting system must not be a frame consisting of columns and a flat slab/plate without beams. (Sec.3.6)

The structure is comprised of columns and flat plates.

C NC N/A PRESTRESSED FRAME ELEMENTS: The lateral-force-resisting frames shall not include any prestressed or post-tensioned elements. (Sec.3.14)

The floor slabs are post-tensioned.

C NC N/A SHORT CAPTIVE COLUMNS: There must be no columns at a level with height/depth ratios less than $75 \%$ of the nominal height/depth ratio of the typical columns at that level. (Sec. 3.4)

There are no short captive columns.

C NC N/A NO SHEAR FAILURES: The shear capacity of the frame columns must be able to develop the moment capacity at the top and the bottom of the columns. (Sec. 3.15)

The column shear capacity is not adequate to develop the moment capacity of the column.

C NC N/A STRONG COLUMN/WEAK BEAM: The sum of the moment capacity of the columns must be $20 \%$ greater than that of the beams at frame joints. (Sec. 3.16)

The structure is comprised of slab-column frames.

C NC N/A BEAM BARS: At least two longitudinal top and two longitudinal bottom bars must extend continuously throughout the length of each frame beam. At least $25 \%$ of the longitudinal bars provided 
at the joints for either positive or negative moment must be continuous throughout the length of the members. (Sec. 3.17) Main frames do not have beams.

C NC N/A COLUMN-BAR SPLICES: All column bar lap splice lengths must be greater than $50 \mathrm{~d}_{\mathrm{b}}$ for Immediate Occupancy and must be enclosed by ties spaced at or less than $8 d_{b}$. (Sec. 3.5)

Column bar splice lengths are less than 50 bar diameter.

C NC N/A BEAM-BAR SPLICES: The lap splices for longitudinal beam reinforcing must not be located within the center half of the member length and shall not be located within the vicinity of potential plastic hinge locations. (Sec. 3.18)

Main frames do not have beams.

C NC N/A COLUMN-TIE SPACING: Frame columns must have ties spaced at or less than $d / 4$ throughout their length and at or less than $8 d_{b}$ at all potential plastic hinge locations. (Sec. 3.19)

Tie spacings are greater than $d / 4$.

C NC N/A STIRRUP SPACING: All beams must have stirrups spaced at or less than $\mathrm{d} / 2$ throughout their length. At potential plastic hinge locations stirrups must be spaced at or less than the minimum of $8 d_{b}$ or $d / 4$. (Sec. 3.20)

No beams are used in the lateral-force-resisting system.

C NC N/A JOINT REINFORCING: Beam-column joints must have ties spaced at or less than $8 d_{b}$. (Sec. 3.21)

No beams are used in the lateral-force-resisting system.

C NC N/A JOINT ECCENTRICITY: There must be no eccentricities larger than $20 \%$ of the smallest column plan dimension between girder and column centerlines. (Sec. 3.22)

No girders are used in the structural system.

C NC N/A STIRRUP AND TIE HOOKS: The beam stirrups and column ties must be anchored into the member cores with hooks of $135^{\circ}$ or more. (Sec. 3.23)

Drawings show that $90^{\circ}$ hooks are used. 
C NC N/A FLAT SLABS: Flat slabs/plates must not be permitted as primary components. (Sec. 3.6)

Post-tensioned flat plate is part of the lateral-load-resisting system.

\section{Diaphragms}

C NC N/A DIAPHRAGM CONTINUITY: The diaphragms must not be composed of split-level floors. (Sec. 3.24)

There are no split-level floors.

C NC N/A PLAN IRREGULARITIES: There must be tensile capacity to develop the strength of the diaphragm at re-entrant corners or other locations of plan irregularities. (Sec. 3.25)

The floor plan is rectangular.

C NC N/A DIAPHRAGM REINFORCEMENT AT OPENINGS: There must be reinforcing around all diaphragm openings larger than $50 \%$ of the building width in either major plan dimension. (Sec. 3.26)

No openings in the floor slab.

\section{Connections}

C NC N/A LATERAL LOAD AT PILE CAPS: Pile caps must have top reinforcement and piles must be anchored to the pile caps. (Sec. 3.27)

The building is on mat foundation. 


\section{Geologic Site Hazards}

The following statements shall be completed for buildings in regions of high or moderate seismicity.

C NC N/A LIQUEFACTION: Liquefaction-susceptible, saturated, loose granular soils that could jeopardize the building's seismic performance must not exist in the foundation soils at depths within $15 \mathrm{~m}$ under the building. (Sec. 4.1.1)

No known liquefaction problems at the site.

C NC N/A SLOPE FAILURE: The building site must be sufficiently remote from potential earthquake-induced slope failures or rockfalls to be unaffected by such failures, or must be capable of accommodating any predicted movements without failure. (Sec. 4.1.2)

The building is on the level surface.

C NC N/A SURFACE FAULT RUPTURE: Surface fault rupture and surface displacement at the building site is not anticipated. (Sec. 4.1.3)

No known faults are near the building.

\section{Condition of Foundations}

C NC N/A FOUNDATION PERFORMANCE: There must be no evidence of excessive foundation movement such as settlement or heave that would affect the integrity or strength of the structure. (Sec. 4.2.1)

No evidence of foundation movement.

\section{Capacity of Foundations}

C NC N/A POLE FOUNDATIONS: Pole foundations must have a minimum embedment depth of $1.5 \mathrm{~m}$. (Sec. 4.3.1)

There are no pole foundations. 
C NC N/A OVERTURNING: The ratio of the effective horizontal dimension, at the foundation level of the lateral-force-resisting system to the building height (base/height) must be greater than 0.4 .

(Sec. 4.3.2)

$12 m / 16.46 m=0.73>0.4$ O.K.

C NC N/A TIES BETWEEN FOUNDATION ELEMENTS: The foundation must have ties adequate to resist seismic forces where footings, piles, and piers are not restrained by beams, slabs, or soils classified as Type 1 or 2. (Sec. 4.33 )

The building is on mat foundation.

C NC N/A SLOPING SITES: The grade difference from one side of the building to another must not exceed one-half the story height at the location of embedment. (Sec. 4.34 )

The building is not located on a sloping site. 


\section{EVALUATION STATEMENTS FOR NONSTRUCTURAL COMPONENTS}

\section{Partitions}

C NC N/A UNREINFORCED MASONRY: Unreinforced masonry or hollow clay tile partitions must be braced at a spacing of equal to or less than $2.5 \mathrm{~m}$. (Sec 5.1.1)

Unreinforced masonry partitions are not braced.

\section{Ceiling Systems}

C NC N/A INTEGRATED CEILINGS: Integrated suspended ceilings at exits and corridors or weighing more than $10 \mathrm{kgf} / \mathrm{m}^{2}$ must be laterally restrained with a minimum of 4 diagonal wires or rigid members attached to the structure above at a spacing of equal to or less than $4 \mathrm{~m}$. (Sec. 5.2.1)

Suspended ceiling is braced with wires and steel angles.

C NC N/A SUPPORT: The integrated suspended ceiling system must not be used to laterally support the tops of gypsum board, masonry, or hollow clay tile partitions. (Sec. 522 )

The partitions are not supported by the suspended ceiling.

C NC N/A SUSPENDED LATH AND PLASTER: Ceilings consisting of suspended lath and plaster or gypsum board must be attached for each 1 square meter of area. (Sec. 5.2.3)

Lath and plaster ceiling are not used.

\section{Light Fixtures}

C NC N/A INDEPENDENT SUPPORT: Light fixtures in suspended grid ceilings must be supported independently of the ceiling suspension system by a minimum of two wires at diagonally opposite corners of the fixtures. (Sec. 5.3.I)

Light fixtures are independently supported from the ceiling. 
C NC N/A EMERGENCY LIGHTING: Emergency lighting must he anchored or braced to prevent falling or swaying during an earthquake or windstorm. (Sec. 5.3.2)

This condition was not ascertained during the filed survey. Further field evaluation is needed.

\section{Cladding and Glazing}

C NC N/A CLADDING ANCHORS: Cladding components weighing more than $50 \mathrm{~kg} / \mathrm{m}^{2}$ must be anchored to the exterior wall framing at a spacing equal to or less than $2 \mathrm{~m}$. (Sec. 5.4.1)

This condition is not ascertained during the field survey. Further field evaluation is needed.

C NC N/A BEARING CONNECTIONS: Where bearing connections are required, there must be a minimum of two bearing connections for each wall panel. (Sec.5.4.2)

This condition does not exist.

C NC N/A DETERIORATION: There must be no evidence of deterioration or corroding in any of the connection elements. (Sec. 5.4.3)

No corroded condition exist.

C NC N/A GLAZING (seismic): Glazing in curtain walls and individual panes over 1.5 square meter in area. located up to a height of 4 $\mathrm{m}$ above an exterior walking surface, must be laminated, annealed or heat strengthened safety glass that will remain in the frame when cracked. (Sec 5.4.4)

All glazing size is less than $1.5 \mathrm{~m}^{2}$.

C NC N/A GLAZING and CLADDING (wind): Glazing and cladding must withstand aerodynamic forces induced by wind as specified in applicable building code provisions. (See 5.9)

The window glazing will withstand a pressure of $128 \mathrm{~kg} / \mathrm{m}^{2}$ (Zone $2,162 \mathrm{~km} / \mathrm{hr}$ ).

Resistance of the anchorage of louvers to the frame members was not checked during the field survey. 


\section{Parapets, Cornices, and Appendages}

C NC N/A URM PARAPETS: There must be no laterally unsupported unreinforced masonry parapets or cornices above the highest anchorage level with height-to-thickness ratios greater than 2 . (Sec. 5.5.1)

The building does not have URM parapets.

C NC N/A CANOPIES: Canopies located at building exits must be anchored at a spacing $3 \mathrm{~m}$ or less. (Sec. 5.5.2)

The building does not have canopies.

C NC N/A WIND LOAD EFFECTS: Parapets, overhangs, and appendages must withstand aerodynamic forces induced by winds with as specified in applicable building code provisions. (Sec. 5.5.3)

The building has reinforced concrete parapets of $0.8 \mathrm{~m}$ high. Wind forces will produce less than $1 \mathrm{~kg} / \mathrm{cm}^{2}$ tensile stress in a plain concrete section. Therefore, the parapet is judged to be adequate to resist wind induced forces.

\section{Masonry Chimneys}

C NC N/A URM: Unreinforced masonry chimney must not extend above the roof surface more than twice the least dimension of the chimney. (Sec. 5.6.1)

The building does not have URM chimneys.

C NC N/A MASONRY: Masonry chimneys must be anchored to the floor and roof. (Sec 5.6.2)

The building does not have masonry chimneys.

\section{$\underline{\text { Stairs }}$}

C NC N/A URM WALLS: Walls around stair enclosures must not consist of unbraced hollow clay tile or unreinforced masonry. (Sec. 5.7.1)

This building has reinforced concrete stair enclosures. 


\section{Elevators}

C NC N/A SUPPORT SYSTEM: All elements of the elevator system must be anchored. (Sec 5.8.1)

All elements are anchored to the concrete enclosure walls.

C NC N/A SHAFT WALLS: All elevator shaft walls must be anchored and reinforced to prevent toppling into the shaft during strong shaking. (Sec. 5.8.2)

The elevator shaft walls are of reinforced concrete.

C NC N/A BRACKETS: The brackets that tie the counterweight rail to the building structure must have a spacing of $3 \mathrm{~m}$ or less. (Sec. 5.8.3)

The brackets are located at each floor level, which is about $3 \mathrm{~m}$ apart.

\section{Roofs}

C NC N/A ROOFS: All elements and connections of the roof and the roof wind-force resisting system must be capable of resisting the wind force inherent in applicable building code provisions. (Sec 5.9)

The roof iss reinforced concrete slab. Therefore, it is judged to be adequate to resist wind pressure of $-1.3 \times 128=-166 \mathrm{~kg} / \mathrm{m}^{2}$. (Weight of concrete slab $\left.=360 \mathrm{~kg} / \mathrm{m}^{2}\right)$.

\section{Summary of Deficiencies}

1. Flat slab is part of lateral-force-resisting system.

2. The floor slabs are comprised of post-tensioning system.

3. The building is susceptible to earthquake induced torsion.

4. The columns and walls have inadequate shear capacities.

5. Longitudinal reinforcing bars in the columns have insufficient lap splice length.

6. Column ties are spaced too widely.

The building requires a detailed evaluation to correct deficiencies. 


\section{Example 2}

\section{Concrete Shear Wall Building}

Fire Station

Santiago, Dominican Republic

\section{Building Description}

This fire station is a three-story reinforced concrete structure. The building was constructed in 1965. No building drawings were available. The building dimentions were measured during the site visit.

The building is supported by four walls in the longitudinal direction. The bottom of the second floor slab show severe deterioration with many exposed and corroded reinforcing steel bars.

For evaluation purpose, this building is categorized as Ordinary Reinforced Concrete Shear Wall Building ( $R=4.5)$.

Lateral force Resisting System

In the longitudinal direction, the primary lateral-force resisting system consists of the concrete shear walls. In the transverse direction, there are no shear walls and no frames. 


\section{DATA SUMMARY SHEET}

Building Designation: Fire Station (Parque de Bomberos)

Location: Santiago, Dominican Republic

Date of Evaluation: 03/08/ 2000 (site visit)

\section{BUILDING DATA.}

Year built: 1965 Year(s) remodeled: N/A

Original Design Code: Not known

Area, (sq. m.) See attached plan

Length: $22.77 \mathrm{~m}$

Width: $12.7 \mathrm{~m}$

No. of stories below ground: none

No. of stories above ground: 3

\section{CONSTRUCTION DATA}

Gravity Load Structural System: Reinforced concrete walls

Exterior Transverse Walls: Concrete masonry tiles $\quad \%$ Opening: 100

Exterior Longitudinal Walls: Reinforced concrete walls \% Opening: Zero

Roof framing and Materials: Concrete folded plates

Intermediate floor framing: Reinforced concrete slabs

Ground floor: Reinforced concrete slab Basement:: N/A

Columns: None $\quad$ Foundation: Not known

General condition of structure: Fair to poor (see photographs)

Evidence of settling. None noted

\section{LATERAL FORCE RESISTING SYSTEM}

Transverse: Wall-slab system

Longitudinal: Shear wall

Ground acceleration (50 yr/10\%): $0.4 \mathrm{~g}$

Design wind speed (Zone): 2

Site soil profile type: 3

Description of terrain: Open __ Suburban___ Urban $\underline{X}$

\section{Required Checklists:}

Basic structural checklist

Supplemental structural checklist

Geologic site hazards and foundation checklist

Nonstructural checklist

$\begin{array}{cc}\frac{\text { Yes }}{\mathrm{x}} & \text { No } \\ \mathrm{x} & \\ & \mathrm{x} \\ & \mathrm{x}\end{array}$




\section{Further Evaluation Requirements:}

Concrete strength needs to be determined. Core samples should be taken for strength test. Foundation types must be determined.

\section{REMARKS:}

The bottom surface of concrete slab has delaminated due to corrosion of the reinforcement (see photographs) 


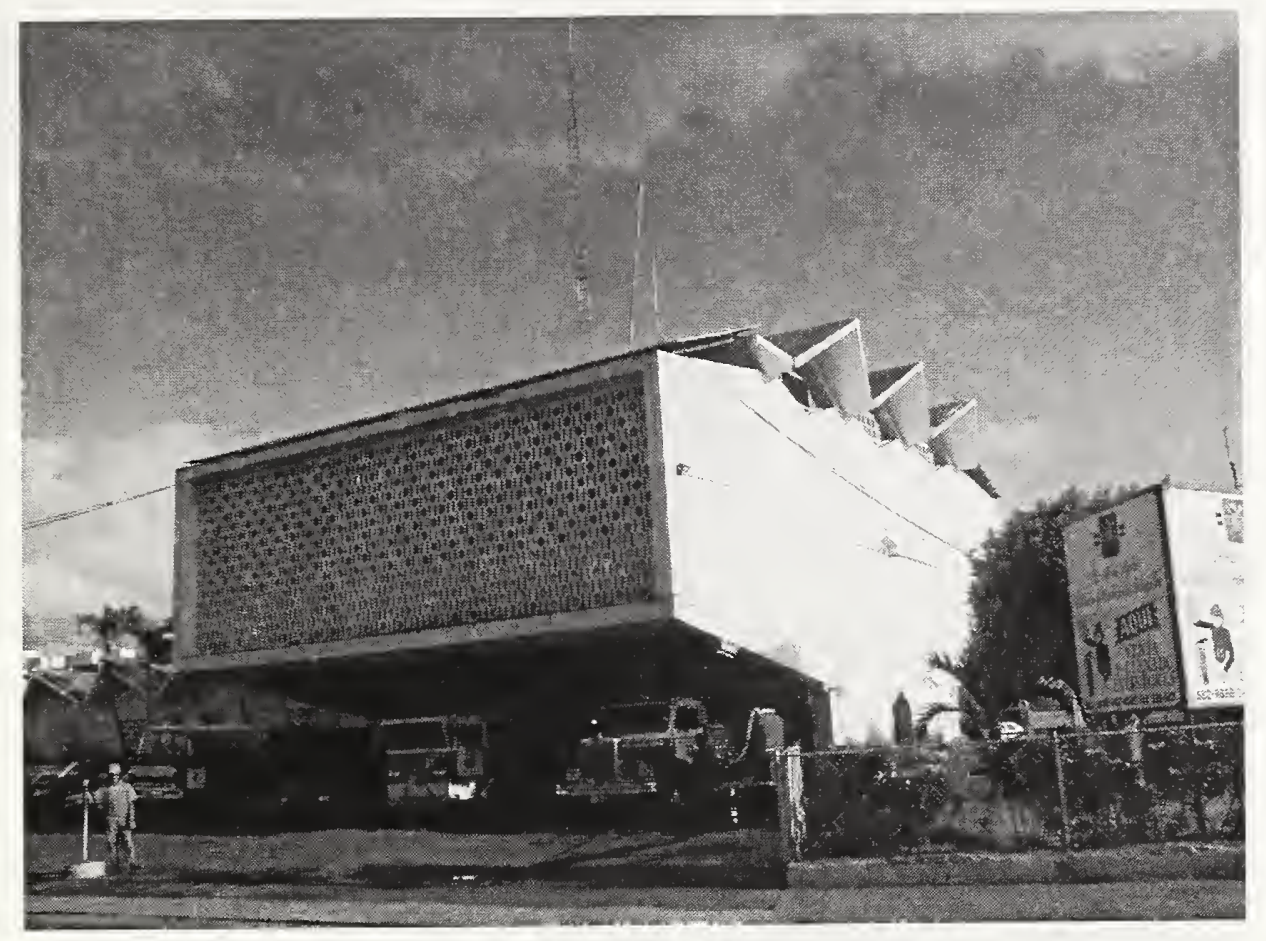

Exterior view of Fire Station

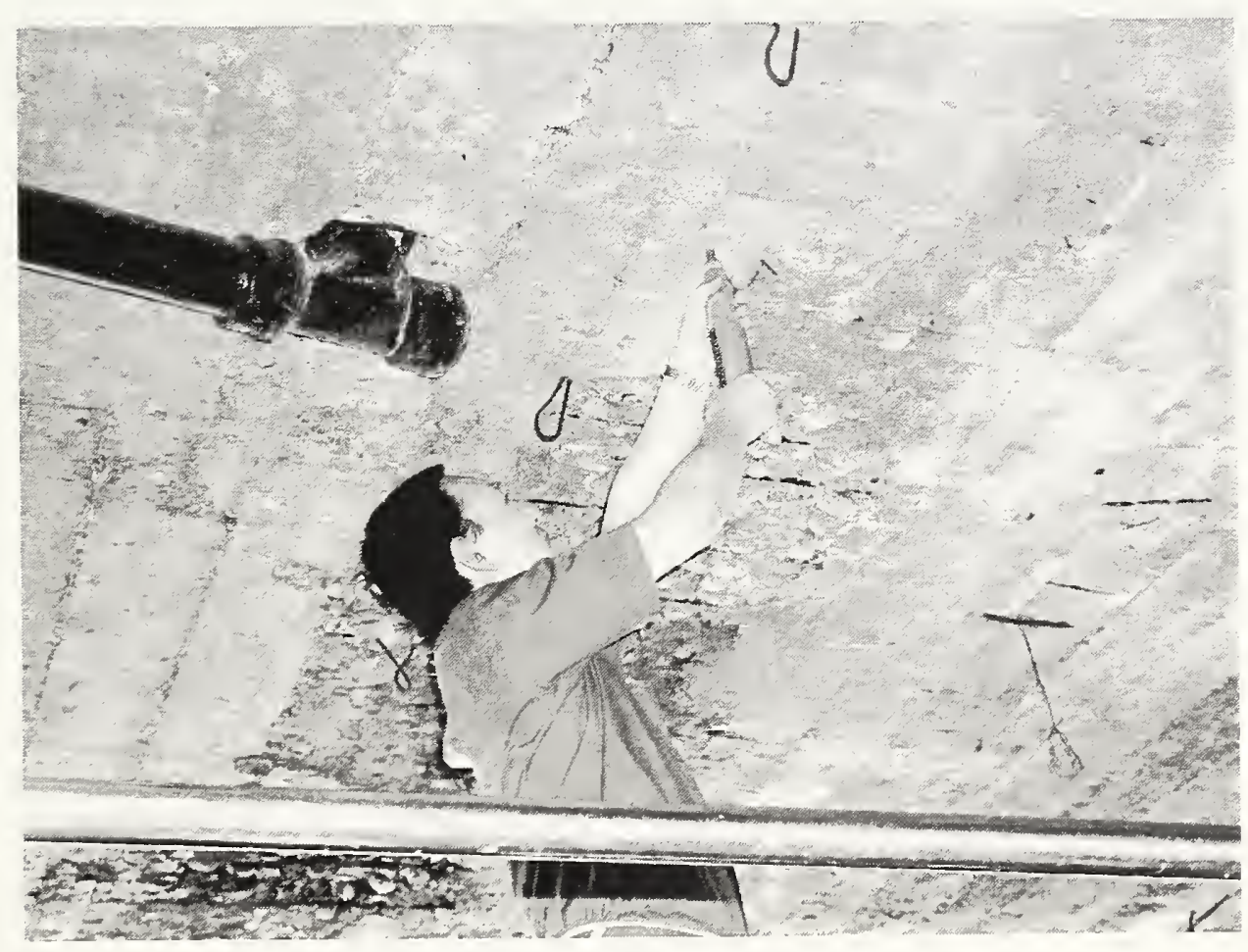

Bottom of Second Floor Slab. 


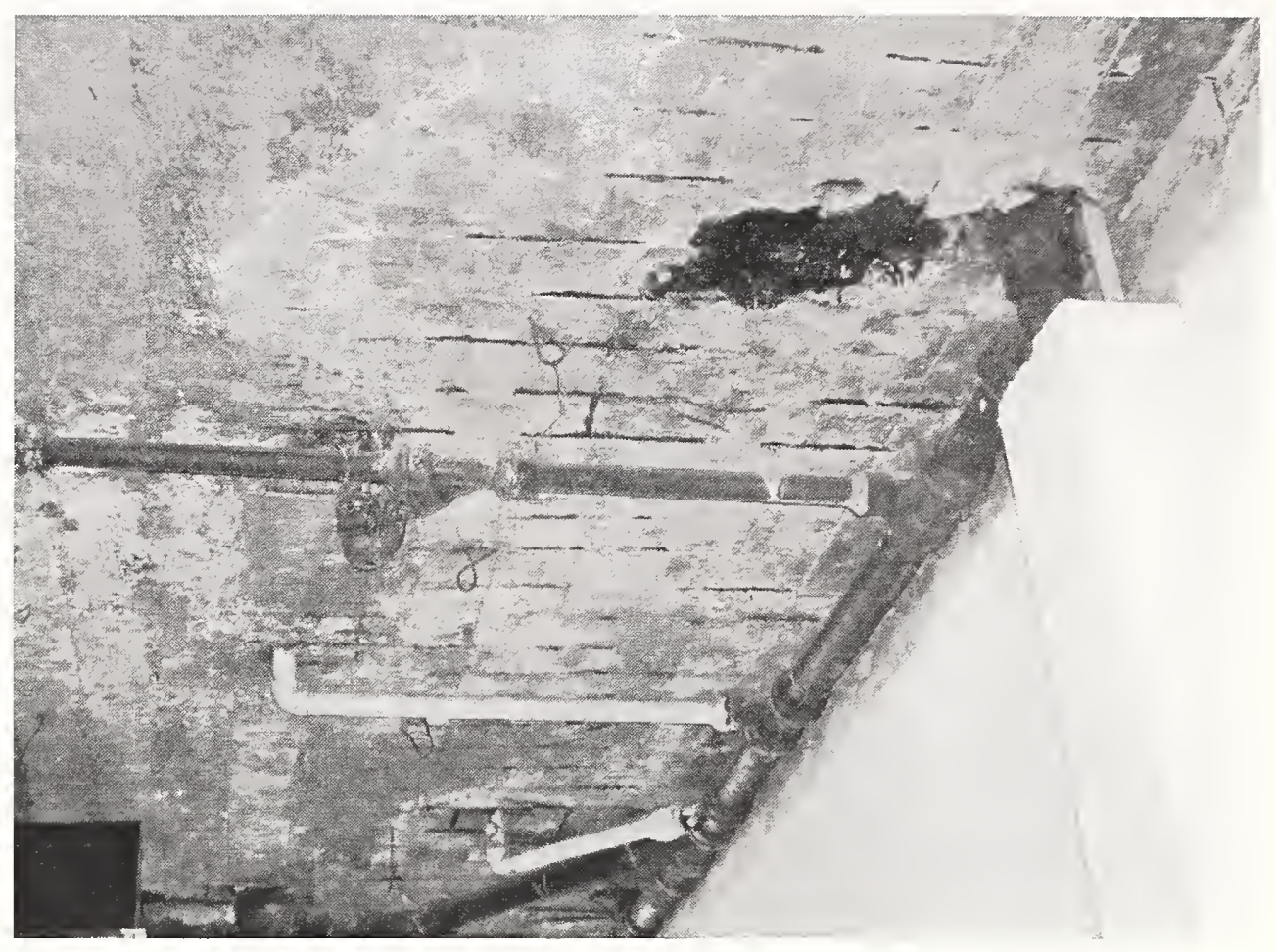

Extensively Spalled Second Floor Slab

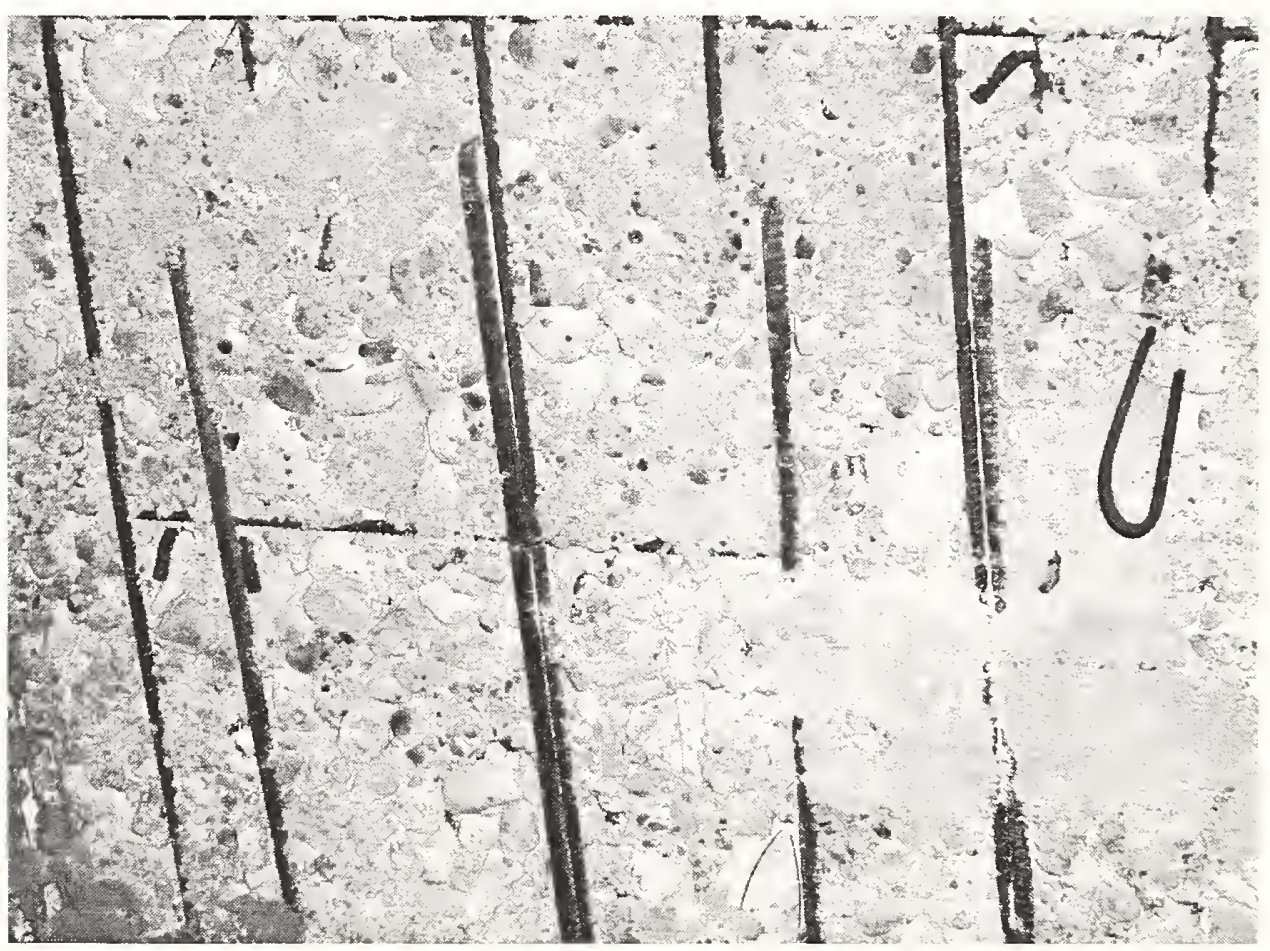

No Cover on Bottom Slab Reinforcement 


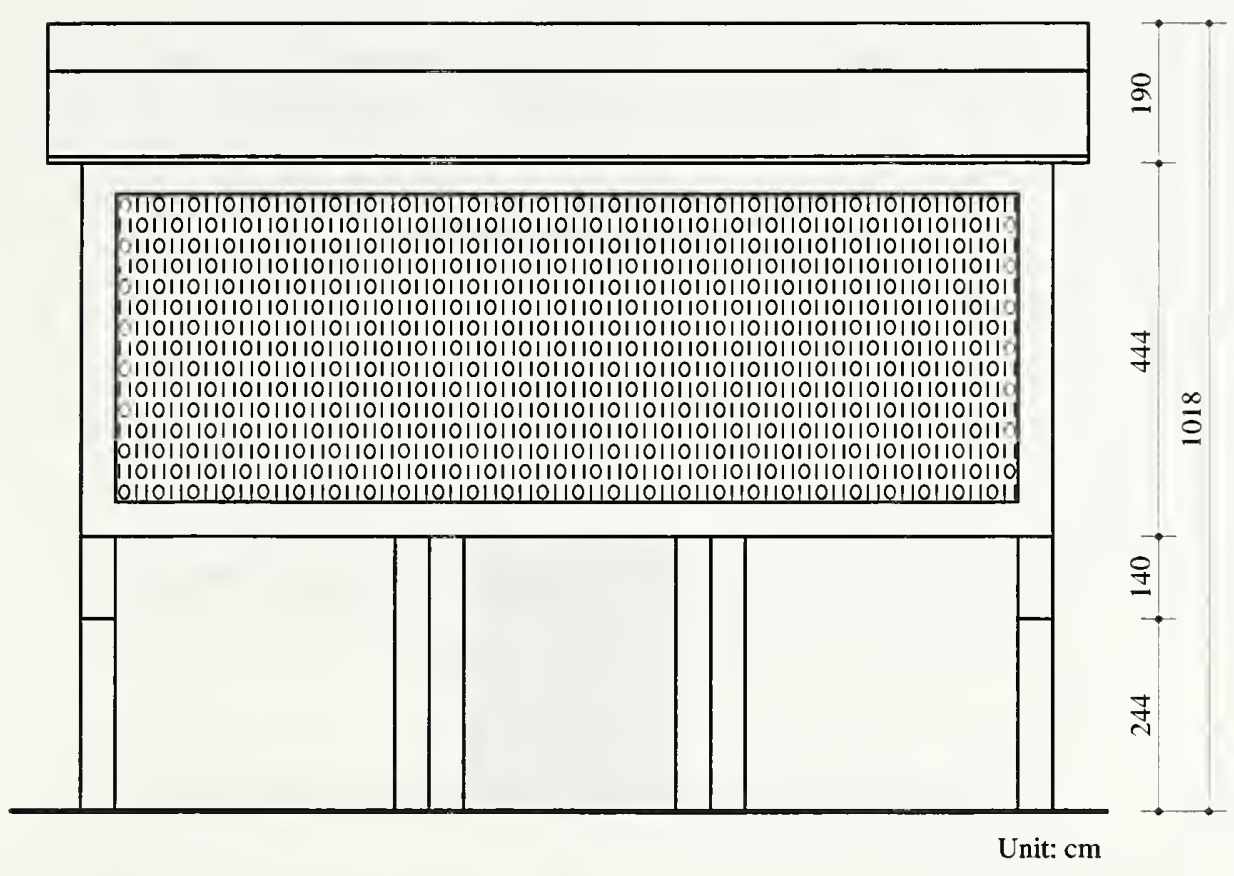

Figure G3 - Front Elevation

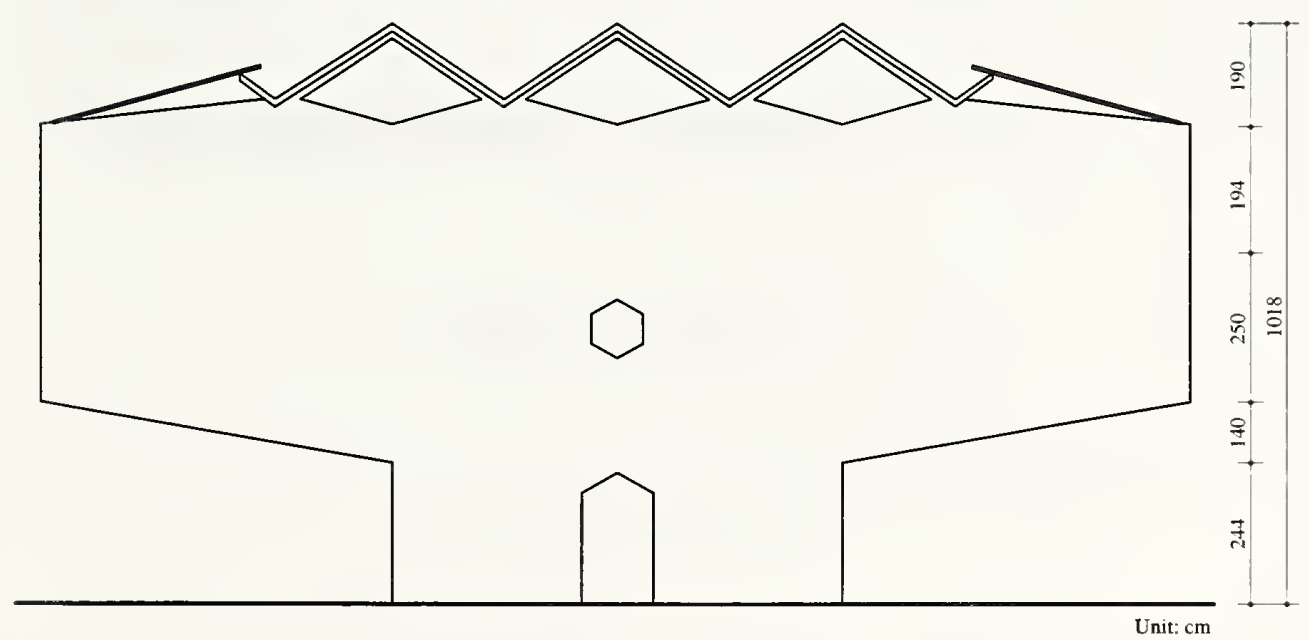

Figure G4 - Side Elevation 


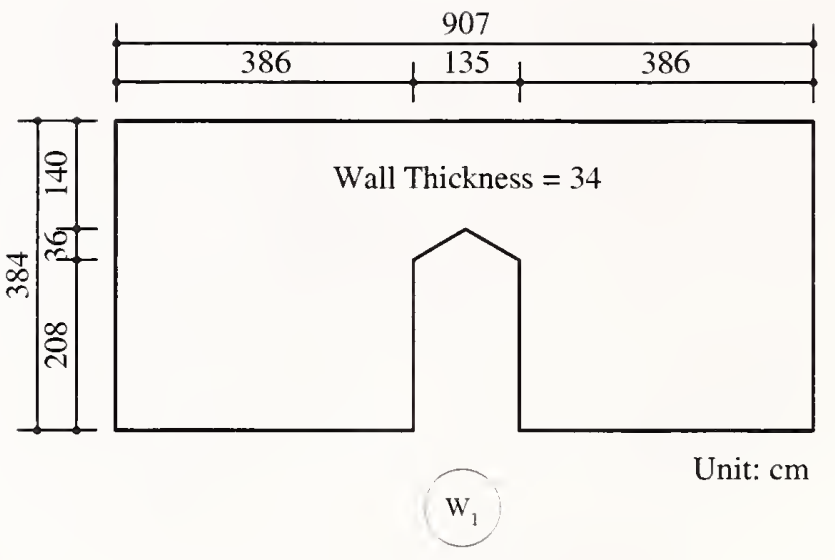

(a) First-Story Wall

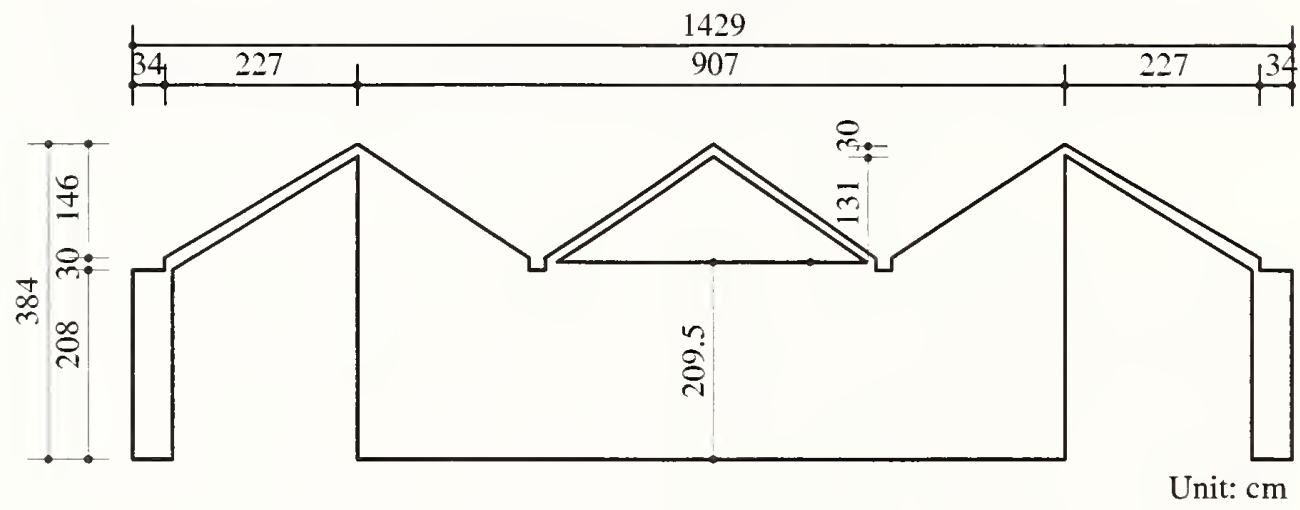

W

(b) Second-Story Wall

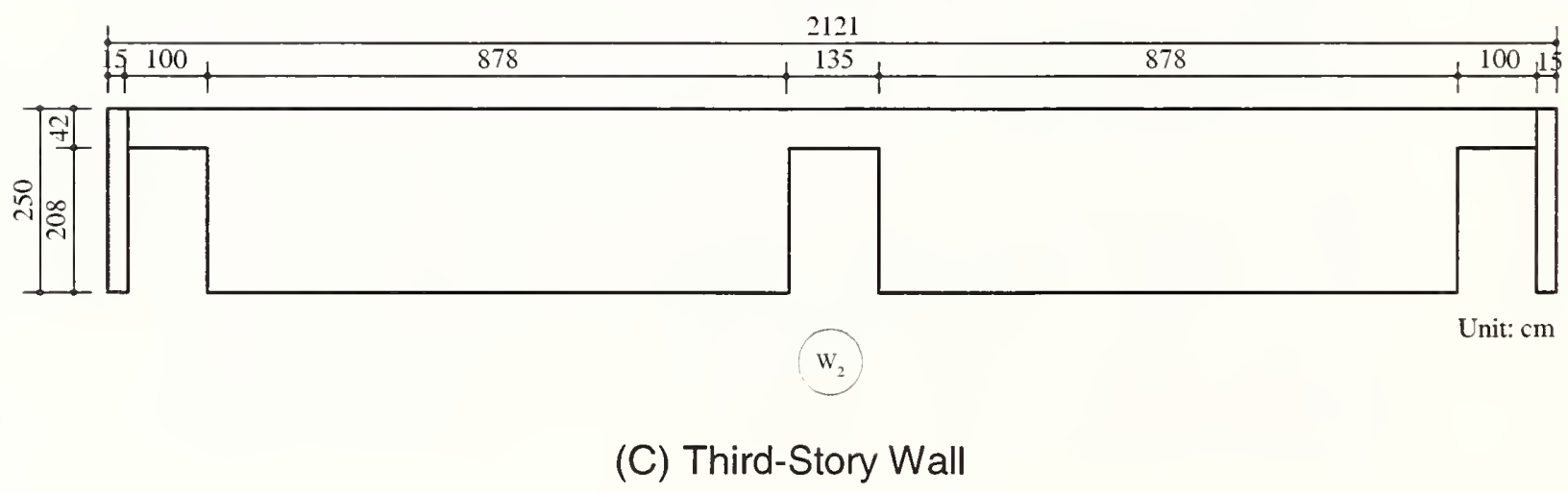

Figure G5 - Wall Dimensions 

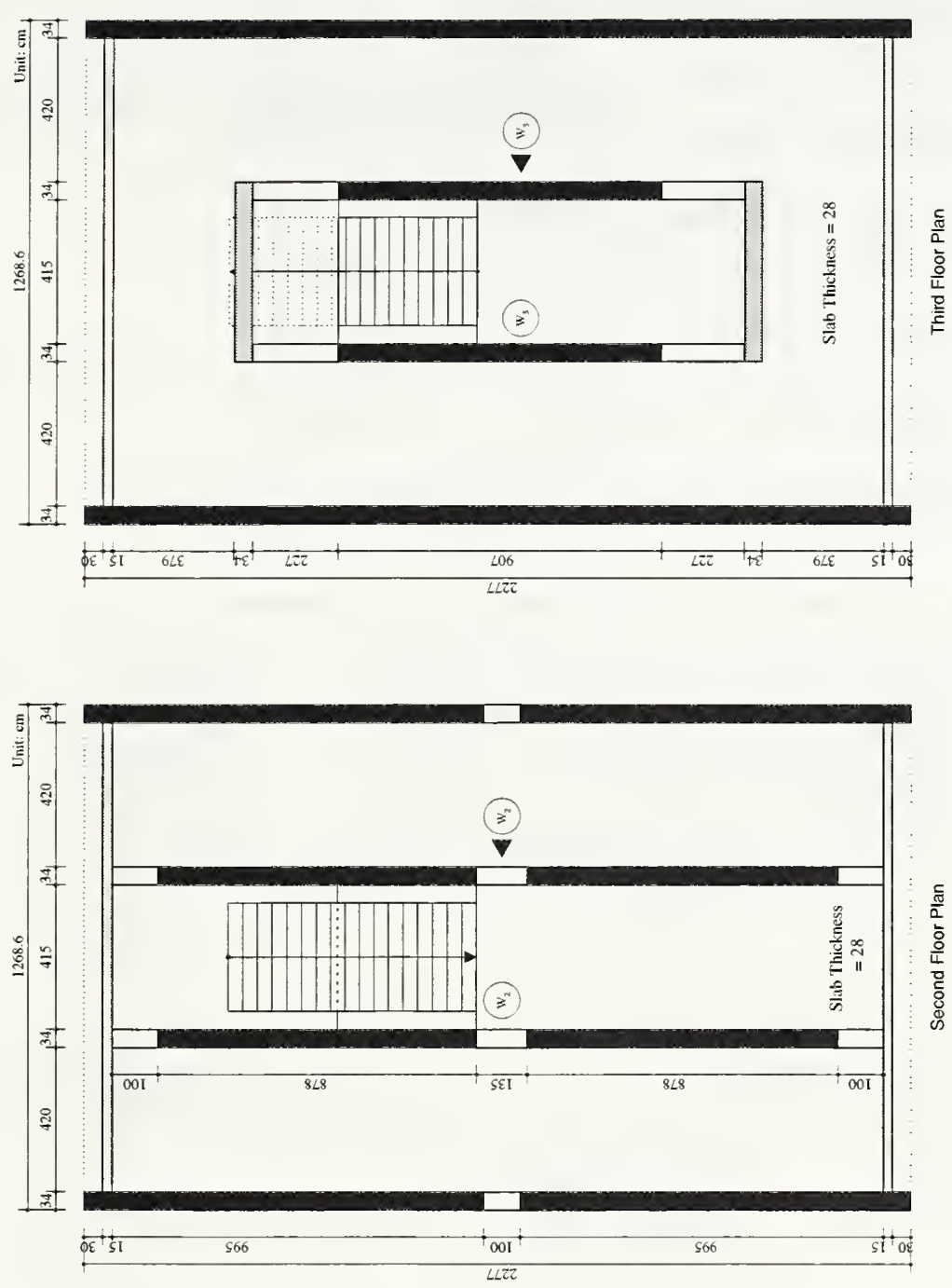

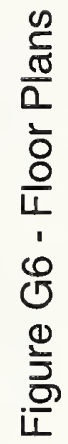

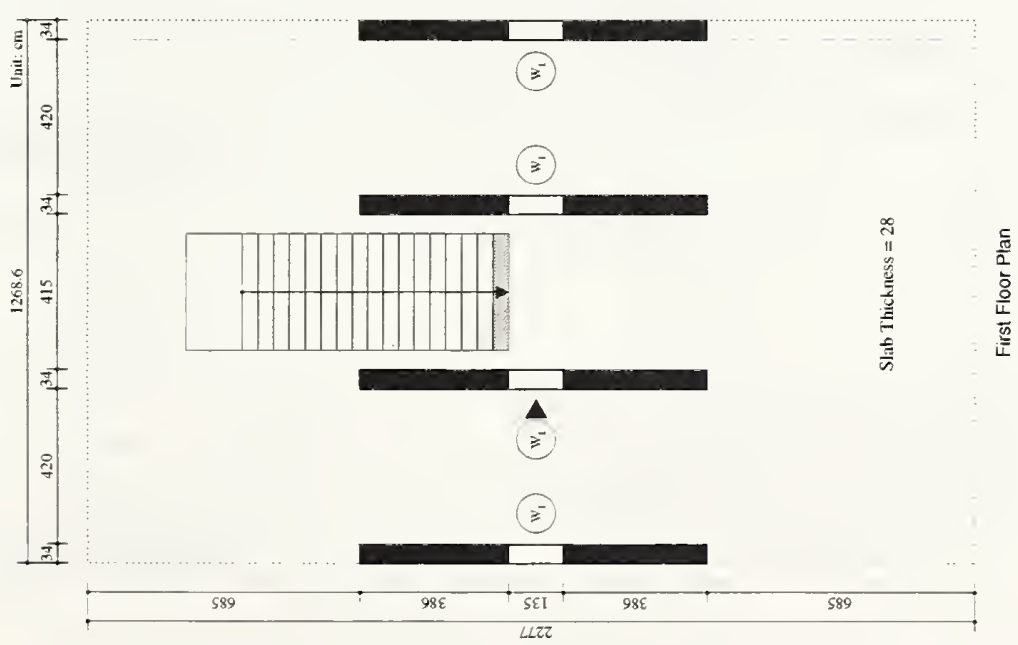


Mass Density of concrete $=2400 \mathrm{~kg} / \mathrm{m}^{3}$

Dead Load

Slab Load: $t=28 \mathrm{~cm}, W=2400 \mathrm{~kg} / \mathrm{m}^{3} * 0.28 \mathrm{~m}=672 \mathrm{~kg} / \mathrm{m}^{2} \gg \gg>\underline{680 \mathrm{~kg} / \mathrm{m}^{2}}$

Calculated mass based on the mass of reinforced concrete $\mathrm{t}=20 \mathrm{~cm}, \mathrm{~W}=2400 \mathrm{~kg} / \mathrm{m}^{3 *} 0.2 \mathrm{~m}^{*} 1.13($ slope $)=542.4 \mathrm{~kg} / \mathrm{m}^{2}>>>>550 \mathrm{~kg} / \mathrm{m}^{2}$

Wall density: $\mathrm{t}=34 \mathrm{~cm}, \mathrm{~W}=2400 \mathrm{~kg} / \mathrm{m}^{3} * 0.34 \mathrm{~m}=816 \mathrm{~kg} / \mathrm{m}^{2} \gg \gg>>120 \mathrm{~kg} / \mathrm{m}^{2}$

Roof density: $t=15 \mathrm{~cm}, W=2400 \mathrm{~kg} / \mathrm{m}^{3} * 0.15 \mathrm{~m}=360 \mathrm{~kg} / \mathrm{m}^{2} \gg \gg \gg 360 \mathrm{~kg} / \mathrm{m}^{2}$

Concrete Block: Density $=60 \mathrm{lb} / \mathrm{ft}^{2}=292.9 \mathrm{~kg} / \mathrm{m}^{2} \gg \gg>>300 \mathrm{~kg} / \mathrm{m}^{2}$

\begin{tabular}{|c|c|c|c|c|c|}
\hline Floor & Load & Unit Load & Area or length & $\mathrm{W}(\mathrm{kg})$ & $\begin{array}{l}\text { Result } \\
\text { W (kg) } \\
\end{array}$ \\
\hline \multirow{5}{*}{$\mathrm{R}$} & Roof & $360 \mathrm{~kg} / \mathrm{m}^{2}$ & $\begin{array}{l}* 2.8 \mathrm{~m} * 13 \mathrm{~m} * 6 \\
* 1 \mathrm{~m} * 13 \mathrm{~m} * 2\end{array}$ & $\begin{array}{l}=78624 \mathrm{~kg} \\
=9360 \mathrm{~kg}\end{array}$ & \multirow[b]{5}{*}{$178,000 \mathrm{~kg}$} \\
\hline & Exterior Wall & $820 \mathrm{~kg} / \mathrm{m}^{2}$ & $\begin{array}{l}* 7.69 \mathrm{~m}^{2} * 2 \\
* 0.97 \mathrm{~m} * 23 \mathrm{~m} * 2\end{array}$ & $\begin{array}{l}=12611 \mathrm{~kg} \\
=36588.4 \mathrm{~kg}\end{array}$ & \\
\hline & Interior Wall & $820 \mathrm{~kg} / \mathrm{m}^{2}$ & $\begin{array}{l}* 2.3 \mathrm{~m} * 1.46 \mathrm{~m} * 2 \\
* 1.41 \mathrm{~m} * 9.07 \mathrm{~m} * 2 \\
* 1.11 \mathrm{~m} * 4.83 \mathrm{~m} * 2\end{array}$ & $\begin{array}{l}=5507.1 \mathrm{~kg} \\
=20973 \mathrm{~kg} \\
=8792.5 \mathrm{~kg}\end{array}$ & \\
\hline & $\begin{array}{c}\text { Conc. Block } \\
\text { Wall }\end{array}$ & $300 \mathrm{~kg} / \mathrm{m}^{2}$ & $* 12 \mathrm{~m} * 0.7 \mathrm{~m} * 2$ & $=5040 \mathrm{~kg}$ & \\
\hline & & & & $\sum 177496 \mathrm{~kg}$ & \\
\hline \multirow{6}{*}{$3 \mathrm{~F}$} & $3 \mathrm{~F} \mathrm{Slab}$ & $680 \mathrm{~kg} / \mathrm{m}^{2}$ & $*((12 \mathrm{~m} * 21.87 \mathrm{~m})-(4.15 \mathrm{~m} * 3.86 \mathrm{~m}))$ & $=167566 \mathrm{~kg}$ & \\
\hline & Exterior Wall & $820 \mathrm{~kg} / \mathrm{m}^{2}$ & $\begin{array}{l}* 0.97 \mathrm{~m} * 23 \mathrm{~m} * 2 \\
* 1.25 \mathrm{~m} * 23 \mathrm{~m} * 2\end{array}$ & $\begin{array}{l}=36588.4 \mathrm{~kg} \\
=47150 \mathrm{~kg}\end{array}$ & \\
\hline & Interior Wall & $820 \mathrm{~kg} / \mathrm{m}^{2}$ & $\begin{array}{l}* 0.97 \mathrm{~m} * 9.07 \mathrm{~m} * 2 \\
* 0.97 \mathrm{~m} * 4.83 \mathrm{~m} * 2 \\
* 23.3 \mathrm{~m}^{2} * 2\end{array}$ & $\begin{array}{l}=14428.6 \mathrm{~kg} \\
=7683.6 \mathrm{~kg} \\
=38212 \mathrm{~kg}\end{array}$ & \\
\hline & $\begin{array}{l}\text { Conc. Block } \\
\text { Wall }\end{array}$ & $300 \mathrm{~kg} / \mathrm{m}^{2}$ & $\begin{array}{l}* 0.97 \mathrm{~m} * 12 \mathrm{~m} * 2 \\
* 1.25 \mathrm{~m} * 12 \mathrm{~m} * 2 \\
\end{array}$ & $\begin{array}{l}=6984 \mathrm{~kg} \\
=9000 \mathrm{~kg}\end{array}$ & \\
\hline & Stairs & $550 \mathrm{~kg} / \mathrm{m}^{2}$ & $* 2 \mathrm{~m} * 6 \mathrm{~m}$ & $=6600 \mathrm{~kg}$ & \\
\hline & & & & $\sum 334212.6 \mathrm{~kg}$ & $335,000 \mathrm{~kg}$ \\
\hline \multirow{6}{*}{$2 \mathrm{~F}$} & 2F Slab & $680 \mathrm{~kg} / \mathrm{m}^{2}$ & $*((12 m * 21.87 m)-(4.15 m * 3.86 m))$ & $=167566 \mathrm{~kg}$ & \\
\hline & Exterior Wall & $820 \mathrm{~kg} / \mathrm{m}^{2}$ & $\begin{array}{l}* 1.25 \mathrm{~m} * 23 \mathrm{~m} * 2 \\
* 27 \mathrm{~m}^{2 * 2}\end{array}$ & $\begin{array}{l}=47150 \mathrm{~kg} \\
=44280 \mathrm{~kg}\end{array}$ & \\
\hline & Interior Wall & $820 \mathrm{~kg} / \mathrm{m}^{2}$ & $\begin{array}{l}* 21.95 \mathrm{~m} * 2 \\
* 17 \mathrm{~m}^{* 2}\end{array}$ & $\begin{array}{l}=36000 \mathrm{~kg} \\
=27880 \mathrm{~kg}\end{array}$ & \\
\hline & $\begin{array}{l}\text { Conc. Block } \\
\text { Wall } \\
\end{array}$ & $300 \mathrm{~kg} / \mathrm{m}^{2}$ & $* 0.95 \mathrm{~m} * 12 \mathrm{~m} * 2$ & $=6840 \mathrm{~kg}$ & \\
\hline & Stairs & $550 \mathrm{~kg} / \mathrm{m}^{2}$ & $* 2 m * 6 m$ & $=6600 \mathrm{~kg}$ & \\
\hline & & & & $\sum 336316 \mathrm{~kg}$ & $337,000 \mathrm{~kg}$ \\
\hline
\end{tabular}

\begin{tabular}{c|c|c}
\hline Floor & Mass $(\mathrm{kg})$ & $\mathrm{W}_{\mathrm{i}}(\mathrm{kg})$ \\
\hline 3 & 178,000 & 178,000 \\
\hline
\end{tabular}




\begin{tabular}{c|c|c}
\hline 2 & 335,000 & 513,000 \\
\hline 1 & 337,000 & 850,000 \\
\hline
\end{tabular}

Story Shear forces (Longitudinal Direction)

$$
\begin{gathered}
V=\frac{Z U S C}{R_{d}} \times W=[1 * 1.3 * 1.5 * 0.635 / 5]=\underline{0.25} * 850,000 \mathrm{~kg}=\underline{212,500 \mathrm{~kg}} \\
(\mathrm{Z}=1.0, \mathrm{~S}=1.5, \mathrm{U}=1.3, \mathrm{C}=0.635, \mathrm{Rd}=5.0)
\end{gathered}
$$

\section{Story Shear forces}

$$
\bar{V}_{j}=0.75 \times V_{j}=0.9 \times \frac{n+j}{n+1}\left(\frac{W_{j}}{W}\right) V \quad \text { Equation }(2-4)
$$

\begin{tabular}{c|c|c|c|c|c}
\hline story & $\mathrm{W}(\mathrm{kg})$ & $\mathrm{W}_{\mathrm{j}}(\mathrm{kg})$ & $(\mathrm{n}+\mathrm{j}) /(\mathrm{n}+1)$ & $\mathrm{W}_{\mathrm{j}} / \mathrm{W}$ & $\bar{V}_{j}(\mathrm{~kg})$ \\
\hline 3 & 178,000 & 178,000 & 1.5 & 0.209 & 60,000 \\
\hline 2 & 335,000 & 513,000 & 1.25 & 0.604 & 144,300 \\
\hline 1 & 337,000 & 850,000 & 1 & 1 & 191,300 \\
\hline
\end{tabular}

\section{Shear Stress in Shear Wall}

\begin{tabular}{|c|c|c|c|c|c|}
\hline \multirow[b]{2}{*}{ Story } & \multirow[b]{2}{*}{$\bar{V}_{j}(\mathrm{~kg})$} & \multirow[b]{2}{*}{$\mathrm{A}_{\mathrm{w}}\left(\mathrm{cm}^{2}\right)$} & \multicolumn{2}{|c|}{$m=1$} & \multirow[b]{2}{*}{$<0.7 \mathrm{MPa}$} \\
\hline & & & $\begin{array}{c}V_{\text {arg }} \\
\left(\mathrm{kg} / \mathrm{cm}^{2}\right) \\
\end{array}$ & $\begin{array}{c}v_{\text {arg }} \\
(\mathrm{MPa}) \\
\end{array}$ & \\
\hline 3 & 60,000 & 216512 & 0.28 & 0.03 & OK \\
\hline 2 & 144,300 & 267444 & 0.54 & 0.05 & $\mathrm{OK}$ \\
\hline 1 & 191,300 & 105000 & 1.82 & 0.18 & $\mathrm{OK}$ \\
\hline
\end{tabular}

$$
v_{\text {arg }}=\frac{1}{m}\left(\frac{\bar{V}_{j}}{A_{w}}\right) \quad \text { Equation }(2-6)
$$

\begin{tabular}{|c|c|c|c|c|c|}
\hline \multirow[b]{2}{*}{ Story } & \multirow[b]{2}{*}{$\mathrm{V}_{\mathrm{j}}(\mathrm{kg})$} & \multirow[b]{2}{*}{$\mathrm{A}_{\mathrm{w}}\left(\mathrm{cm}^{2}\right)$} & \multicolumn{2}{|c|}{$m=1$} & \multirow[b]{2}{*}{$<0.7 \mathrm{MPa}$} \\
\hline & & & $\begin{array}{c}v_{\mathrm{arg}} \\
\left(\mathrm{kg} / \mathrm{cm}^{2}\right)\end{array}$ & $\begin{array}{c}v_{\text {arg }} \\
(\mathrm{MPa})\end{array}$ & \\
\hline 3 & 60,000 & 0 & - & - & $\mathrm{NG}$ \\
\hline 2 & 144,300 & 0 & - & - & NG \\
\hline 1 & 191,300 & 0 & - & - & $\mathrm{NG}$ \\
\hline
\end{tabular}

Longitudinal direction

Transverse direction 


\section{EVALUATION STATEMENTS FOR CONCRETE SHEAR WALL BUILDINGS WITH STIFF DIAPHRAGMS}

\section{BASIC STRUCTURAL CHECKLIST}

This Basic Structural checklist must be completed for both Life Safety and Immediate Occupancy evaluation.

\section{Building System}

C NC N/A LOAD PATH: The structure contains a complete load path for seismic force effects from any horizontal direction that serves to transfer the inertial forces from the mass to the foundation (NOTE: Write a brief description of this linkage for each principal direction.) (Sec. 3.1)

No shear walls in the transverse direction.

C NC N/A WEAK STORY: The strength of the lateral-force-resisting system in any story must not be less than $80 \%$ of the strength in an adjacent story, above or below. (Sec. 3.31)

The total cross sectional area of the first-story shear walls is less than $80 \%$ of the total area of the second-story shear walls.

C NC N/A SOFT STORY: The stiffness of the lateral-force-resisting system in any story must not he less than $70 \%$ of the stiffness in an adjacent story above or below, or less than $80 \%$ of the average stiffness of the three stories above or below.

(Sec. 3.3.2)

The total cross sectional area of the first-story shear walls is less than $80 \%$ of the total area of the second-story shear walls.

C NC N/A GEOMETRY: There must be no changes in horizontal dimension of the lateral-force-resisting system of more than $30 \%$ in a story relative to adjacent stories, excluding one-story penthouses. (Sec. 3.3.4) 
The length of the first-story wall is less than $70 \%$ of the length of the second-story wall.

C NC N/A MASS: There must be no change in effective mass more than $50 \%$ from one story to the next, excluding light roof.

(Sec. 3.3.5)

The total cross sectional area of the first-story shear walls is less than $80 \%$ of the total area of the second-story shear walls.

C NC N/A VERTICAL DISCONTINUITIES: All vertical elements in the lateral-force-resisting system must be continuous to the foundation. (Sec. 3.3.6)

Shear walls are continuous to the foundation.

C NC N/A EARTHQUAKE INDUCED TORSION: The distance between the story center of mass and the story center of rigidity must be less than $20 \%$ of the building width in either plan dimension. (Sec. 3.3.7)

The building is symmetrical about its principal axes.

C NC N/A WIND INDUCED TORSION: The lateral-force-resisting elements form a well balanced system that is capable of resisting wind forces acting from any direction and is not subjected to significant torsion. For a non-flexible structure with a reasonably regular shape in plan, the distance, measured along either principal axis of the building plan, between the point of application of the mean load induced by wind normal to that axis and the center of rigidity must be less than 15 percent of the width of the structure in either major plan dimension. (For this evaluation a set of structural drawings is necessary.) (Sec. 3.3.7)

The building is symmetrical about its principal axes.

C NC N/A DETERIORATION OF CONCRETE: There must be no visible deterioration of concrete or reinforcing steel in any of the vertical- or lateral-force-resisting elements. (Sec. 3.7)

Extensive delamination of concrete slab exposing reinforcing steel in the bottom of slab (see photographs). 
C NC N/A POST-TENSIONING ANCHORS: There must be no evidence of corrosion or spalling in the vicinity of post-tensioning or end fittings. Coil anchors must not have been used. (Sec. 3.8)

No post-tensioning is used in this building.

C NC N/A CONCRETE WALL CRACKS: All existing diagonal cracks in wall elements must be less than $1.0 \mathrm{~mm}$, must not be concentrated in one location, and must not form an X pattern. (Sec. 3.28)

There are no visible sign of cracks in the walls.

\section{Lateral Force Resisting System}

C NC N/A COMPLETE FRAMES: Steel or concrete frames classified as secondary components must form a complete vertical load carrying system. (Sec. 3.29)

The structure does not have frames.

C NC N/A REDUNDANCY: The number of lines of shear walls in each principal direction must be greater than or equal to 2. (Sec. 3.9)

No shear walls in the transverse direction.

C NC N/A SHEAR STRESS CHECK: The shear stress in the concrete shear walls must be less than $1.0 \mathrm{MPa}\left(10 \mathrm{kgf} / \mathrm{cm}^{2}\right)$ or $\sqrt{\mathrm{f}_{\mathrm{c}}} / 4$, if the total cross sectional area of the walls in a story is less than $3 \%$ of the floor area. If greater than $3 \%$, no shearing stress check is needed. (Sec. 3.11)

Longitudinal direction: $1.82<10 \mathrm{kgf} / \mathrm{cm}^{2} \quad O . K$. Transverse direction: No shear walls N.G.

C NC N/A REINFORCING STEEL: The ratio of reinforcing steel area to gross concrete area must be greater than 0.0015 in the vertical direction and 0.0025 in the horizontal direction. The spacing of reinforcing steel must be equal to or less than $450 \mathrm{~mm}$.

(Sec. 3.30)

Reinforcing steel quantity is not known. 
C NC N/A DIAPHRAGM OPENINGS AT THE SHEAR WALLS:

Diaphragm openings immediately adjacent to the shear walls must be less than $25 \%$ of the wall length. (Sec. 3.31)

No slab opening s are adjacent to the shear walls.

\section{Connections}

C NC N/A TRANSFER TO SHEAR WALLS: Diaphragms must be reinforced and connected for transfer of loads to the shear walls (Sec. 3.32)

The slabs are integral with the shear walls.

C NC N/A FOUNDATION DOWELS: Walls must be doweled into the foundation. (Sec.3.33)

The presence of dowels was not determined during the field survey. 


\section{Additional Structural Checklist for Concrete Shear Wall Buildings With Stiff Diaphragms for Immediate Occupancy}

This Additional Structural Checklist must be completed when the structure is evaluated for immediate occupancy. The Basic Structural Checklist must be completed prior to completing this checklist.

\section{Lateral Force Resisting System}

C NC N/A DEFLECTION COMPATIBILITY: Secondary components must have the shear capacity to develop the flexural strength of the elements and must have ductile detailing. (Sec. 3.34)

The building has no column.

C NC N/A FLAT SLABS: Flat slabs/plates must not be permitted as primary components. (Sec. 3.6)

The building does not have flat slab.

C NC N/A COUPLING BEAMS: The stirrups in all coupling beams over means of egress must be spaced at or less than $\mathrm{d} / 2$ and must be anchored into the core with hooks of $135^{\circ}$ or more. (Sec. 3.35)

The building has no coupling beams.

C NC N/A OVERTURNING: All shear walls must have aspect ratios less than 4 to 1 . Wall piers need not be considered. (Sec. 3.36)

The aspect ratios of the shear walls are less than 4 to 1.

C NC N/A CONFINEMENT REINFORCING: For shear walls with aspect ratios greater than 2.0, the boundary elements must be confined with spirals or ties with spacing less than $8 d_{b}$. (Sec. 3.37)

The aspect ratios of shear walls are less than 2.0.

C NC N/A REINFORCING AT OPENINGS: There must be added trim reinforcement around all wall openings. (Sec. 3.38)

The presence of trim reinforcement was no confirmed. 
C NC N/A WALL THICKNESS: Thickness of bearing walls must not be less than $1 / 25$ the minimum unsupported height or length, nor less than $100 \mathrm{~mm}$. (Sec. 3.39)

The thickness of wall is $150 \mathrm{~mm} . \quad 150 / 2500=1 / 16.7>1 / 25$

\section{Diaphragms}

C NC N/A DIAPHRAGM CONTINUITY: The diaphragms must not be composed of split-level floors. (Sec. 3.24)

The building has no split level floors.

C NC N/A DIAPHRAGM OPENINGS AT SHEAR WALLS: Diaphragm openings immediately adjacent to the shear walls must be less than $15 \%$ of the wall length. (Sec. 3.31)

There are no diaphragm openings adjacent to the walls.

C NC N/A PLAN IRREGULARITIES: There must be tensile capacity to develop the strength of the diaphragm at re-entrant corners or other locations of plan irregularities. (Sec. 3.25)

The building has a rectangular floor plan.

C NC N/A DIAPHRAGM REINFORCEMENT AT OPENINGS: There must be reinforcing around all diaphragm openings larger than $50 \%$ of the building width in either major plan dimension. (Sec. 3.26)

There are no slab openings.

\section{Connections}

C NC N/A LATERAL LOAD AT PILE CAPS: Pile caps must have top reinforcement and piles must be anchored to the pile caps. (Sec. 3.27)

The build rests on the wall footings.

C NC N/A TRANSFER TO SHEAR WALLS: Diaphragm connection to shear walls must be able to develop the lesser of the shear strength of the wall or diaphragm. (Sec. 3.32)

All slabs are integral with the walls. 


\section{EVALUATION STATEMENTS FOR GEOLOGIC SITE HAZARDS AND FOUNDATIONS}

\section{Geologic Site Hazards}

The following statements shall be completed for buildings in regions of high or moderate seismicity.

C NC N/A LIQUEFACTION: Liquefaction-susceptible, saturated, loose granular soils that could jeopardize the building's seismic performance must not exist in the foundation soils at depths within $15 \mathrm{~m}$ under the building. (Sec. 4.1.1)

No known liquefaction problems at the site.

C NC N/A SLOPE FAILURE: The building site must be sufficiently remote from potential earthquake-induced slope failures or rockfalls to be unaffected by such failures, or must be capable of accommodating any predicted movements without failure.

(Sec. 4.1.2)

The building is on the level surface.

C NC N/A SURFACE FAULT RUPTURE: Surface fault rupture and surface displacement at the building site is not anticipated. (Sec. 4.1.3)

No known faults are near the building.

\section{Condition of Foundations}

C NC N/A FOUNDATION PERFORMANCE: There must be no evidence of excessive foundation movement such as settlement or heave that would affect the integrity or strength of the structure. (Sec. 4.2.1)

No evidence of foundation movement was noted.

\section{Capacity of Foundations}

C NC N/A POLE FOUNDATIONS: Pole foundations must have a minimum embedment depth of $1.5 \mathrm{~m}$. (Sec. 4.3.1)

There are no pole foundations. 
C NC N/A OVERTURNING: The ratio of the effective horizontal dimension, at the foundation level of the lateral-force-resisting system to the building height (base/height) must be greater than 0.4.(Sec. 4.3.2)

$$
9.1 \mathrm{~m} / 10.2 \mathrm{~m}=0.9>0.4 \text { O.K. }
$$

C NC N/A TIES BETWEEN FOUNDATION ELEMENTS: The foundation must have ties adequate to resist seismic forces where footings, piles, and piers are not restrained by beams, slabs, or soils classified as Type 1 or 2. (Sec. 4.33 )

The presence of ties is not verified during the filed survey.

C NC N/A SLOPING SITES: The grade difference from one side of the building to another must not exceed one-half the story height at the location of embedment. (Sec. 4.34 )

The building is on the level surface.

\section{Summary of Deficiencies}

1. No walls are available to resist the lateral force in the transverse direction.

2. The bottom of the second floor slab is deteriorated extensively. Many reinforcing bars are exposed due to delamination of concrete.

3. Concrete slab is, in general, in poor condition. Compressive strength of concrete must be determined using core specimens,

4. The condition of foundation must be determined. The structure may sustain overtuning failure due to foundation failure.

The building requires a detailed evaluation to correct deficiencies. 




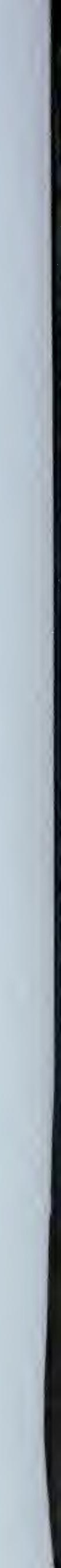

